\title{
WestVirginiaUniversity
}

THE RESEARCH REPOSITORY @ WVU

Graduate Theses, Dissertations, and Problem Reports

1999

\section{Compressive strength prediction for composite unmanned aerial vehicles}

\author{
Edward Albert Wen \\ West Virginia University
}

Follow this and additional works at: https://researchrepository.wvu.edu/etd

\section{Recommended Citation}

Wen, Edward Albert, "Compressive strength prediction for composite unmanned aerial vehicles" (1999). Graduate Theses, Dissertations, and Problem Reports. 982.

https://researchrepository.wvu.edu/etd/982

This Thesis is protected by copyright and/or related rights. It has been brought to you by the The Research Repository @ WVU with permission from the rights-holder(s). You are free to use this Thesis in any way that is permitted by the copyright and related rights legislation that applies to your use. For other uses you must obtain permission from the rights-holder(s) directly, unless additional rights are indicated by a Creative Commons license in the record and/ or on the work itself. This Thesis has been accepted for inclusion in WVU Graduate Theses, Dissertations, and Problem Reports collection by an authorized administrator of The Research Repository @ WVU. For more information, please contact researchrepository@mail.wvu.edu. 


\title{
Compressive Strength Prediction For Composite Unmanned Aerial Vehicles
}

\author{
Edward A. Wen \\ Thesis Submitted to the \\ College of Engineering And Mineral Resources \\ At West Virginia University \\ in Partial Fulfillment of the Requirements for the \\ Degree of
}

Master of Science
in
Aerospace Engineering

Ever Barbero, Ph.D., Chair and Advisor

John Loth, Ph.D.

Gary Morris, Ph.D.

Department of Mechanical/Aerospace Engineering

Morgantown, West Virginia University

1999

Keywords: Composites, Compression, Prediction, Testing 


\title{
Abstract
}

\section{Compressive Strength Prediction for Composite}

\author{
Unmanned Aerial Vehicles
}

Edward A. Wen

A rational methodology is presented to predict the compressive strength of carbon/epoxy compression specimens and prototype production parts using the model presented by Barbero in the Journal of Composite Materials, Vol. 32, No.5/1998. The experimental technique is an adaptation of the optical method first proposed by Yurgartis (1987) and can be directly applied to actual development, quality control or failure investigation programs. There is very good agreement between actual and predicted compressive strength at $-125 \mathrm{~F}$ and room temperature. At $180 \mathrm{~F}$, the predicted strength is conservative. Aurora Flight Sciences provided the prototype production parts and partial funding under the "Material Characterization Study for UAV Wing Development" contract. The results of the material characterization study of two carbon/epoxy prepregs presented to Aurora Flight Sciences are also shown here. An extension of the method presented by Barbero is also proposed for laminates with average global misalignment, $\alpha_{\mathrm{G}}$, in $\left[+\alpha_{\mathrm{G}}\right]_{\mathrm{n}}$ or $\left[-\alpha_{\mathrm{G}}\right]_{\mathrm{n}}$ stacking sequence. 


\section{Acknowledgement}

I would like to express tremendous thanks to my advisor, Dr. Ever Barbero, for his guidance and support throughout this project. There were many difficult moments encountered in the testing program that could not be solved without Dr. Barbero's help. Dr. Barbero drew upon many of his resources in order that we could complete the testing program.

I would also like to thank Aurora Flight Sciences of West Virginia for allowing WVU MAE to take on the Material Characterization portion of the NASA program, "Structures Technology Development for Wings of Unmanned Aerial Vehicles". Specifically, I thank Les Montford, Randy Tatman, Clint Church and Alistair Wroe for their support. I also would like to thank another member of industry, Joseph Noyes of the Kestrel Aircraft Company, for his advice on testing methods and techniques.

The success of this project is has been facilitated by the work of many WVU students. Peter Cooke did a superb job of cutting the samples and quantifying the fiber misalignment to our compressed schedule. I am indebted to Bill Carenbauer who generously volunteered his time to help set-up and optimize our surface grinding operation. Additionally, I am grateful to Bill Briers, Tom Damiani, Matt Fox for their assistance, to Drs. Stiller and Plucinsky (Chem E) for the helium pycnometer density tests and to Somjai Kajorncheappungam (Chem E) for the TMA and DSC tests.

Last but not least, I would like to thank my mother, Amy Wen, and Tory Platt for their patience, understanding and support throughout the project. 


\section{Table of Contents}

Title Page $\quad$ i

Abstract

Acknowledgements

Table of Contents $\quad$ iv

List of Tables $\quad$ vii

List of Figures viii

Nomenclature $\quad$ xi

Chapter 1: Introduction and Literature Review 1

1.1 Introduction 1

1.2 Literature Review 3

Chapter 2: Theoretical Modeling 9

2.1 Composite Shear Response 9

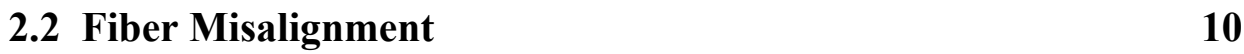

2.3 Imperfection Sensitivity 11

2.4 Continuum Damage Model 12

2.5 Explicit Equation 13

$\begin{array}{ll}\text { 2.6 Global Misalignment } & 15\end{array}$

Chapter 3: Material Characterization and Beam Testing 24 
3.1 Compression/Shear Test Selection 25

3.2 Compression/Shear Specimen Preparation 25

$\begin{array}{ll}\text { 3.3 Data Normalization } & 26\end{array}$

3.4 Difficulties in Obtaining F1c 27

$\begin{array}{lll}3.4 .1 \text { Sanding } & 28\end{array}$

3.4.2 Peel Ply and Caul Plates 28

3.4.3 Surface Ground / Solid Compression Head 29

3.4.4 Bolt Torque $\quad 29$

3.4.5 Bond Tabs at High Temperatures 30

3.5 Experimental Results $\quad 30$

$\begin{array}{ll}\text { 3.6 Beam Preparation } & 31\end{array}$

\begin{tabular}{ll} 
3.7 & Beam Testing \\
\hline
\end{tabular}

3.8 Beam Test Results 32

Chapter 4: Prediction of Compressive Strength 52

4.1 Optical Technique $\quad 52$

4.2 Modification to Optical Technique $\quad 54$

$\begin{array}{ll}4.3 \text { Preparation } & 55\end{array}$

4.4 Data Reduction and Interpretation $\quad 56$

$\begin{array}{ll}\text { 4.5 Fiber Volume Correction } & 57\end{array}$

4.6 Confidence Intervals on Measured Data 58

4.7 Confidence Intervals on Predicted Data 60 
$\begin{array}{lr}\text { Chapter 5: Prediction Results } & 68\end{array}$

$\begin{array}{ll}5.1 \text { Normal Distribution } & 68\end{array}$

$\begin{array}{ll}5.2 & \text { Predicted Strength } \\ \end{array}$

$\begin{array}{lr}\text { Chapter 6: Summary and Conclusions } & 80\end{array}$

Chapter 7: Recommendations $\quad 82$

$\begin{array}{ll}\text { References } & 83\end{array}$

$\begin{array}{lr}\text { Appendicies } & 85\end{array}$

$\begin{array}{llr}\text { Appendix A Test Methods/Panel History } & 85\end{array}$

$\begin{array}{lll}\text { Appendix B } & \text { Phase I Test Results } & 91\end{array}$

$\begin{array}{lll}\text { Appendix C Phase II Test Results } & 99\end{array}$ 


\section{List of Tables}

Chapter 3

$\begin{array}{ll}\text { 3.1 Aurora Flight Sciences Test Matrix } & 33\end{array}$

3.2 Phase I Test Results 34

3.3 Highlights of Compression Testing

3.4 Phase II Test Results, Page 1 36

3.5 Phase II Test Results, Page 2 37

3.6 Phase II Test Results, Page $3 \quad 38$

Chapter 4

4.1 Fiber Diameters $\quad 61$

4.2 Average Angle and Skew, 949/M30GC Compression Specimens 61

4.3 Average Angle and Skew, 948A1/M40J Compression Specimens 61

4.4 Average Angle and Skew, 949/M30GC Beam 1 Samples 62

4.5 Average Angle and Skew, 948A1/M40J Beam 2 Samples 62

4.6 G12, F6, F1c Confidence Intervals 949/M30GC 62

4.7 G12, F6, F1c Confidence Intervals 948A1/M40J 63

4.8 Standard Deviation of Misalignment Angle Confidence Intervals, 948A1/M40J

4.9 Standard Deviation of Misalignment Angle Confidence Intervals, 949/M30GC

Chapter 5

$\begin{array}{ll}5.1 \text { Actual vs. Predicted Compressive Strength } & 71\end{array}$ 


\section{List of Figures}

Chapter 1

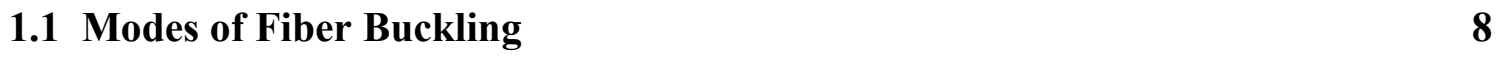

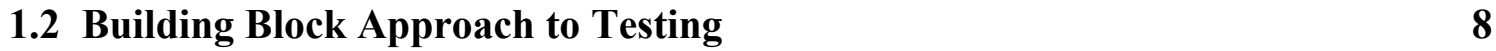

Chapter 2

2.1 Range of Shear Stiffness when using Quadratic Polynomial 18

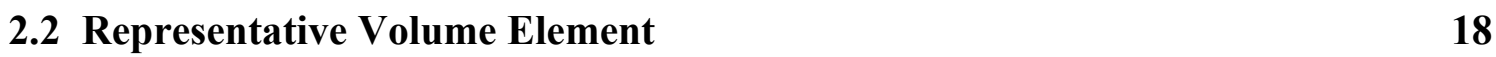

2.3 Equilibrium States for Various Values of Misalignment 19

2.4 Imperfectiom Sensitivity Plot 19

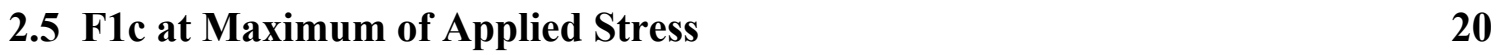

2.6 Representative Volume Element with Global Misalignment 20

2.7 Numerical Integration and Quadratic Polynomial Function 21

2.8 Probability Density Function at 0, 1.0 Average Global Misalignment 21

2.9 Probability Density Function at Average Global Misalignments 22

2.10 Cumulative Distribution Function 22

2.11 Applied Stress at Different Global Misalignments 23

2.12 949/M30GC F1c vs. Average Global Misalignment 23

Chapter 3

$\begin{array}{ll}\text { 3.1 IITRI Test Set-up } & 39\end{array}$

3.2 Compression Specimen Dimensions $\quad 39$

3.3 SACMA Compression Test Set-up $\quad 40$

3.4 Shear Specimen Dimensions 41 
3.5 Shear Test Set-up

3.6 Lay-up Sequence

3.7 Significant Change in Slope at Max. Shear Load

3.8 No Significant Change in Slope at Max. Shear Load 42

3.9 Bag Face vs. Tool Face

3.10 Effects of Ball Joint Head

3.11 Void Content Increase with Ply/Debulk Increase

3.12 Longitudinal Compressive Strength vs. Temperature

3.13 Longitudinal Compressive Modulus vs. Temperature 45

3.14 In-Plane Shear Strength vs. Temperature 46

3.15 In-Plane Shear Modulus vs. Temperature 46

3.16 Longitudinal Tensile Strength vs. Temperature

3.17 Longitudinal Tensile Modulus vs. Temperature 47

3.18 C-Beam Dimensions 48

3.19 C-Beam Cross Sectional Views 48

3.20 Four-Point Bending Test 49

3.21 Teflon Spacers to Allow Deflection

3.22 Beam 1 Test Results 50

3.23 Beam 2 Test Results 50

3.24 Beam Void Content Increase with Location 51

Chapter 4 
$\begin{array}{ll}4.2 & \text { Specimen Skew Example }\end{array}$

4.3 Reducing Skew by Combination of Distributions 66

4.4 Specimen Polishing Procedure $\quad 66$

$\begin{array}{ll}\text { 4.5 Beam Sample Polishing Procedure } & 67\end{array}$

4.6 Measurement of Ellipses That Intersect Selection Line 67

Chapter 5

5.1 Cumulative Distribution Function for Specimen with Lowest Skew 72

5.2 Cumulative Distribution Function for Specimen with Highest Skew 72

5.3 Cumulative Distribution Function of 948A1/M40J 73

5.4 949/M30GC Actual vs. Predicted Compressive Strength 73

5.5 948//M40J Actual vs. Predicted Compressive Strength 74

5.6 949/M30GC Beam 1 \& 2 Actual vs. Predicted Compressive Strength $\quad 74$

$\begin{array}{ll}\text { 5.7 Formula vs. Experimental, Literature Data } & 75\end{array}$

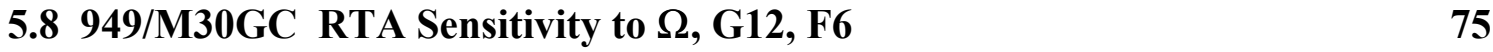

5.9 949/M30GC RTA Maximum Compressive Strength 76

5.10 949/M30GC RTA Normalized Maximum Compressive Strength $\quad 76$

$\begin{array}{lll}5.11 & 948 A 1 / M 40 J & \text { RTA Maximum Compressive Strength }\end{array}$

5.12 948A1/M40J Normalized RTA Maximum Compressive Strength $\quad 77$

5.13 949/M30GC RTA Compressive Strength vs. Ave. Global Misalignment 78

5.14 948A1/M40J RTA Compressive Strength vs. Ave. Global Misalignment 78

5.15 949/M30GC RTA F1c vs. Ave. Global Misalignment , $\Omega \quad 79$

5.16 948A1/M40J RTA F1c vs. Ave. Global Misalignment, $\Omega \quad 79$ 


\section{Nomenclature}

$\mathrm{f}(\mathrm{)})=$ Probability density function, PDF

$\mathrm{F}(\mathrm{)})=$ Cumulative distribution function, $\mathrm{CDF}$

$\mathrm{FV}=$ Fiber volume

$\mathrm{F}_{1 \mathrm{C}}=$ Longitudinal compressive strength

$\mathrm{F}_{6} \quad=$ In-plane shear strength

$\mathrm{G}_{12}=$ In-plane shear modulus

$\mathrm{W}=$ Potential energy

$\alpha=$ Angle of local misalignment, or simply "misalignment"

$\alpha_{\mathrm{G}}=$ Average angle of global misalignment

$\alpha_{\mathrm{g}}=$ Angle of global misalignment

$\Omega=$ Standard deviation of local misalignment angle

$\sigma \quad=$ Compression stress

$\tau=$ Shear stress

$\gamma=$ Shear strain

$\mathrm{v}_{\mathrm{f}} \quad=$ Volume fraction of fibers 


\section{Chapter 1: Introduction and Literature Review}

\subsection{Introduction}

In the last 25 years, composite materials have proven themselves to be a cost effective alternative to metals. Starting from aerospace applications, designers are continually expanding their use into other industries such as marine, infrastructure, sports recreation and medical instruments. Despite extensive experience with composites, a large amount of testing is required (compared to metals) to have confidence in a particular design. In the next decade, composite manufacturers and engineers will be challenged to reduce the amount of testing required by improving manufacturing quality and analysis techniques.

While the tensile strength of composite materials is very well understood, the compressive strength of composites may still have significant variations from expected values [1]. The main factors affecting compression strength are:

- Matrix properties

- Local/Global misalignment of fibers

- Void content

- Moisture and other contamination

When the direction of a fiber is not the intended direction, the angle difference is called global misalignment. Local misalignment or just "misalignment", is the angle at which individual fibers vary from the average fiber direction. In the case of a single ply of preimpregnated composite material, prepreg, misalignment is an inherent property of the 
material and cannot be improved upon by the shop worker or tape laying machine. However when two or more plys are in a lay-up, the misalignment will either remain constant or get worse. Obviously, the shop worker or tape-laying machine will affect the amount of global misalignment when making a lay-up.

Because of the possible reductions to compressive strength caused by the items above, the aerospace industry uses a fixed ultimate compression strain allowable that provides a margin of safety for variations in the material. Depending on the design, extensive testing is required to validate the compression.

Ideally, compression strength could be measured from production parts without costly test fixtures and without destroying the part. This investigation strives to reach this ideal by showing that a compression strength model [2] and optical examination technique [3] can predict strength of unidirectional composites in a production setting. Fiber misalignment and matrix properties on compressive strength are measured and input into the theoretical model. Although they are not active parameters in this study, global misalignment and void content are measured and recorded. Moisture and contamination effects are minimized since the tests were done in ambient conditions and in a relatively clean workshop. Additionally, this study proposes an alternative method to predict the compressive strength of composites with average global misalignment $\alpha_{G}$ in a $\left[+\alpha_{G}\right]_{n}$ or $\left[-\alpha_{G}\right]_{n}$ schedule. This method is an extension of the model proposed in [2].

Aurora Flight Sciences of West Virginia partly sponsored this research for the purpose of determining properties of two material systems under investigation, 949/M30GC and 948A1/M40J. These materials were being evaluated for possible use on 
an Unmanned Aerial Vehicle (UAV). Two beams were constructed and tested at Aurora Flight Sciences were also used to determine the accuracy of this technique.

\subsection{Literature Review}

There is an enormous body of literature on the subject of prediction of compression strength of unidirectional, 0 degree composites from basic material properties in the time period 1965 to 1999 . A brief review is shown here.

Rosen first proposed an analytical model to predict compressive strength laminates in 1965 [4]. Rosen modeled a composite with straight fibers and assumed linear material properties. Using energy methods in his derivation, he assumed that fiber buckling was the mode of failure and found that in the limit, compressive strength equals the elastic shear modulus. Microbuckling could be one of two types: In-phase (shear) mode or Out-of-phase (extensional) mode as shown in Figure 1.1. The shear mode required lower stress for failure but his predictions were two to three times higher than actual values. Only when the shear stiffness was linearly varied to account for inelastic behavior, did the results come closer to the actual values.

An important refinement of Rosen's model was made in 1978 by Wang [5] which included initial fiber misalignment, non-linear shear stiffness and non-linear analysis. The misalignment factor was determined by fitting predicted and experimental data and the non-linear shearing stiffness was modeled by piecewise linear segments. Using high and low temperature tests, Wang found good agreement between predicted and actual values. 
In 1981, Maewal [6] modeled the buckling behavior using stability theory based on Koiter's theory of elastic stability. The results were very unexpected. When using linear material properties, such as shear stiffness, fiber buckling was found to be insensitive to initial misalignment and not expected to significantly reduce microbuckling stress. This contradicted the results found by [5].

In the same year, Martinez and Piggott [7] devised a modified pultrusion technique to study the effects of misaligned fibers in compression. By twisting tows of fibers before introducing them into the resin, the authors claim to have added an average misalignment angle of $\theta$. Their data showed that up to $\theta=10$ degrees misalignment, there was no significant effect on strength. More than likely, the "misalignment" induced by this technique was similar to the case of a balanced, symmetric lay-up with $[+\theta /-\theta]_{\mathrm{s}}$. The strength of this type lay-up is given by the stress transformation [8] and results in a cosine square term applied to F1c. Thus at 10 degrees, the reduction in strength is only 3\%. The authors also investigated the fiber matrix interface and concluded that poor adhesion between fibers and matrix also had a detrimental effect on strength. Separately, Piggott [9] concluded in 1981 that "in order to make a composite with good compressive properties, the fiber should be hard, as straight as possible and well bonded to the matrix. The matrix should have a high yield stress, tensile strength and compressive strength." This statement seems to contradict the earlier study since "straight" fibers imply low misalignment.

A different approach to predicting compression failure was introduced by Budiansky in 1983 [10]. Rather than microbuckling, Budiansky studied the mechanics of fiber kinking. By assuming straight fibers and linear material properties, he found that a 
zero-degree kink angle could reproduce Rosen's results. As was well known, the kink band angle is usually 30-40 degrees and so Budiansky modified the approach to include non-linear material properties.

In 1987, Tang, Lee, and Springer [11] studied the effects of cure pressure on void content in a lay-up. By adjusting pressure during the cure cycle, they were able to change the void content, which they measured optically. In compression strength and interlaminar shear strength tests, they found that decreasing the void content helps these properties up to a point. Below 3-4\% void content, the strengths do not improve significantly. One questionable area in this report is the high void content $10 \%, 6 \%, 5 \%$ reported for cure pressures $20,55,80$ psig respectively. This may be due to calibration of the optical method used. Nevertheless, the authors did establish a relationship between compressive strength and other key parameters, such as void content.

In the same year, Yurgartis [3] developed an important optical technique to measure the initial fiber misalignment allowing it to be measured for the first time. This opened the way for researchers in the late 80's and early 90's to quantify and deepen the analysis of compression. Using the optical technique, Mrse and Piggott [12], Yurgartis and Sternstein [13], Barbero and Tomblin [14], Lagoudas and Saleh [15], Haberle [1] found that higher initial fiber misalignment did, in fact, reduce compression strength. Among these, [13], [16] added more evidence about the direct relationship between compressive strength and shear stiffness. Furthermore, Steif [17] proposed that the tangent hyperbolic function could be used to characterize shear stiffness because it successfully captured the antisymmetric nature of shear stiffness. Previously, piecewise 
continuous linear segments or truncated polynomials were adequate but were very cumbersome when used in stability analysis.

Shuart [18] studied the effects of global misalignment on $[ \pm \theta]_{\mathrm{s}}$ laminates in a paper published in 1989. Shuart proposed three different failure mechanisms depending on $\theta$. For $0<\theta<15$ degrees, interlaminar shear was the dominant failure mode. For $15<\theta<50$, it was in-plane matrix shearing and for $50<\theta<90$, matrix compression was the failure mode. His model included non-linear analysis and initial fiber waviness. The strength predictions were very good for $50<\theta<90$, but for $0<\theta<50$ they were generally conservative by a 0 to $30 \%$ margin.

In 1997, Tomblin, Godoy and Barbero [19] used stability theory to show that fiber buckling was sensitive to initial misalignment when non-linear shear stiffness (tangent hyperbolic) was used. When linear shear stiffness was used, fiber buckling was found to be insensitive to initial misalignment as [6] had proposed 15 years earlier. Later, [14] combined the continuous damage mechanics work of Kachanov [20] and a statistical approach to fiber misalignment to arrive at a numerical solution to the prediction of compressive strength. In 1998, Barbero [2] derived an explicit equation for compression strength which utilized the continuous damage mechanics and statistical approaches used in [14].

Despite the large body of work focused on correlating compressive strength with other basic material properties, the majority of studies use empirical parameters to correlate strength. Only a few studies base the prediction of compression specimen strength on actual measured properties of the specimen [1], [14], [21]. To date, there is 
no known study that correlates compressive strength of production parts with basic material properties (shear stiffness and strength, but excluding compressive strength).

In industry, the compressive strength of production parts is predicted by finite element analysis using a database of material properties. Later, compressive strength and other design parameters are confirmed with a testing program. In the May 1999 ASTM Symposium on Composite Structures, [22] presented the "Building Block" structural qualification program for the RAH-66 Comanche Attack Helicopter as shown in Figure 2.2. As can be seen, structural qualification is composed of several levels of testing to gain confidence in the material allowables and analysis methods. Many times this is because the performance of a material as a laboratory specimen is better than as a production part. Lab specimens are fabricated under ideal conditions and tested in very controlled circumstances whereas production parts are open to the many variables in manufacturing and testing.

Because the full "Building Block" testing program is costly and time consuming, efforts are underway to use a "Modified Building Block" approach when possible [23] and reducing testing in the areas shown in Figure 1.2. In this process, the amount of testing is reduced to the minimum required based on previous testing experience and engineering judgement. The minimum required tests will usually involve one or more of the following: compressive strength, compressive strength after impact, shear strength and compression-shear interaction.

Industry has signaled a clear need to better predict the strength of composites to reduce development time and cost. At the same time, the literature shows that studies in the 90's have made practical compressive strength prediction more and more a reality. 
In-Phase (Shear) Mode

Out-of-Phase

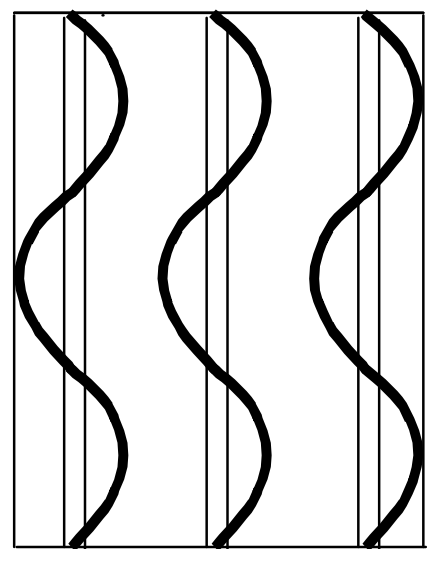

(Extensional) Mode

Figure 1.1 Modes of Fiber Buckling

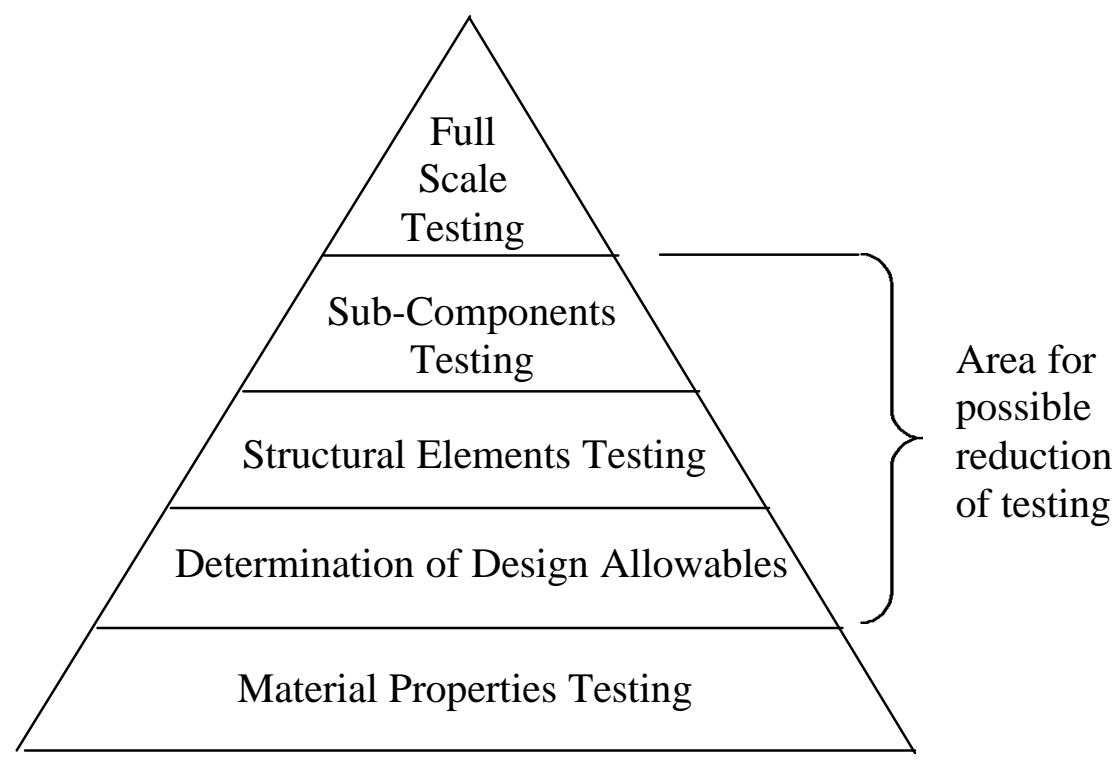

Figure 1.2 Building Block Approach to Testing 


\section{Chapter 2: Theoretical Modeling}

The theoretical model presented by Barbero in [2], [14] draws upon many of the references cited in the literature review. Fundamentally, it is a unique approach because it integrates a statistical representation of the composite with a continuum damage mechanics model to arrive at an explicit equation for compressive strength in terms of measured properties, shear modulus G12, shear strength F6 and the standard deviation of the fiber misalignment angle, $\Omega$.

\subsection{Composite Shear Response}

The shear stress-strain relationship for polymer-matrix composites is not linear and can be represented as

$$
\tau=\mathrm{F}_{6} \tanh \left(\frac{\mathrm{G}_{12}}{\mathrm{~F}_{6}} \gamma\right)
$$

or a quadratic polynomial such as

$$
\tau=\mathrm{G}_{12} \gamma-\mathrm{C}_{2} \gamma^{2} .
$$

The hyperbolic tangent function nicely represents the anti-symmetric nature of the shear response. The quadratic polynomial has the advantage of being easier to manipulate than the hyperbolic tangent expression but must be used where the fit is good. Consequently, the tangent hyperbolic was used when finding the exact but implicit solution that is solved by numerical methods in [14], and the quadratic polynomial was used when deriving an explicit solution in [2]. The derivation of the explicit solution is shown here. 
The constant $\mathrm{C} 2$ can be found solving the above two equations for $\mathrm{C} 2$ and restricting $\gamma$ to not exceed $\gamma_{\text {lim. }}$

$$
\begin{aligned}
& \gamma_{\lim }=2 \frac{F_{6}}{G_{12}} \\
& C_{2}=-\frac{\left(G_{12}\right)^{2}}{4 F_{6}}
\end{aligned}
$$

where $\gamma_{\text {lim }}$ is an upper bound to the shear strain at which most composite materials, carbon-epoxy and glass-polyester, fail in compression. A comparison is shown in Figure 2.1 between the two equations and experimental results for 949/M30GC using the ASTM 5379 shear test.

Other micromechanical models that use in-situ properties, such as shear modulus of the matrix, Gm, were purposely avoided. This is because it would be very difficult to verify if the compression strength prediction was correct since the in-situ properties are very difficult to measure and could be different than properties in the bulk matrix.

\subsection{Fiber Misalignment}

Since the misalignment of fibers is very small, a microscope is used to measure this misalignment in the cross-section. The technique is described in detail in Chapter 4. Experimentally, the distribution of angles has been shown to be Gaussian or normal, hence the probability is given by

$$
f(\alpha)=\frac{1}{\Omega \sqrt{2 \pi}} e\left(\frac{-\alpha^{2}}{2 \Omega^{2}}\right)-\infty<\alpha<\infty
$$


where $\Omega$ is the standard deviation, $\alpha$ is the misalignment angle and $f(\alpha)$ is the probability density function. The probability of getting an angle between $-\alpha$ and $\alpha$ is given by the integral

$$
F(\alpha)=\int_{-\alpha}^{\alpha} f\left(\alpha^{\prime}\right) d \alpha^{\prime}
$$

Changing to the normalized misalignment variable $\mathrm{z}$, defined as

$$
\mathrm{z}=\frac{\alpha}{\Omega \sqrt{2}}
$$

the cumulative distribution function can now be described as a "folded" function as below

$$
\mathrm{F}(\mathrm{z})=\operatorname{erf}(\mathrm{z})=\frac{2}{\sqrt{\pi}} \int_{0}^{z} \exp \left(-z^{\prime 2}\right) d z^{\prime}
$$

Since the integral of a transcendental equation is difficult to manipulate later, it is approximated by a quadratic polynomial,

$$
\mathrm{F}(\mathrm{z})=1.179643858 \mathrm{z}-0.3455580967 \mathrm{z}^{2}
$$

for the interval $0<\alpha<3 \Omega$, which is sufficiently broad to model the problem at hand [2].

\subsection{Imperfection Sensitivity Equation}

The relationship between buckling stress and misalignment is called the imperfection sensitivity curve. Unlike equilibrium based models that compute shear strain only at the inflection points of the given fiber shape, the shear strain energy of the entire 
Representative Volume Element, RVE, is modeled in the equation. This model assumes that all fibers are misaligned at the same angle as shown in Figure 2.2.

The model uses the principle of total potential energy and assumes axial effects can be neglected. In this one dimensional case, an expression can be written where only the shear energy is considered in the total potential energy

$$
W=\int_{0}^{l} \int_{\mathrm{A}}^{\gamma} \int_{0}^{\gamma} \mathrm{F}_{6} d \gamma d A d x-P \Delta l
$$

where $\mathrm{P}$ is the end load; $\Delta l$ is the end shortening; $\tau$ and $\gamma$ are the shear stress and strain; $l$ and $A$ are the length and area of the RVE. Using the shear stress as described in equation (2.2), equation (2.9) can be solved for the equilibrium stress as

$$
\sigma(\alpha, \gamma)=\frac{\gamma \mathrm{G}_{12}}{\gamma+\alpha}+\frac{8}{3} \frac{\mathrm{C}_{2} \gamma^{2}}{3(\gamma+\alpha) \pi}
$$

This equilibrium equation produces a family of curves for 949/M30GC as in Figure 2.3. Thus for every angle $\alpha$, there is a maximum value of compression strength before buckling occurs. The curve that joins all the maxima is

$$
\sigma(\alpha)=\frac{4 \sqrt{2} C_{2} \alpha\left(-8 C_{2} \alpha+3 \pi G_{12}\right)}{3 \pi \sqrt{-C_{2} \alpha\left(-8 C_{2} \alpha+3 \pi G_{12}\right)}}-\frac{16 C_{2} \alpha}{3 \pi}+G_{12}
$$

\subsection{Continuum Damage Model}

At any time during the loading of the specimen, the applied stress is equal to the effective stress in the composite times the area that remains unbuckled

$$
\bar{\sigma}=\sigma(\alpha)[1-\omega(\alpha)]
$$


In this equation, $0 \leq \omega(\alpha) \leq 1$ is the area of the buckled fibers per unit of initial composite area. For any value of effective stress, all fibers having more than the corresponding value of misalignment given in Figure 2.4 have buckled. The area of the composite with buckled fibers $\omega(\alpha)$ is proportional to the area under the normal distribution located beyond the misalignment angle $\pm \alpha$. Therefore $\omega(\alpha)$ is given by:

$$
\omega(\alpha)=1-\int_{-\alpha}^{\alpha} f\left(\alpha^{\prime}\right) d \alpha^{\prime}=2 \int_{\alpha}^{\infty} f\left(\alpha^{\prime}\right) d \alpha^{\prime}
$$

Substituting into equation (2.13) the compressive strength of a composite can be found as

$$
F_{1 \mathrm{c}}=\max \left[\sigma(\alpha) \int_{-\alpha}^{\alpha} f\left(\alpha^{\prime}\right) d \alpha^{\prime}\right]
$$

Graphically, F1c can be seen as the maximum of the applied stress curve in Figure 2.5.

\subsection{Explicit Equation}

Substituting equation (2.9) for the integral in equation (2.15), the applied stress equation (2.13) becomes

$$
\bar{\sigma}(z)=\sigma(z) F(z) .
$$

which simplifies subsequent derivations.

To find the maximum explicitly, equation (2.16) is expanded into a truncated polynomial about $\alpha=\Omega\left(\right.$ or $\left.\mathrm{z}=(1 / 2)^{1 / 2}\right)$, which is an adequate range for a broad class of materials [2]. The root of the derivative can then be found explicitly as 


$$
\begin{aligned}
F_{1 c}= & {\left[\begin{array}{l}
1019.011 G_{12} C_{2}^{2} \Omega^{3}-375.3162 C_{2}^{3} \Omega^{4}-845.7457 G_{12}^{2} C_{2} \Omega^{2} \\
+g\left(282.113 G_{12} C_{2} \Omega^{2}-148.1863 G_{12}^{2} \Omega-132.6943 C_{2}^{2} \Omega^{3}\right)
\end{array}\right] } \\
& \times\left[\begin{array}{c}
457.3229 C_{2}^{3} \Omega^{2}-660.77 G_{12} C_{2}^{2} \Omega^{2}-22.43143 G_{12}^{2} C_{2} \Omega \\
+g\left(161.6881 C_{2}^{2} \Omega^{2}-138.3753 G_{12} C_{2} \Omega-61.38939 G_{12}^{2}\right)
\end{array}\right],
\end{aligned}
$$

where $\mathrm{g}$ is the following

$$
g=\sqrt{C_{2} \Omega\left(8.0 C_{2} \Omega-9.424778 G_{12}\right)} .
$$

Substituting $\mathrm{C}_{2}$ and g, equation (2.4) and (2.18), into (2.17), the following expression can be written:

$$
\begin{aligned}
\frac{F_{1 c}}{G_{12}}=\frac{\chi}{24 \pi} \frac{C_{3}}{C_{4}} & \\
\mathrm{C}_{3}= & -10979.6-8432.03 \chi^{2}-19037.205 \chi-124.653 \chi^{4}-\frac{103961}{64} \chi^{3} \\
& +\left(12191.07+1881.87 \chi^{2}+176.286 \chi^{3}+7979.978 \chi\right) \sqrt{\frac{\chi^{2}}{2}+2.356 \chi} \\
\mathrm{C}_{4}= & \left(-7.146 \chi^{3}-41.298 \chi^{2}+5.608 \chi\right) \sqrt{\frac{\chi^{2}}{2}+2.356 \chi} \\
& +\left(10.106 \chi^{2}+34.594 \chi-61.389\right)\left(\frac{\chi^{2}}{2}+2.356 \chi\right) \\
\chi= & \frac{\mathrm{G}_{12} \Omega}{F_{6}}
\end{aligned}
$$


Taking into account that the dimensionless compression strength, $\mathrm{F}_{1 \mathrm{~d}} / \mathrm{G}_{12}$, can be modeled in terms of a dimensionless number, $\chi$, the following numerical approximation can be made of the ungainly equation (2.19) as follows:

$$
\begin{aligned}
& \frac{F_{1 c}}{G_{12}}=\left(\frac{\chi}{a}+1\right)^{b} \\
& a=.21 \\
& b=-.69
\end{aligned}
$$

Constants $\mathrm{a}$ and $\mathrm{b}$ are found by using a full factorial design within the range

$$
\begin{aligned}
0.5075 \mathrm{Msi} & <G_{12}<1.160 \mathrm{Msi} \\
5.8 \mathrm{ksi} & <\mathrm{F}_{6}<23.2 \mathrm{ksi} \\
1^{\circ}<\Omega & <3.5^{\circ}
\end{aligned}
$$

This gives $n=3^{3}=27$ points for which the dimensionless compression strength can be computed using equation (2.19) to find constants a and $b$.

\subsection{Global Misalignment}

When a lay-up has average global misalignment $\alpha_{G}$ and is balanced and symmetric $\left[ \pm \alpha_{G}\right]_{s}$, the maximum compressive stresses can be found by stress transformation [8]. The compressive stress is given by $(F 1 c) \times\left(\operatorname{cosine}^{2}\left(\alpha_{G}\right)\right)$. There is good agreement with the data for $0<\alpha_{G}<10$ degrees [18]. However, there exists no known method for estimating the strength of laminates with average global misalignment and $\left[+\alpha_{G}\right]_{n}$ or $\left[-\alpha_{G}\right]_{n}$ stacking schedule. 
When there is global misalignment, the representative volume element is as shown in Figure 2.6. The potential energy (2.9) and equilibrium (2.11) equations still apply but the distribution of fiber angles (2.5) and normalized misalignment variable (2.7) are shifted by the average angle, $\alpha_{\mathrm{G}}$.

$$
\begin{gathered}
f\left(\alpha, \alpha_{G}\right)=\frac{1}{\Omega \sqrt{2 \pi}} e\left(\frac{-\left(\alpha-\alpha_{G}\right)^{2}}{2 \Omega^{2}}\right),-\infty<\alpha<\infty \\
\mathrm{z}=\frac{\alpha-\alpha_{G}}{\Omega \sqrt{2}}
\end{gathered}
$$

The probability density function from 0 to $\infty$ is no longer the probability density function (2.8) because there is no symmetry about zero. Therefore, the quadratic polynomial approximation (2.9) cannot be used. Instead, the function can be integrated numerically as shown in Figure 2.7 which is for the case of 0 degree average global misalignment and fixed value of $\Omega=1.15$ degrees. Notice that there are slight differences between the previous quadratic polynomial approximation and the discrete numerical integration within the range of $0<\alpha<3 \Omega$ for which equation (2.9) is valid. To illustrate the integration, Figure 2.8 shows the case of 1.0 degree average global misalignment. The function is folded about zero and the two distributions are added together. For comparison, the probability density function for 0 degree average global misalignment is shown too.

Using this technique, a family of probability density functions at various average global misalignment angles can be determined as shown in Figure 2.9. Figure 2.10 shows the integration of these curves (2.21) to obtain the cumulative distribution function at these angles of average global misalignment. When multiplied by the effective stress 
(2.12), the resulting applied stress curves are shown in Figure 2.11. The maximum of each curve represents the compressive strength at the given average global misalignment angle with $\Omega=1.15$ degrees. This technique is informally called the "Method of Shifted Distributions".

Note that Figure 2.7 through 2.11 were for a fixed value of $\Omega$. If $\Omega$ was taken at different values, it would produce a family of curves for F1c as a function of $\Omega$ and $\alpha_{\mathrm{G}}$. Figure 2.12 shows the compressive strength F1c as a function of $\alpha_{G}$ when the standard deviation of fiber misalignment is fixed at various values. An individual curve represents a part fabricated with a prepreg lay-up that has $\Omega$ and oriented with an average global misalignment of $\alpha_{G}$ with respect to the nominal direction. 


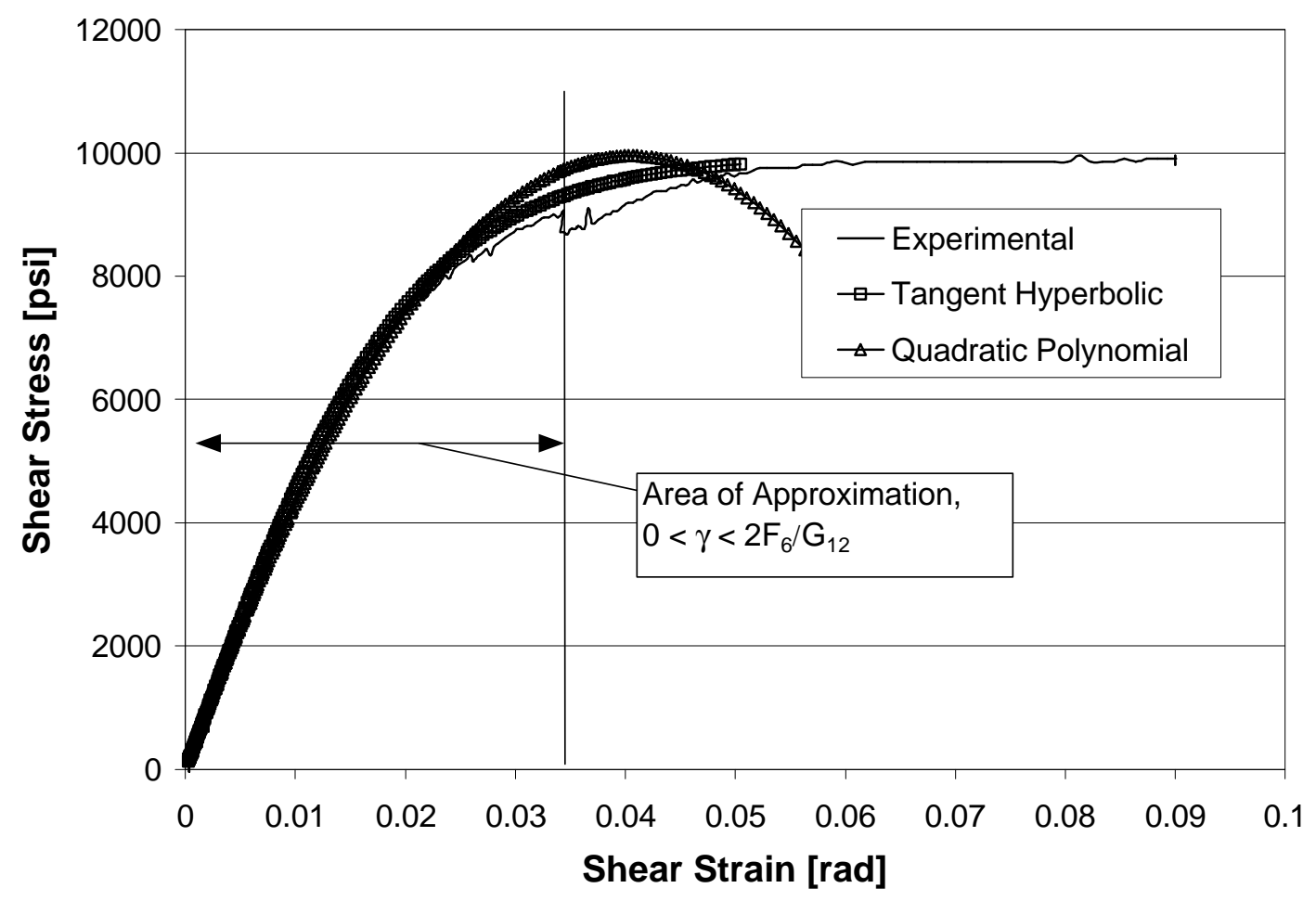

Figure 2.1 Range of Shear Stiffness when using Quadratic Polynomial

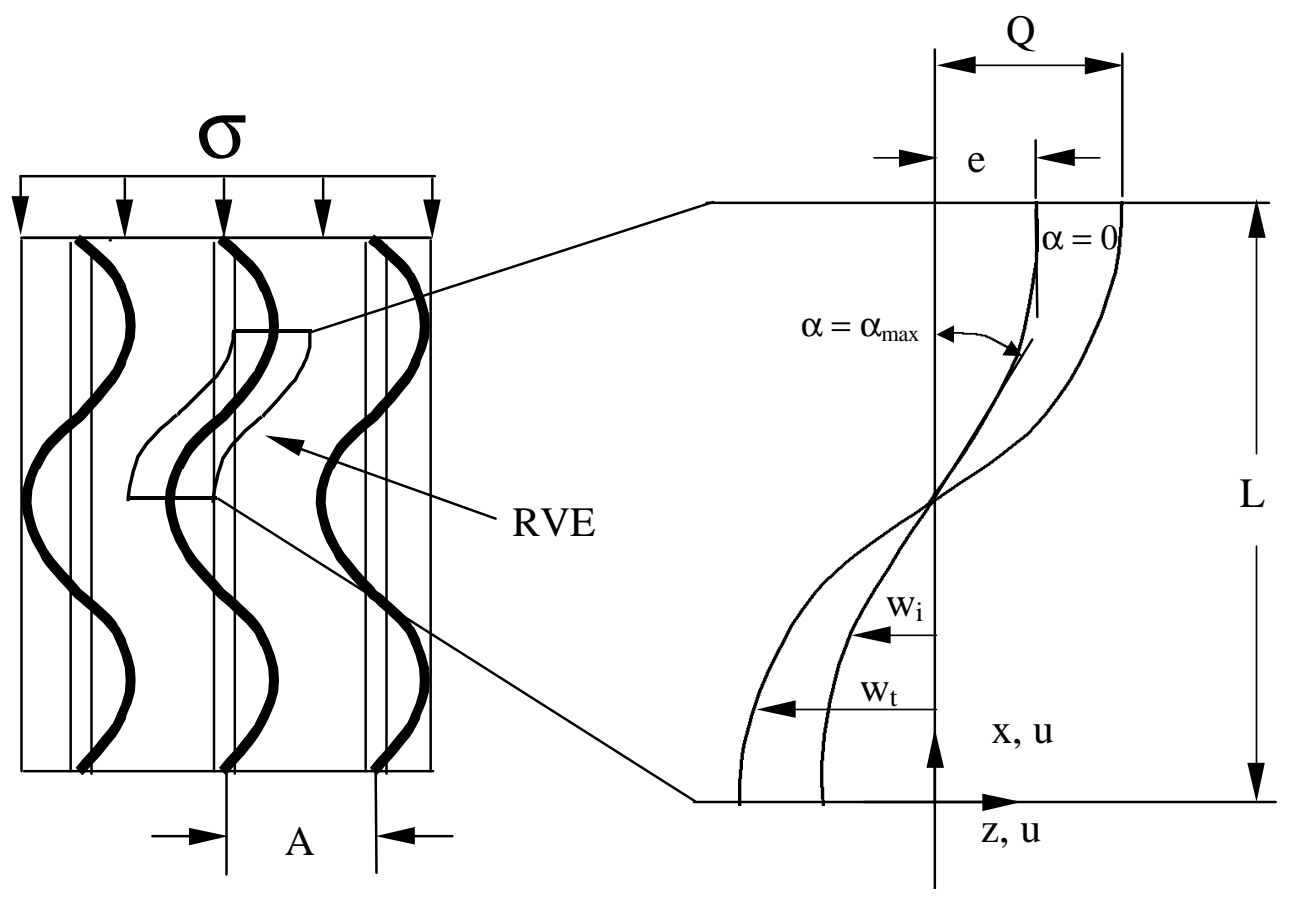

Figure 2.2 Representative Volume Element 


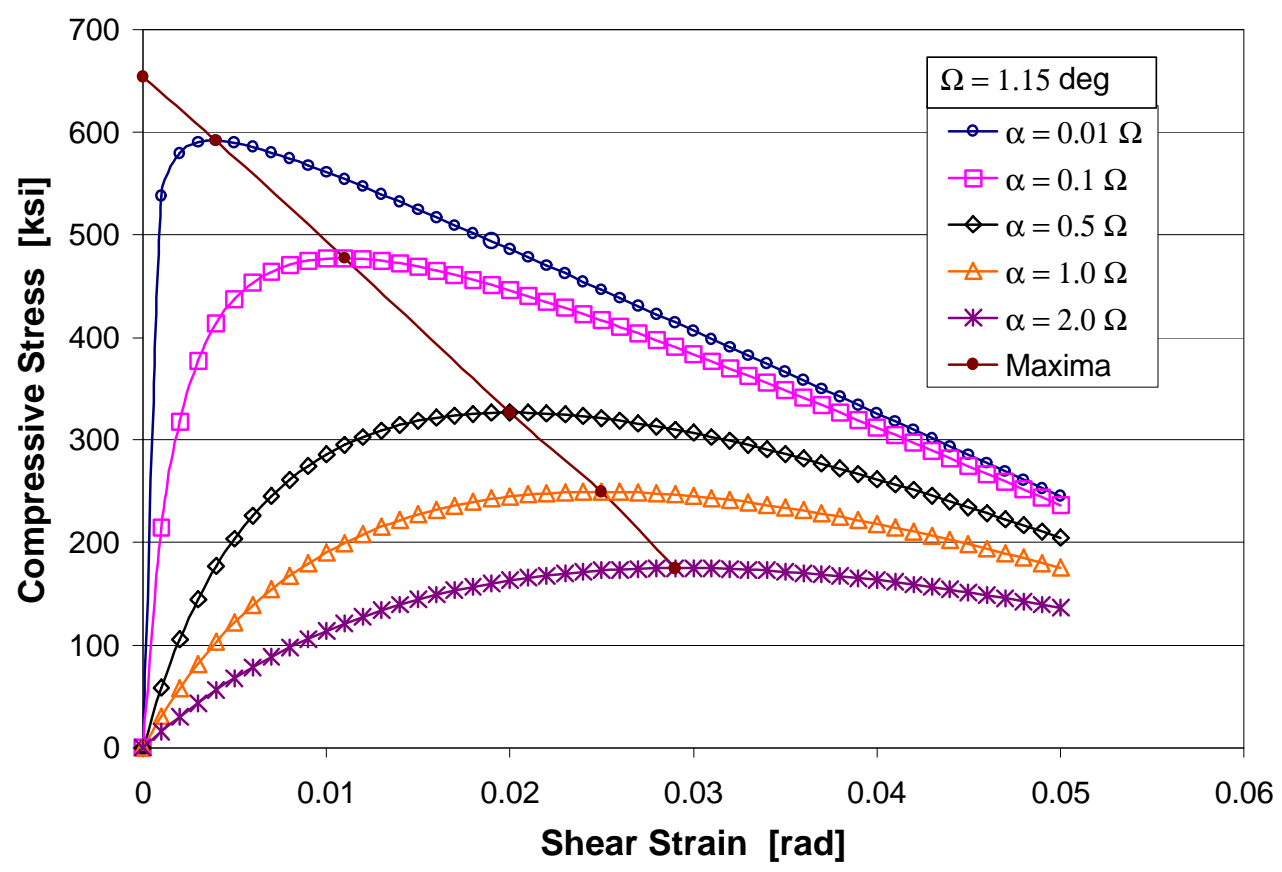

Figure 2.3 Equilibrium States for Various Values of Misalignment

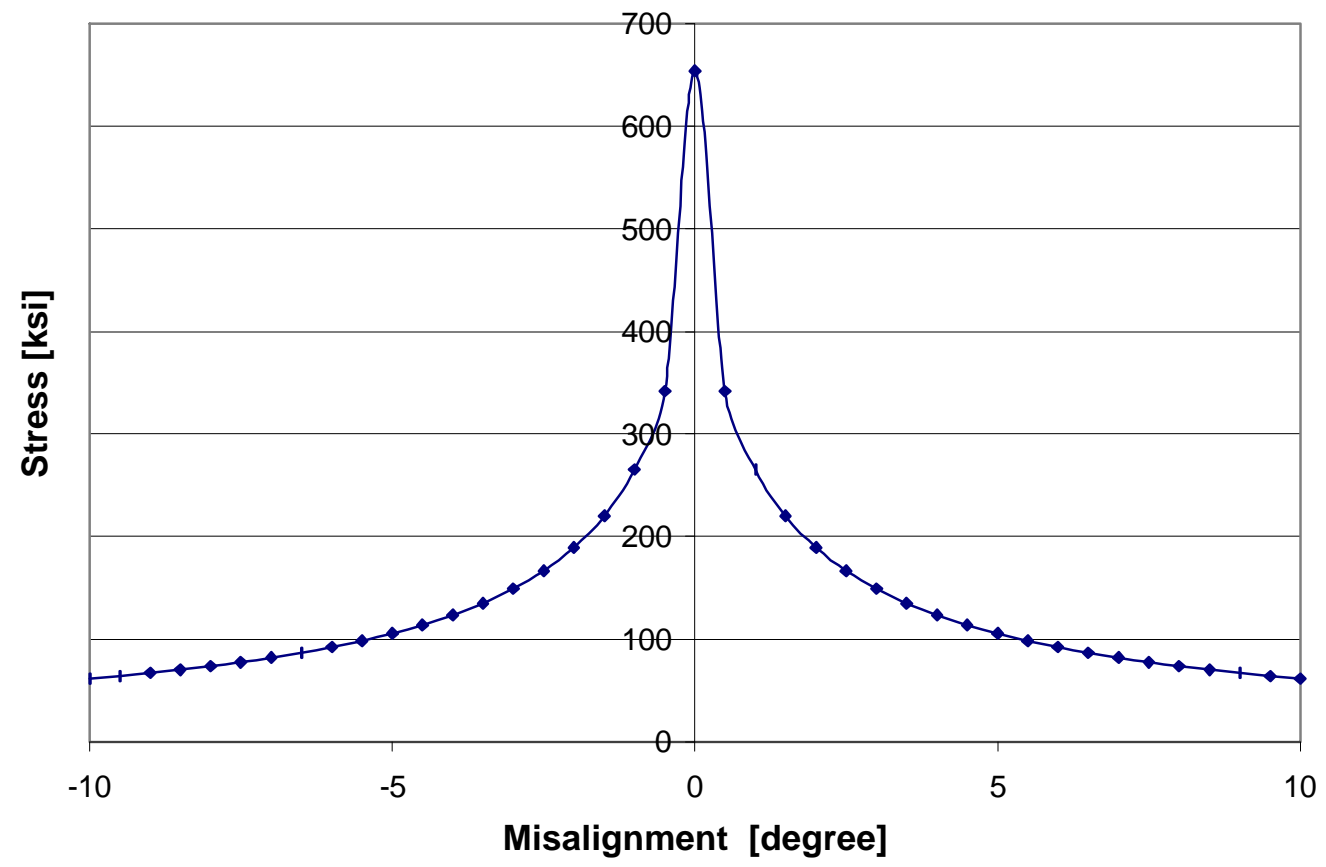

Figure 2.4 Imperfection Sensitivity Plot 


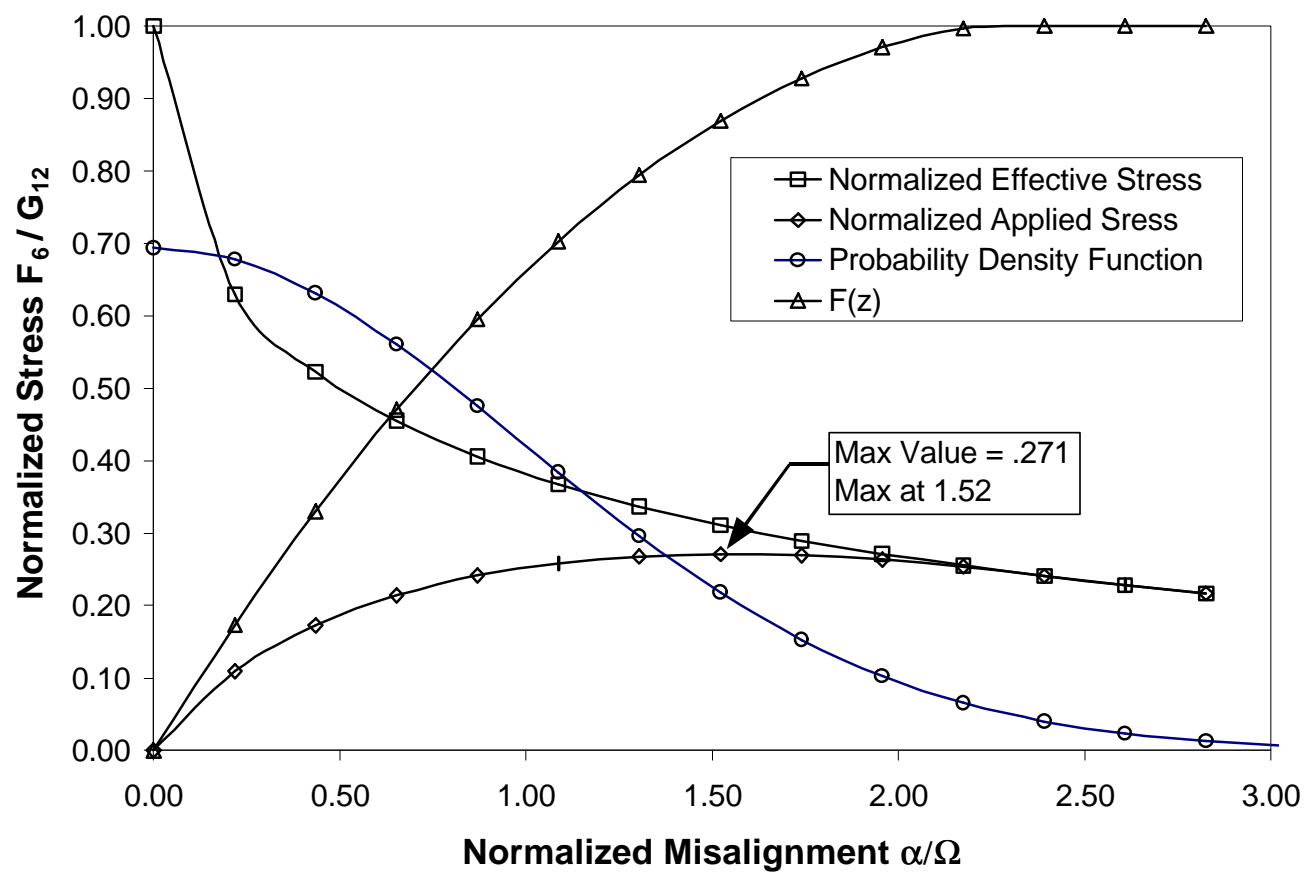

Figure 2.5 F1c at Maximum of Applied Stress

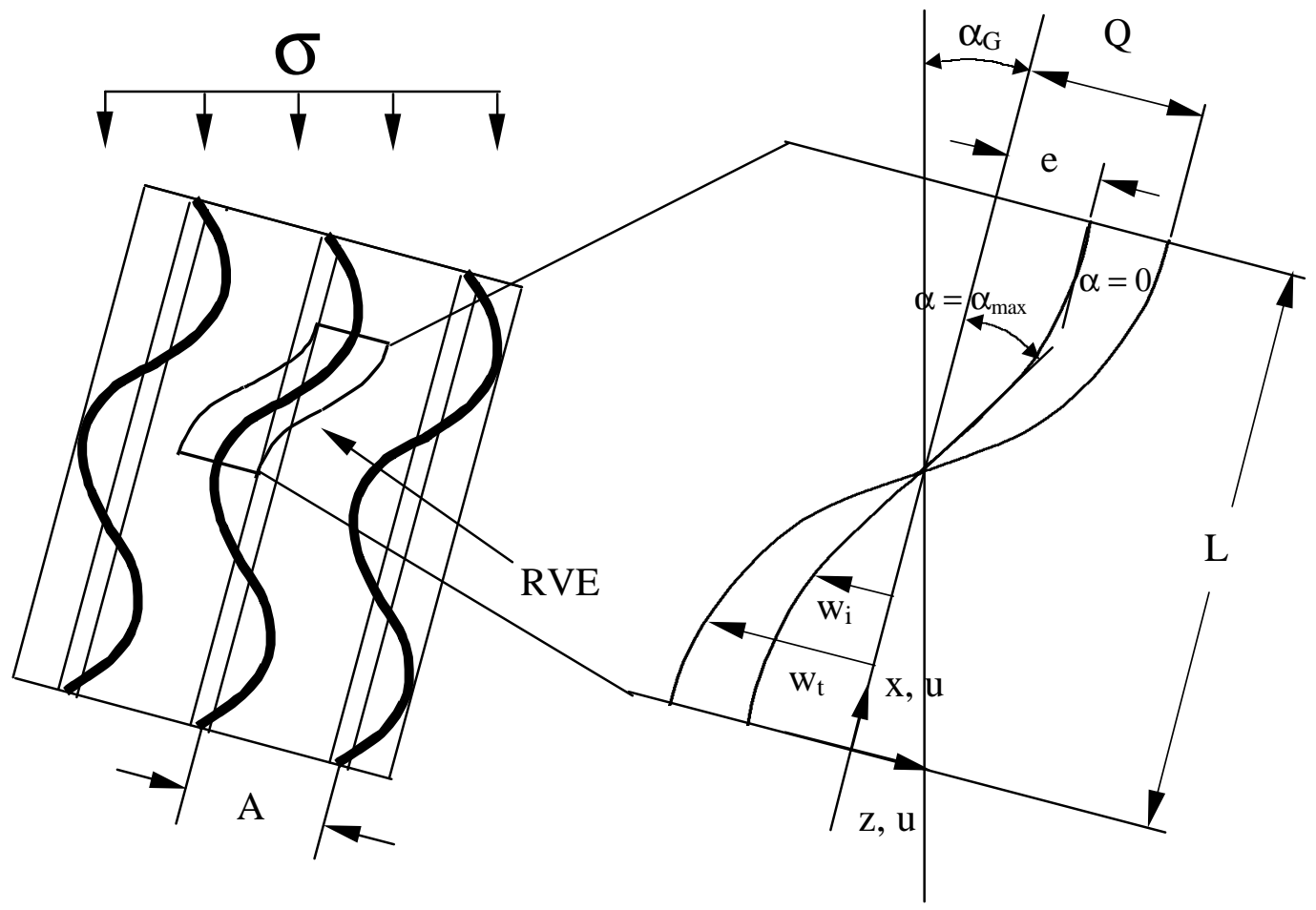

Figure 2.6 Representative Volume Element with Global Misalignment 


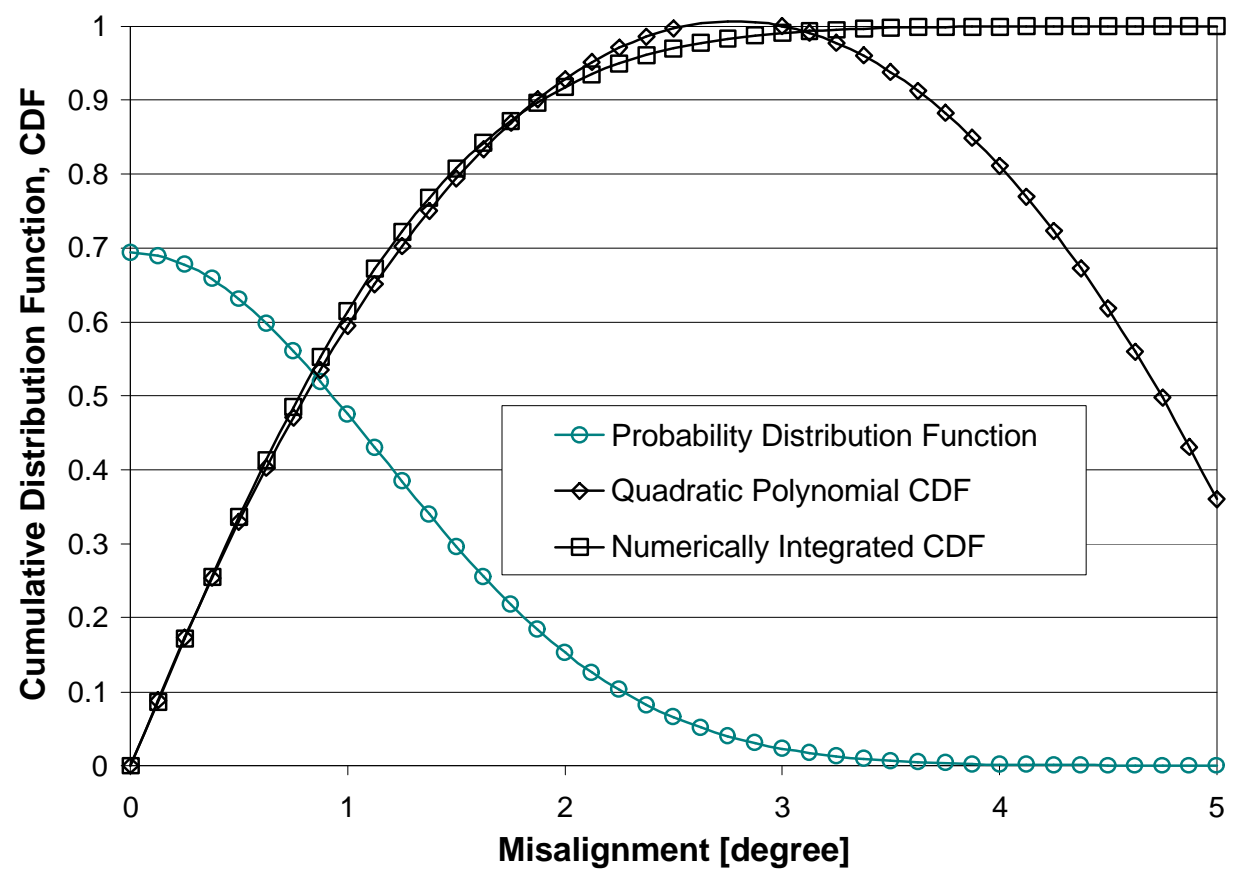

Figure 2.7 Numerical Integration and Quadratic Polynomial Function

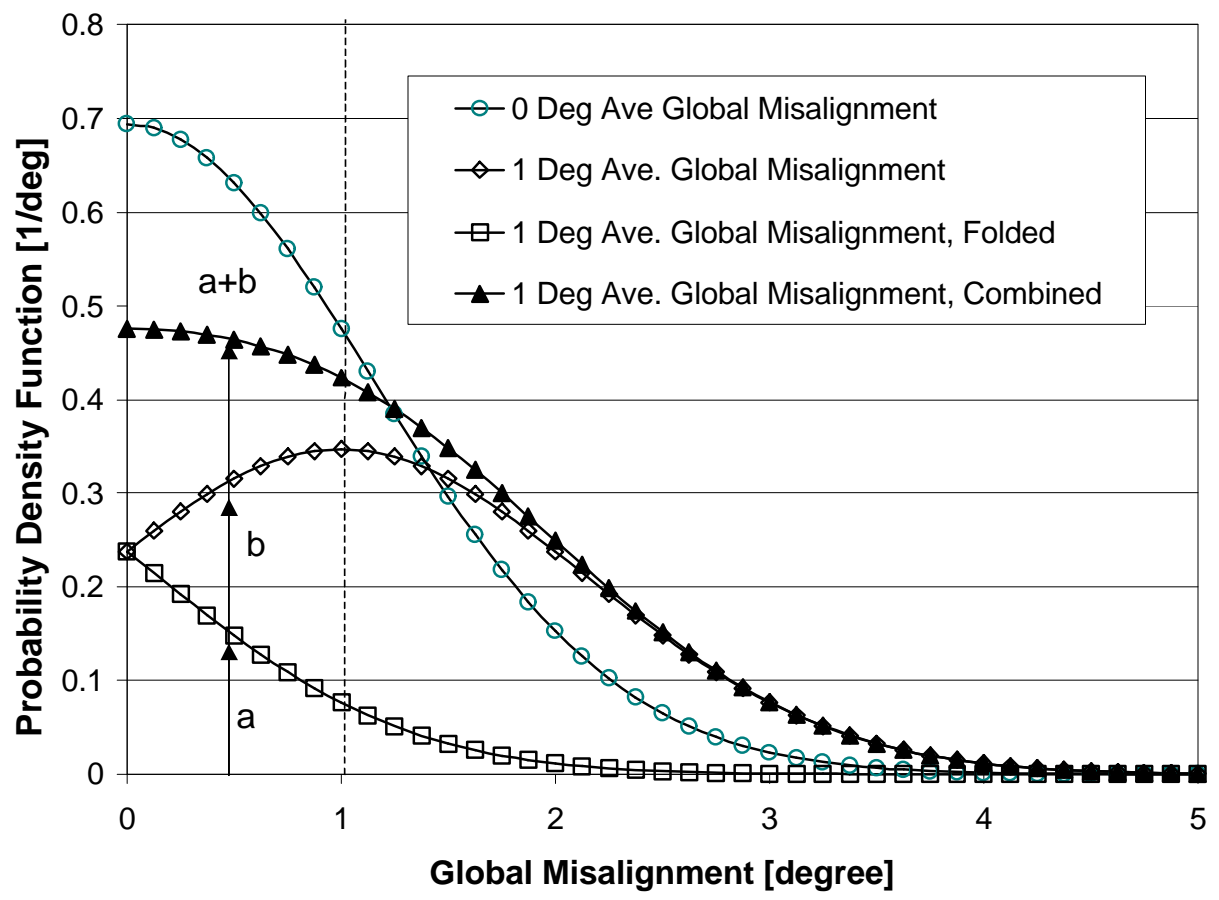

Figure 2.8 Probability Density Function at 0, 1.0 Ave. Global Misalignment 


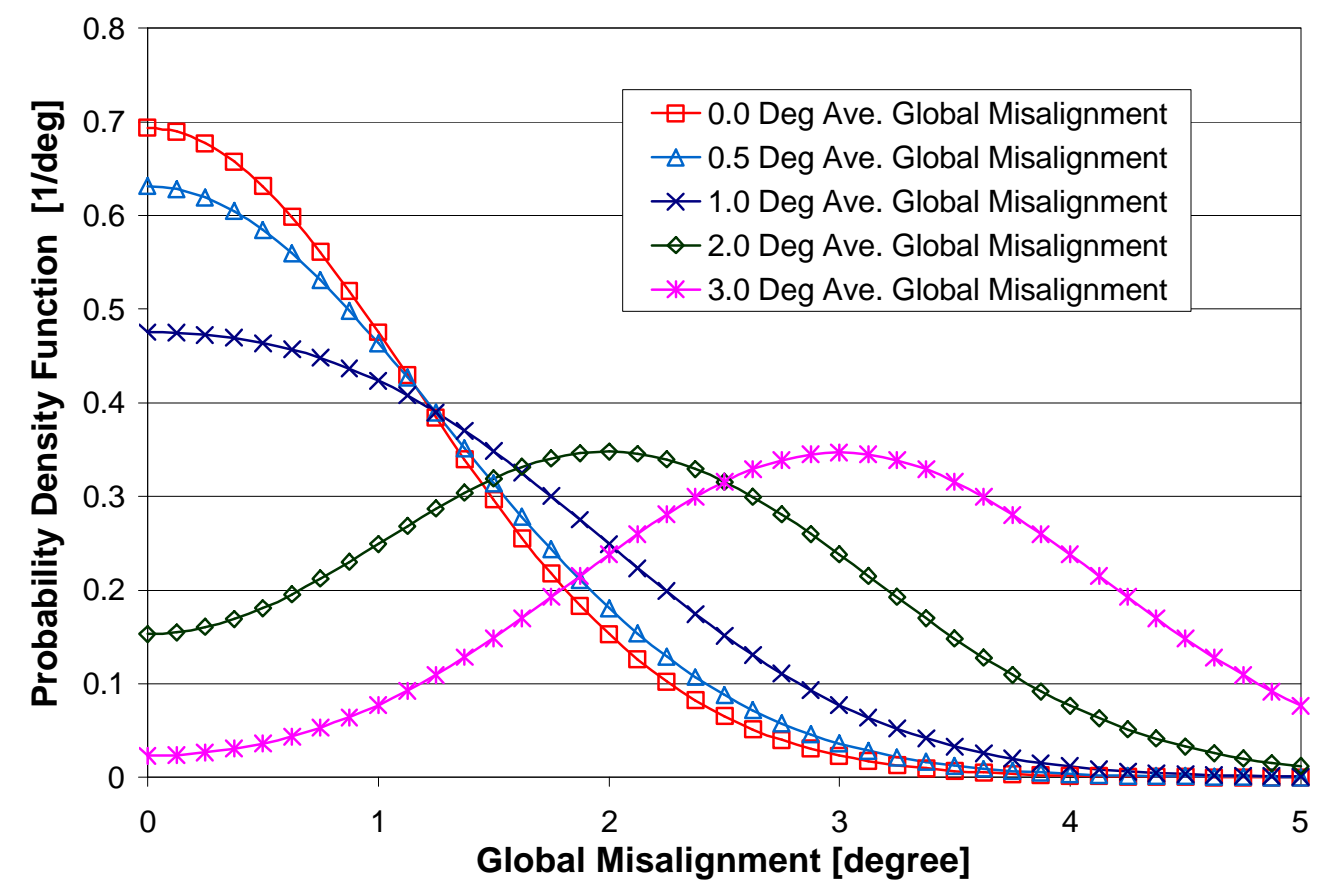

Figure 2.9 Probability Density Functions at Ave. Global Misalignments

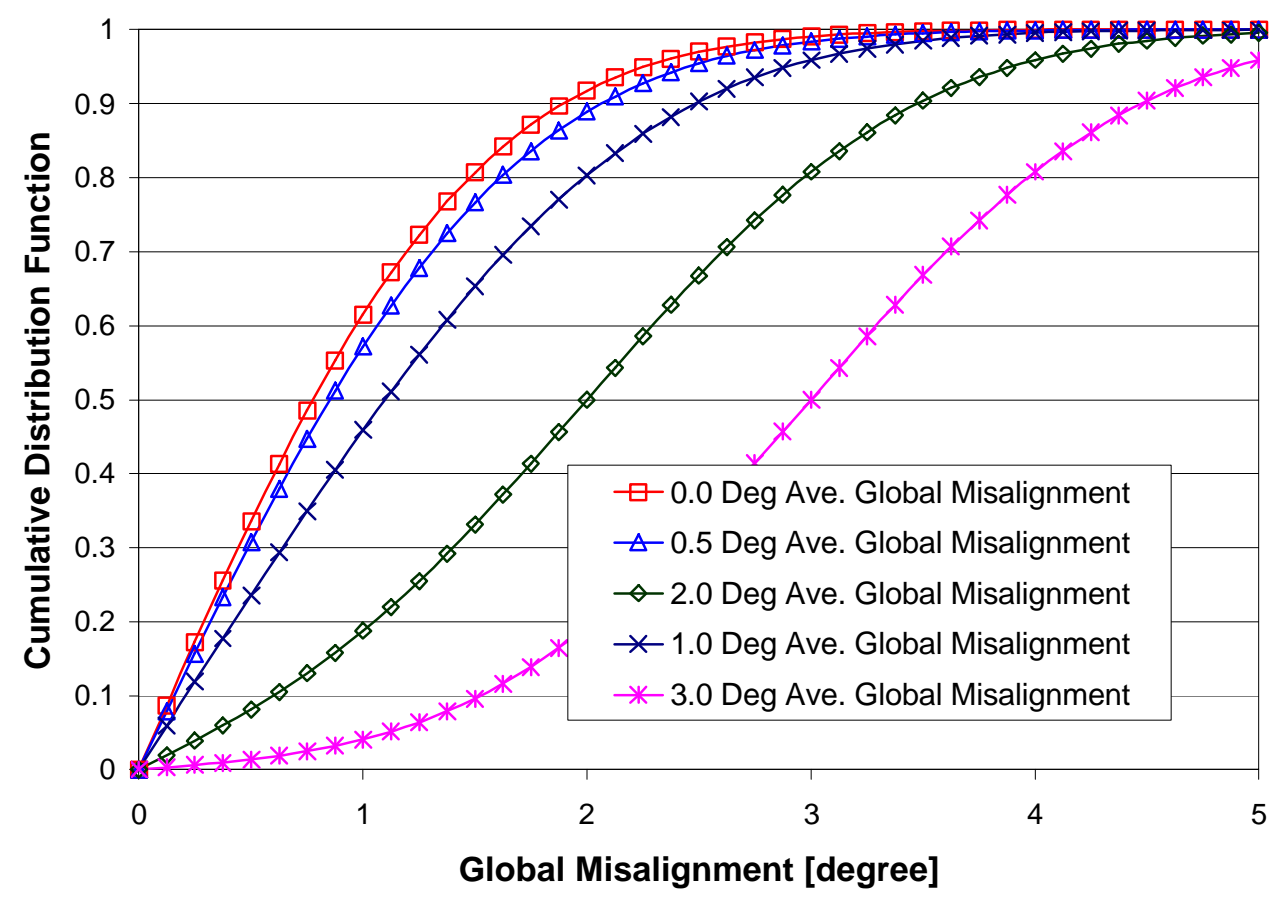

Figure 2.10 Cumulative Distribution Functions 


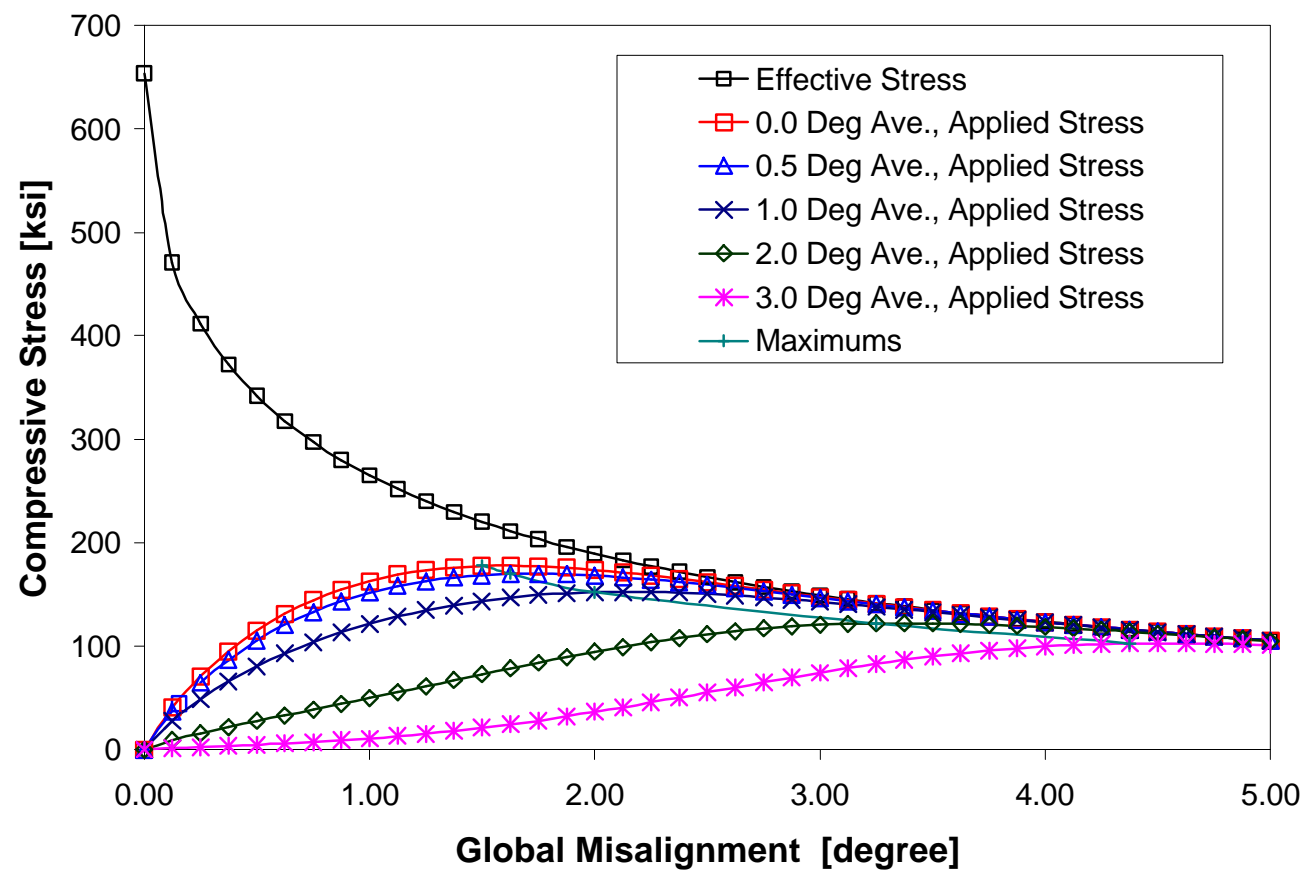

Figure 2.11 Applied Stress at Different Global Misalignments

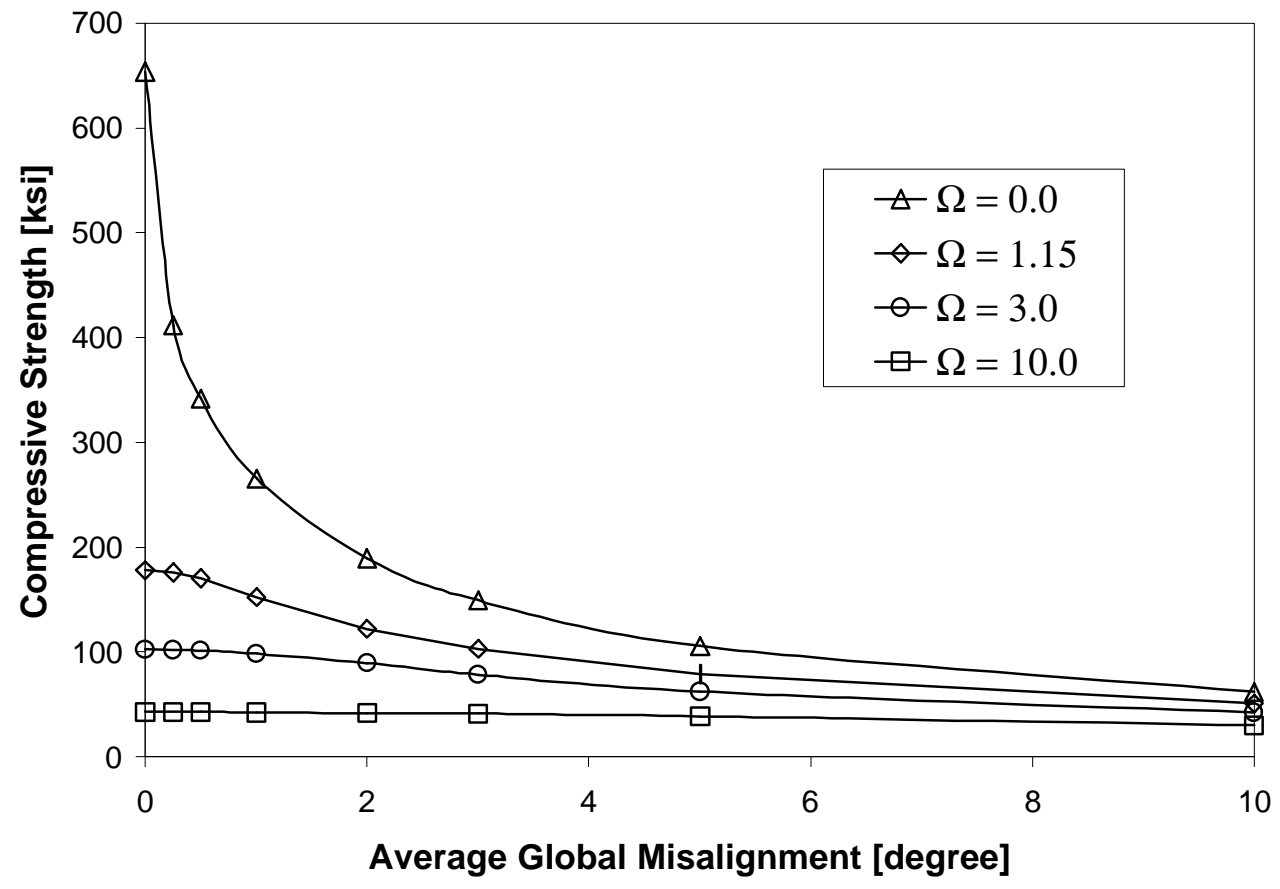

Figure 2.12 949/M30GC F1c vs. Average Global Misalignment 


\section{Chapter 3: Material Characterization and Beam Testing}

The matrix of tests requested by Aurora Flight Sciences to characterize the Cytech Fiberite 949 HYE/M30GC and the 948A1 HYE/M40J material systems at -125F, RTA, 180F is shown in Table 3.1. The first material, 949 HYE/M30GC, is a carbon/epoxy prepreg commonly used for golf club shafts and tennis rackets. The second material, 948A1 HYE/M40J, is also a carbon/epoxy prepreg that has an intermediate modulus fiber and a relatively stiffer matrix.

Phase I tests were arranged to study the effects of "debulking" on void sensitive properties. For example, to debulk a lay-up of 100 plys of prepreg, the lay-up is vacuum bagged every 10 plys to reduce voids or air pockets that occur in the process. This study looked at 5, 10 and 20 plys/debulk in the hope of finding the "knee" in the curve where increasing the number of plys/debulk had diminishing improvement in material properties. In Phase I, the compression tests were contracted to Touchstone Research Laboratories.

Phase II tests were intended to study the effects of temperature on mechanical properties. Phase II high and low temperature tests were contracted to Orange County Material Test Labs (OCM). All the results of the material characterization program are shown here but only the compression and shear tests are discussed in detail. 


\subsection{Compression/Shear Test Selection}

Initially, the ASTM D3410 “IITRI" test was used for Phase I compression testing. It utilizes a shear loaded specimen as shown in Figure 3.1. Since the IITRI test gave low values of compression strength as in Table 3.2, the SACMA SRM-1R-94 procedure was selected for all subsequent compression tests (Figures 3.2, 3.3). Because of its end loaded specimen, this test typically provides compressive strengths $5 \%$ better than the D3410 "IITRI" method. The SACMA test also allowed easier comparison with manufacturer's data because composite parts manufacturer's and prepreg producers use it more often.

To measure shear strength and modulus, the D5379 "Iosipescu" method was selected (Figures 3.4 and 3.5). MicroMeasurements Shear Gages N2P-08-C032A-500 were used since they average the shear strain over the entire region between the notches of the specimen. Modulus data was taken between 1000-6000 microstrains from back-toback shear gages and the results from each side were averaged together. A detailed description of the test methods can be found in Appendix A.

\subsection{Compression/Shear Specimen Preparation}

The prepregs were laid up by hand and cured in an oven at $275 \mathrm{deg} F$ for 90 minutes with approximately 27 in. $\mathrm{Hg}$ vacuum bag pressure. A 7 ply [0 deg] panel was 
made for the compression specimens and a 20 ply [0 deg] panel was used for the shear modulus and shear strength specimens. The 7 ply panel was cured with peel ply and caul plates on both sides of the panel so that the surface would have very little waviness and the thickness would be relatively uniform (Figure 3.6). To achieve low global misalignment, great care was taken to align the 7 plies of the prepreg to the manufactured edge of the tape. The 20 ply panel was cured without caul plates or peel ply because the variations in thickness were judged to be small when compared to the total thickness. Panel sizes were 12 " X 18-24". The manufacturing history of each panel made in this study can be found in Appendix A.

The specimen tabs were bonded to the panels using technique similar to the one outlined in [1]. A room temperature cure paste adhesive, Magnabond 6380, was used to bond prefabricated glass/carbon tabs to a panel before cutting. A tile saw was used to rough cut the specimen panel to size. A surface grinder installed with a diamond blade was then used to make the final cuts. The surface grinder mounted with an 80 grit wheel was used to grind the surfaces square. A diamond bit on a milling machine ground the notches in the shear specimen.

\subsection{Data Normalization}

The panel thickness for the fiber driven property tests was very small approximately 0.040 inches. Since local variations in thickness could cause big changes in the final results, the thicknesses were normalized to an average value. This method is consistent with MIL-HDBK-17-E practices. 


$$
\text { Normalized Value }=\text { Test Value } \times \frac{\text { Specimen Thickness }}{\text { Nominal Thickness }}
$$

The nominal thickness was found by taking the average thickness of several specimens that were sanded with 50 strokes of 400 grit sandpaper in the gage section prior to bonding strain gages.

Since the panel thickness for the matrix driven properties was much larger, approximately 0.125 inches, local variations in thickness were not judged to cause a strong effect on the results. Therefore, the data reported was the raw data and was not normalized. In-plane shear strength, F6, was taken where there was a significant change in the slope of the load-displacement plot (Figure 3.7). In some cases, especially with the tougher resin 949, there was no significant change and so F6 was taken at the slight dip between the initial curved section and the linear section of the load-displacement plot (Figure 3.8).

At the customer's request, the material properties were reported at the fiber volumes $(F V)$ in which they were tested and not normalized to a constant $F V$ value (i.e. $\mathbf{6 0 \%} \mathrm{FV}$ ). In order to predict strength with G12 and F6, these values are normalized to the FV of F1c for the compressive strength specimens as is shown in Chapter 4.

\subsection{Difficulties in Obtaining $F_{1 c}$}

Compression is by far the most difficult of the tests shown in the test matrix because it requires a high level of precision in the specimen and very good test set-up. 
Many attempts were made to get the final values reported in the previous tables. Highlights of the compression tests are shown in Table 3.3.

\subsubsection{Sanding}

Initially, the specimen panels were made without peel ply or caul plates because peel ply and caul plates they were used only selectively for fabrication of actual parts made at Aurora Flight Sciences. This produced a panel with a rough, wavy surface on the bag face and a smooth surface on the tool face (Figure 3.9).

The panels were sanded on the bag face to make a smooth surface for the tabs and to get a uniform thickness for measurement of thickness. Tests No. 1 and 2 in Table 3.3 showed that the sanding had reduced the strength from 170 to $140 \mathrm{ksi}$. Sanding had effectively removed one ply from the panel. However, even without sanding, the strength values were low compared to manufacturer's values and it would not be clear what thickness to use for comparison of strength.

\subsubsection{Peel Ply \& Caul Plates}

In order to remove the waviness on the bag face and to straighten the fibers to increase the strength, peel ply and caul plates were used on both sides of the lay-up. These were used on the manufacturer's panel when they produced their specimen but again, were only selectively used in the shop at Aurora Flight Sciences. Tests No. 2,3 in 
Table 3.3 showed that the peel ply/caul plates did improve strength, but still not to the level of the manufacturer.

\subsubsection{Surface Ground/Solid Compression Head}

Originally, the edges of the compression specimen were cut with a diamond saw blade mounted on a modified grinding table. This cut the edges smoothly but at a slight angle. To compensate for this angle, it was believed that a ball joint head would adjust the compression head to fit the exact angle of the end specimen. In truth, the adjustable head was most likely causing a premature failure of the specimen by concentrating the load in the area when the collapse first takes place (Figure 3.10).

To solve this problem, a surface grinder was purchased to grind accurate, square ends on the specimen after being cut by the diamond saw. The test fixture was modified from a ball joint head to a solid head. Tests No. 3,4 in Table 3.3 showed that these changes increased the compression strength significantly.

\subsubsection{Bolt Torque}

Bolt torque on the fixture made a significant difference on final strength as in Test No. 4,5 in Table 3.3. The SACMA standard does call out a range of bolt torques but other similar standards such as the modified D695 call for hand tight bolts. After discovering this fact, bolts were held to a constant torque on the WVU tests to approximately 5 in-lbs. 


\subsubsection{Bond Tabs at High Temperature}

There was a concern that because the two testing labs used film adhesives cured at $250 \mathrm{~F}$, it would cause a post-cure to this material system (which is cured at 275F). This would artificially increase their strength values. WVU used a room temperature cure adhesive throughout the program but Tests No. 6,7 in Table 3.3 showed that there was no noticeable improvement in strength from the post-cure of WVU's own specimens. If there was an effect, it was small compared to other aspects of the testing.

\subsection{Experimental Results}

The test results summary from Phase I is shown on Table 3.2. The details of Phase I results are in Appendix B. The effects of debulking were not clear from the Phase I results. It is expected that voids increase with increasing plys/debulk and therefore mechanical properties (excluding density) decrease with increasing plys/debulk. Indeed in the "Delta" column of the table, many of the properties show a small decrease in properties. However, the two most important properties, Longitudinal Compressive Strength and In-Plane Shear Strength, are increasing with increasing plys/debulk. This brings into question the validity of the entire Phase of this study.

More than likely, the panels ( 1 foot by 2 foot) made were too small to show any effect of voids and larger panels, e.g. 20 feet long, would show a meaningful difference. As shown in Figure 3.11, the void content at the center of a 20 ply panel with 5 plys/debulk is $1.066 \%$. On the same size panel but with 20 plys/debulk, the void content 
is $1.736 \%$. This is a $63 \%$ increase in void content but the absolute value is still below $2 \%$, which is considered to be low. Thus, the differences in material properties were probably hidden by the variations in test specimen preparation, test set-up, etc.

Fortunately, the effect of temperature on mechanical properties is clear in the Phase II results. Higher temperatures are expected to lower the material properties and the Tables 3.4, 3.5, 3.6 confirm these expectations. The details of Phase II results are in Appendix C. Graphs of these trends are shown in Figures 3.12 through 3.17. It is important to note there is a sharp decrease in shear modulus when going from RTA to 180 F (Figure 3.15).

\subsection{Beam Preparation}

Two C-section beams were made at Aurora Flight Sciences of West Virginia. These beams were made of the $949 \mathrm{HYE} / \mathrm{M} 30 \mathrm{GC}$ and were relatively thick hand lay-ups cured at $275 \mathrm{~F}$ with 27 in $\mathrm{Hg}$ vacuum pressure (Figure 3.18). The beam caps were much thicker towards the ends and thinner in the test section in the center. In Beam 1, the test section caps consisted of 60 plys of $0 \mathrm{deg}$ and $\pm 45 \mathrm{deg}$ on top and bottom. In Beam 2 , the test section had 56 plys with one \pm 45 deg ply every 8 plys of 0 deg. The shear web at the test section was made of a honeycomb core with \pm 45 deg plies for shear stiffness and 90 deg plies for transverse stiffness. Twenty eight total strain gages were placed on the beam with twelve gages on the test section as shown in Figure 3.19. 


\subsection{Beam Testing}

Two C-section beams were tested in four point bending at Aurora Flight Sciences (Figure 3.20). These beams were restrained at their ends and pulled at two points roughly $1 / 4$ of the length from the ends. Teflon pieces were used to separate the loading fixture from the beam table to allow it to displace in the transverse direction. Roller pins allowed the loading fixture to move along the table (Figure 3.21).

\subsection{Beam Test Results}

The strain gage data shown in Figure 3.22 and 3.23 show that the highest compressive strain experienced on Beam 1 was 7500 microstrains and on Beam 2 was 7772 microstrains. From visual inspection, it was confirmed that compression (and not shear) was the most likely mode of failure because of the presence of kink bands at the damaged area. There was also a significant void content tested in Beam 1. Figure 3.24 shows the increase in voids from $2.679 \%$ at the end of the beam, to $4.636 \%$ close to the middle. Nevertheless, the ultimate strain capability of the beams were very close to the 8043 microstrains ultimate capability of the 949/M30GC compression specimens. 


\begin{tabular}{|c|c|c|c|c|c|c|c|c|}
\hline & & & \multirow{2}{*}{\multicolumn{4}{|c|}{$\frac{\text { Phase I }}{949 / M 30 G C}$}} & \multicolumn{2}{|c|}{ Phase II } \\
\hline & & & & & & & \multirow{2}{*}{$\begin{array}{l}\text { 949/M30GC } \\
\text { Ply/ Debulk }\end{array}$} & \multirow{2}{*}{$\begin{array}{l}\text { 948A1/M40J J } \\
\text { Ply/ Debulk }\end{array}$} \\
\hline & & & & Ply/ & ebulk & & & \\
\hline Test & Property & Temp [F] & 5 & 7 & 10 & 20 & 7 or 20 & 7 or 20 \\
\hline \multirow{6}{*}{$\begin{array}{c}\text { Compression } \\
\text { SRM-1R-94 } \\
\text { (SACMA) } \\
\text { \& } \text { D3410-95 (IITRI) }\end{array}$} & \multirow{3}{*}{$\begin{array}{c}\text { Longitudinal Compressive } \\
\text { Modulus \& Ultimate Strength: } \\
E_{1 C}, F_{1 C}\end{array}$} & +180 & - & - & - & - & 5 & 10 \\
\hline & & RTA & 3 & $(5)^{a}$ & 4 & 3 & - & (20) \\
\hline & & -125 & - & - & - & - & 5 & 5 \\
\hline & \multirow{3}{*}{$\begin{array}{c}\text { Transverse Compressive } \\
\text { Modulus \& Ultimate Strength: } \\
\mathrm{E}_{2 \mathrm{C}}, \mathrm{F}_{2 \mathrm{C}}\end{array}$} & +180 & - & - & - & - & - & - \\
\hline & & RTA & 5 & - & 5 & - & - & (6) \\
\hline & & -125 & - & - & - & - & - & - \\
\hline \multirow{3}{*}{$\begin{array}{l}\text { Shear } \\
\text { D 5379-93 } \\
\text { (losipescu) }\end{array}$} & \multirow{3}{*}{$\begin{array}{c}\text { Shear Modulus \& Ultimate } \\
\text { Shear Strength: } \\
\mathrm{G}_{12}, \mathrm{~F}_{12}\end{array}$} & +180 & - & - & - & - & 5 & 5 \\
\hline & & RTA & (5) & - & (5) & (5) & - & (5) \\
\hline & & -125 & - & - & - & - & 5 & 5 \\
\hline \multirow{6}{*}{$\begin{array}{l}\text { Tension } \\
\text { D 3039-95a }\end{array}$} & \multirow{3}{*}{$\begin{array}{c}\text { Longitudinal Tensile Modulus, } \\
\text { Ultimate Strength \& } \\
\text { Longitudinal Poisson's Ratio: } \\
\mathrm{E}_{1 \mathrm{~T}}, \mathrm{~F}_{1 \mathrm{~T}}, \mathrm{v}_{12}\end{array}$} & +180 & - & - & - & - & - & 5 \\
\hline & & RTA & - & - & - & - & (6) & (6) \\
\hline & & -125 & - & - & - & - & - & 5 \\
\hline & \multirow{3}{*}{$\begin{array}{l}\text { Trans. Tensile Modulus, Ult. } \\
\text { Strength \& Transverse } \\
\text { Poisson's Ratio: } \\
\mathrm{E}_{2 \mathrm{~T}}, \mathrm{~F}_{2 \mathrm{~T}}, \mathrm{v}_{21}\end{array}$} & +180 & - & - & - & - & - & - \\
\hline & & RTA & (5) & - & (5) & (5) & - & (5) \\
\hline & & -125 & - & - & - & - & - & - \\
\hline Density D 792-91 & Bulk Density w/Pycnometer & RTA & (10) & - & (5) & (10) & (20) & (5) \\
\hline Void Content & Theor.\&Bulk Density w/Pycno. & RTA & (10) & - & (5) & (10) & (20) & (5) \\
\hline Glass Transition D 3418-97 & $\operatorname{Tg} w / D S C$ & @ Tg & - & - & - & - & (2) & (2) \\
\hline Long/Trans CTE E831-93 & Long./Trans. $\alpha_{T} \mathrm{w} / \mathrm{DTA}$ & -125 to +180 & - & - & - & - & 3 & 3 \\
\hline
\end{tabular}

Note a: "( )" denotes number of tests done by WVU. If \# of strength tests differ from \# of modulus tests, the \# of strength tests are shown here.

Touchstone Research Labs performed all tests in Phase I not done by WVU.

Orange County Materials Test Labs performed all tests in Phase II not done by WVU.

Table 3.1 Aurora Flight Sciences Test Matrix 


\begin{tabular}{|c|c|c|c|c|c|c|c|c|}
\hline \multirow[b]{2}{*}{ Property } & \multirow[b]{2}{*}{ Notation } & \multirow[b]{2}{*}{ Units } & \multicolumn{3}{|c|}{ Average Values } & \multirow{2}{*}{$\begin{array}{c}\text { Delta } \\
5 \text { to } 20 \text { ply } \\
{[\%]}\end{array}$} & \multirow{2}{*}{$\begin{array}{c}\text { Retest } \\
\text { plys/debulk }\end{array}$} & \multirow{2}{*}{$\begin{array}{l}\text { Fiberite } \\
\text { Values }\end{array}$} \\
\hline & & & $\begin{array}{c}5 \\
\text { plys/debulk }\end{array}$ & $\begin{array}{c}10 \\
\text { plys/debulk }\end{array}$ & $\begin{array}{c}20 \\
\text { plys/debulk }\end{array}$ & & & \\
\hline 1. Long. Compressive Strength & $\mathrm{F} 1_{\mathrm{C}}$ & {$[\mathrm{ksi}]$} & $112.0^{1}$ & $130.5^{1}$ & $135.2^{1}$ & $20.7 \%$ & $185.0^{2}$ & $195.8^{2,3}$ \\
\hline 2. Long. Compressive Modulus & $\mathrm{E} 1_{\mathrm{C}}$ & [Msi] & $18.18^{4}$ & $17.97^{4}$ & $17.96^{4}$ & $-1.21 \%$ & $23.0^{5}$ & low $20{ }^{\prime}{ }^{6}$ \\
\hline 3. Trans. Compressive Strength & $\mathrm{F} 2_{\mathrm{C}}$ & {$[\mathrm{ksi}]$} & 24.9 & 24.6 & - & $-1.20 \%$ & - & - \\
\hline 4. Trans. Compressive Modulus & $\mathrm{E} 2_{\mathrm{C}}$ & [Msi] & 1.070 & 1.028 & - & $-3.93 \%$ & - & - \\
\hline 5. In-Plane Shear Strength & $\mathrm{F}_{12}$ & {$[\mathrm{ksi}]$} & 9.80 & 10.04 & 10.06 & $2.61 \%$ & - & $9.72^{7,8}$ \\
\hline 6. In-Plane Shear Modulus & $\mathrm{G}_{12}$ & [Msi] & $0.576^{9}$ & $0.541^{9}$ & $0.537^{9}$ & $-6.77 \%$ & - & - \\
\hline 7.Trans. Tensile Strength & $\mathrm{F}_{2 \mathrm{~T}}$ & [ksi] & 4.68 & 4.69 & 4.76 & $1.71 \%$ & - & - \\
\hline 8.Trans. Tensile Modulus & $E_{2 T}$ & [Msi] & 1.059 & 1.040 & 1.008 & $-4.82 \%$ & - & - \\
\hline Minor Poisson's Ratio & $\mathrm{v}_{21}$ & - & 0.00903 & 0.00894 & 0.00762 & $-15.61 \%$ & - & - \\
\hline 9. Apparent (Bulk) Density & $\mathrm{rho}_{\mathrm{a}}$ & {$[\mathrm{gm} / \mathrm{cc}]$} & 1.4848 & 1.4833 & 1.4788 & $-0.40 \%$ & - & - \\
\hline Void Content: Near Edge ${ }^{10}$ & Void & {$[\%]$} & 1.857 & 1.781 & 2.092 & $12.65 \%$ & - & - \\
\hline Void Content: Near Center ${ }^{10}$ & Void & [\%] & 1.066 & - & 1.736 & $62.85 \%$ & - & - \\
\hline \multicolumn{4}{|c|}{ 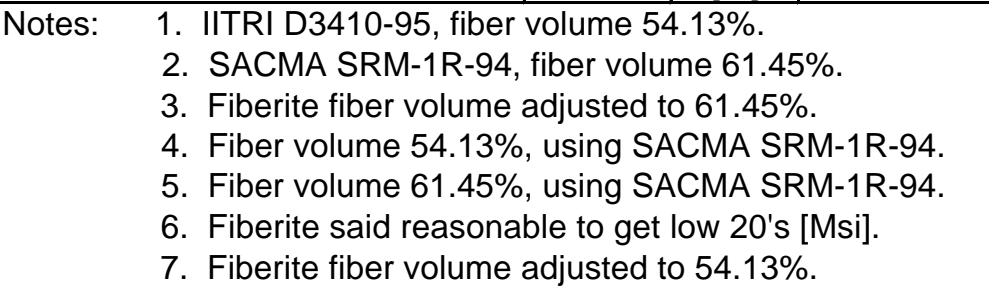 } & & \multicolumn{4}{|c|}{$\begin{array}{l}\text { 8. Inter-laminar Shear Strength used, no In-Plane } \\
\text { Strength provided. } \\
\text { 9. Revised with correct usage of shear gage data. } \\
\text { 10. Panel length } 22 " \text {, width } 12 " \text {, thickness .120". }\end{array}$} \\
\hline
\end{tabular}

Table 3.2 Phase I Test Results 


\begin{tabular}{|c|c|c|c|c|c|c|c|c|c|c|c|c|}
\hline No. & $\begin{array}{l}\text { Panel } \\
\text { NTP- }\end{array}$ & Sanded & Unsanded & $\begin{array}{l}\text { Peel Ply \& } \\
\text { Caul Plate }\end{array}$ & $\begin{array}{l}\text { Surface } \\
\text { Ground }\end{array}$ & $\begin{array}{c}\text { w/ } 250 \mathrm{~F} \\
\text { Post Cure }\end{array}$ & $\begin{array}{c}\text { Ball Joint } \\
\text { Head }\end{array}$ & $\begin{array}{l}\text { Solid } \\
\text { Head }\end{array}$ & $\begin{array}{c}\text { Bolts } \\
\text { Hand Tight }\end{array}$ & $\begin{array}{l}\text { Bolts } \\
\text { Tight }\end{array}$ & $\begin{array}{c}948 \mathrm{~A} 1 / \mathrm{M} 40 \mathrm{~J} \\
{[\mathrm{ksi}]}\end{array}$ & $\begin{array}{c}\text { 949/M30GC } \\
{[\mathrm{ksi}]} \\
\end{array}$ \\
\hline 1. & 8,7 & $Y$ & & & & & $Y$ & & Y & & $140^{1}$ & 139 \\
\hline 2. & 8 & & $Y$ & & & & $Y$ & & Y & & $170^{1}$ & ---- \\
\hline 3. & 11,15 & & Y & $Y$ & & & Y & & Y & & 182 & 143 \\
\hline 4. & 17,15 & & $Y$ & Y & $Y$ & & & Y & Y & & 194 & 185 \\
\hline 5. & 17 & & $Y$ & Y & $Y$ & & & $Y$ & & Y & 216 & ---- \\
\hline 6. & 16 & & $Y$ & $Y$ & $Y$ & Y & & $Y$ & $Y$ & & 204 & ---- \\
\hline 7. & 16 & & $Y$ & $Y$ & $Y$ & & & $Y$ & Y & & 219 & ---- \\
\hline
\end{tabular}

Average of Dashed Box Values 208

Notes: 1 . Used .039" sanded thickness for stress calculation.

Table 3.3 Highlights of Compression Testing 


\begin{tabular}{|c|c|c|c|c|c|c|c|c|c|}
\hline \multirow{2}{*}{$\begin{array}{r}\text { Property } \\
\end{array}$} & \multirow[b]{2}{*}{ Notation } & \multirow[b]{2}{*}{ Units } & \multirow[b]{2}{*}{ Temp } & \multicolumn{3}{|c|}{ 948A1 HYE/M40J } & \multicolumn{3}{|c|}{949 HYE/M30GC } \\
\hline & & & & Mean & FV\% & Cv & Mean & $\mathrm{FV} \%$ & $\mathrm{Cv}$ \\
\hline \multirow[t]{3}{*}{ 1. Longitudinal Compressive Strength } & $F_{1 C}$ & {$[\mathrm{ksi}]$} & $180 \mathrm{~F}$ & 194 & 59 & 9.83 & 149 & 61 & 2.92 \\
\hline & & & RTA & 208 & 59 & 5.83 & 185 & 61 & 9.34 \\
\hline & & & $-125 \mathrm{~F}$ & 223 & 59 & 6.76 & 226 & 61 & 4.13 \\
\hline \multirow[t]{3}{*}{ 2. Longitudinal Compressive Modulus } & $E_{1 C}$ & [Msi] & $180 \mathrm{~F}$ & 24.8 & 59 & 4.00 & 21.0 & 61 & 0.83 \\
\hline & & & RTA & 28.8 & 59 & 4.34 & 23.0 & 61 & 0.92 \\
\hline & & & $-125 \mathrm{~F}$ & 41.7 & 59 & 5.13 & 41.8 & 61 & 8.48 \\
\hline 3. Transverse Compressive Strength & $\mathrm{F}_{2 \mathrm{C}}$ & {$[\mathrm{ksi}]$} & RTA & 27.2 & 52 & 5.06 & 24.9 & 54 & 3.29 \\
\hline 4. Transverse Compressive Modulus & $E_{2 C}$ & [Msi] & RTA & 1.15 & 52 & 7.63 & 1.07 & 54 & 3.49 \\
\hline \multirow[t]{3}{*}{ 5. In-Plane Shear Strength } & $\mathrm{F}_{12}$ & {$[\mathrm{ksi}]$} & $180 \mathrm{~F}$ & 8.93 & 52 & 1.12 & 6.07 & 54 & 5.40 \\
\hline & & & RTA & 11.35 & 52 & 1.59 & 9.80 & 54 & 5.07 \\
\hline & & & $-125 \mathrm{~F}$ & 14.28 & 52 & 5.72 & 16.01 & 54 & 4.58 \\
\hline \multirow[t]{3}{*}{ 6. In-Plane Shear Modulus } & $\mathrm{G}_{12}$ & [Msi] & $180 \mathrm{~F}$ & 0.439 & 52 & 6.23 & 0.365 & 54 & 5.64 \\
\hline & & & RTA & 0.625 & 52 & 1.56 & 0.576 & 54 & 3.67 \\
\hline & & & $-125 F$ & 0.676 & 52 & 4.65 & 0.627 & 54 & 2.51 \\
\hline \multirow[t]{3}{*}{ 7. Longitudinal Tensile Strength } & $F_{1 T}$ & {$[\mathrm{ksi}]$} & $180 \mathrm{~F}$ & 368 & 59 & 2.03 & --- & 61 & ---- \\
\hline & & & RTA & 336 & 59 & 5.99 & 451 & 61 & 5.55 \\
\hline & & & $-125 \mathrm{~F}$ & 290 & 59 & 11.27 & ---- & 61 & ---- \\
\hline \multirow[t]{3}{*}{ 8. Longitudinal Tensile Modulus } & $\mathrm{E}_{1 \mathrm{~T}}$ & [Msi] & $180 \mathrm{~F}$ & 33.0 & 59 & 6.44 & ---- & 61 & --- \\
\hline & & & RTA & 32.5 & 59 & 1.74 & 24.7 & 61 & 1.65 \\
\hline & & & $-125 F$ & 31.7 & 59 & 2.42 & ---- & 61 & ---- \\
\hline
\end{tabular}

Table 3.4 Phase II Test Results, Page 1 


\begin{tabular}{|c|c|c|c|c|c|c|c|c|c|}
\hline & & & & $948 A 1$ & $E / N$ & 40J & $949 \mathrm{H}$ & /M30 & $\mathrm{GC}$ \\
\hline Property & Notation & Units & Temp & Mean & FV\% & $\mathrm{Cv}$ & Mean & FV\% & $\mathrm{Cv}$ \\
\hline 9. Major Poisson Ratio & $\mathrm{v}_{12}$ & [ ] & & 0.310 & 59 & 9.96 & ---- & 61 & ---- \\
\hline & & & RTA & 0.288 & 59 & 11.31 & 0.275 & 61 & 11.05 \\
\hline & & & $-125 \mathrm{~F}$ & 0.277 & 59 & 13.26 & ---- & 61 & --- \\
\hline 10. Minor Poisson Ratio & $\mathrm{v}_{21}$ & [ ] & RTA & 0.01024 & 52 & 47.43 & 0.00903 & 54 & 11.54 \\
\hline 11. Transverse Tensile Strength & $\mathrm{F}_{2 \mathrm{~T}}$ & [ksi] & RTA & 5.47 & 52 & 6.81 & 4.68 & 54 & 7.28 \\
\hline 12. Transverse Tensile Modulus & $E_{2 T}$ & [Msi] & RTA & 1.00 & 52 & 2.93 & 1.06 & 54 & 4.40 \\
\hline 13. Panel Apparent Density: Edge, $t=\sim .125 "$ & $\rho$ & {$[\mathrm{gm} / \mathrm{cc}]$} & RTA & 1.5043 & 52 & 0.02 & 1.4788 & 54 & 0.03 \\
\hline 14. Panel Void Content A: Edge, $t=\sim .125 "$ & Void & {$[\%]$} & RTA & 2.019 & 52 & $\mathrm{n} / \mathrm{a}$ & 2.092 & 54 & $\mathrm{n} / \mathrm{a}$ \\
\hline Panel Void Content B: Center, $\mathrm{t}=\sim .125 "$ & Void & {$[\%]$} & RTA & ---- & --- & $\mathrm{n} / \mathrm{a}$ & 1.736 & 54 & $\mathrm{n} / \mathrm{a}$ \\
\hline Panel Void Content C: Center, $\mathrm{t}=\sim .041^{\prime \prime}$ & Void & {$[\%]$} & RTA & $---\cdot$ & --- & $\mathrm{n} / \mathrm{a}$ & 1.468 & 61 & $\mathrm{n} / \mathrm{a}$ \\
\hline 15. Beam Void Content A: End, Near Web & Void & {$[\%]$} & RTA & ---- & --- & $\mathrm{n} / \mathrm{a}$ & 2.679 & --- & $\mathrm{n} / \mathrm{a}$ \\
\hline Beam Void Content B: Center, Near Web & Void & [\%] & RTA & ---- & --- & $\mathrm{n} / \mathrm{a}$ & 4.267 & --- & $\mathrm{n} / \mathrm{a}$ \\
\hline Beam Void Content C: Center, Near Edge & Void & [\%] & RTA & --- & --- & $\mathrm{n} / \mathrm{a}$ & 4.636 & --- & $\mathrm{n} / \mathrm{a}$ \\
\hline 16. Glass Transition Temperature & $T_{g}$ & {$[\mathrm{~F}]$} & $\mathrm{n} / \mathrm{a}$ & 303 & 59 & $\mathrm{n} / \mathrm{a}$ & 254 & 61 & $\mathrm{n} / \mathrm{a}$ \\
\hline 17. Long. Coeff. of Thermal Expansion & $\alpha_{\mathrm{Lm}}$ & {$[\mathrm{in} / \mathrm{inF}]$} & $\mathrm{n} / \mathrm{a}$ & -0.80 & 52 & 27.43 & -1.10 & 54 & 81.24 \\
\hline 18. Trans. Coeff. of Thermal Expansion & $\alpha_{\mathrm{Tm}}$ & {$\left[{ }^{\mu \mathrm{in}} / \mathrm{inF}\right]$} & $\mathrm{n} / \mathrm{a}$ & 20.0 & 52 & 2.26 & 18.6 & 54 & 4.41 \\
\hline
\end{tabular}

"----": Not Scheduled for Testing

"n/a": Not Applicable

Table 3.5 Phase II Test Results, Page 2 


\begin{tabular}{|c|c|c|c|c|c|c|c|c|c|}
\hline \multirow[b]{2}{*}{ Property } & \multirow[b]{2}{*}{ Notation } & \multirow[b]{2}{*}{ Units } & \multirow[b]{2}{*}{ Temp } & \multicolumn{3}{|c|}{ 948A1 HYE/M40J } & \multicolumn{3}{|c|}{949 HYE/M30GC } \\
\hline & & & & Mean & FV\% & Cv & Mean & FV\% & $\mathrm{Cv}$ \\
\hline \multirow[t]{3}{*}{ 19. Longitudinal Compressive Ult. Strain } & \multirow[t]{3}{*}{$\varepsilon_{1 C}$} & \multirow[t]{3}{*}[\mu\mathrm{in}/\mathrm{in}]{} & $180 \mathrm{~F}$ & 7823 & 59 & $\mathrm{n} / \mathrm{a}$ & 7095 & 61 & $n / a$ \\
\hline & & & RTA & 7222 & 59 & $\mathrm{n} / \mathrm{a}$ & 8043 & 61 & $\mathrm{n} / \mathrm{a}$ \\
\hline & & & $-125 \mathrm{~F}$ & 5348 & 59 & $\mathrm{n} / \mathrm{a}$ & 5407 & 61 & $\mathrm{n} / \mathrm{a}$ \\
\hline \multirow[t]{3}{*}{ 20. Longitudinal Tensile Ult. Strain } & \multirow[t]{3}{*}{$\varepsilon_{1 \top}$} & \multirow[t]{3}{*}[\mu\mathrm{in}/\mathrm{in}]{} & $180 \mathrm{~F}$ & 10578 & 59 & $\mathrm{n} / \mathrm{a}$ & ---- & 61 & $\mathrm{n} / \mathrm{a}$ \\
\hline & & & RTA & 9821 & 59 & $\mathrm{n} / \mathrm{a}$ & 16854 & 61 & $\mathrm{n} / \mathrm{a}$ \\
\hline & & & $-125 F$ & 8736 & 59 & $\mathrm{n} / \mathrm{a}$ & --- & 61 & $\mathrm{n} / \mathrm{a}$ \\
\hline
\end{tabular}

"----": Not Scheduled for Testing

"n/a": Not Applicable

Table 3.6 Phase II Test Results, Page 3 


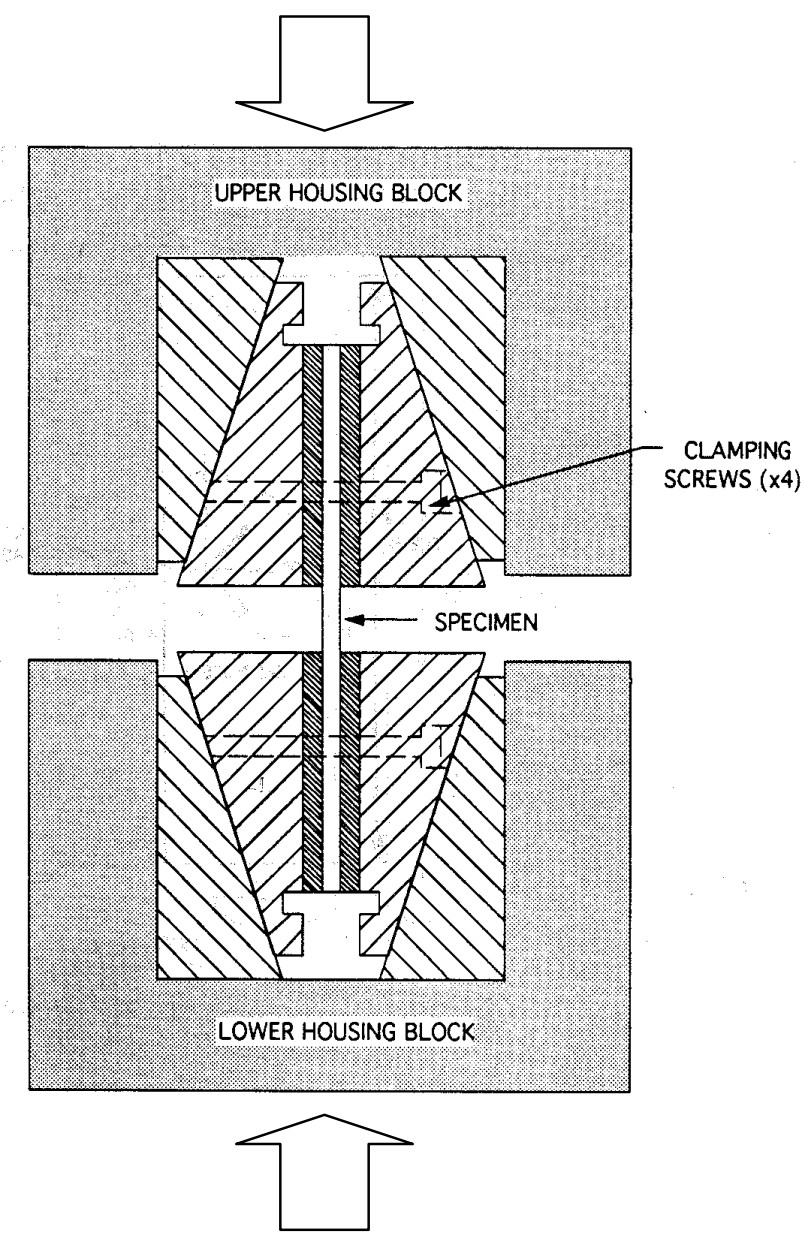

Figure 3.1 IITRI Test Set-Up
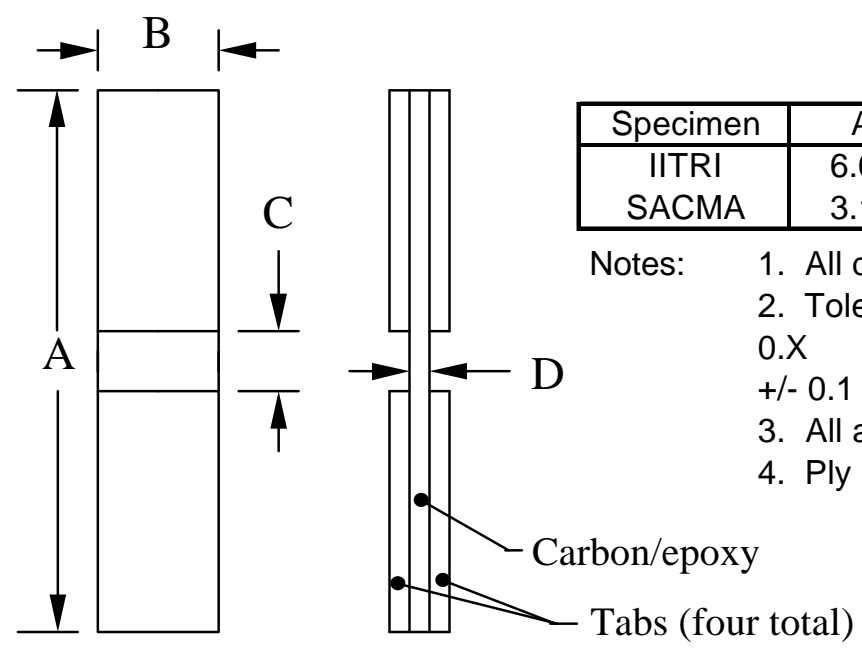

Figure 3.2 Compression Specimen Dimensions 


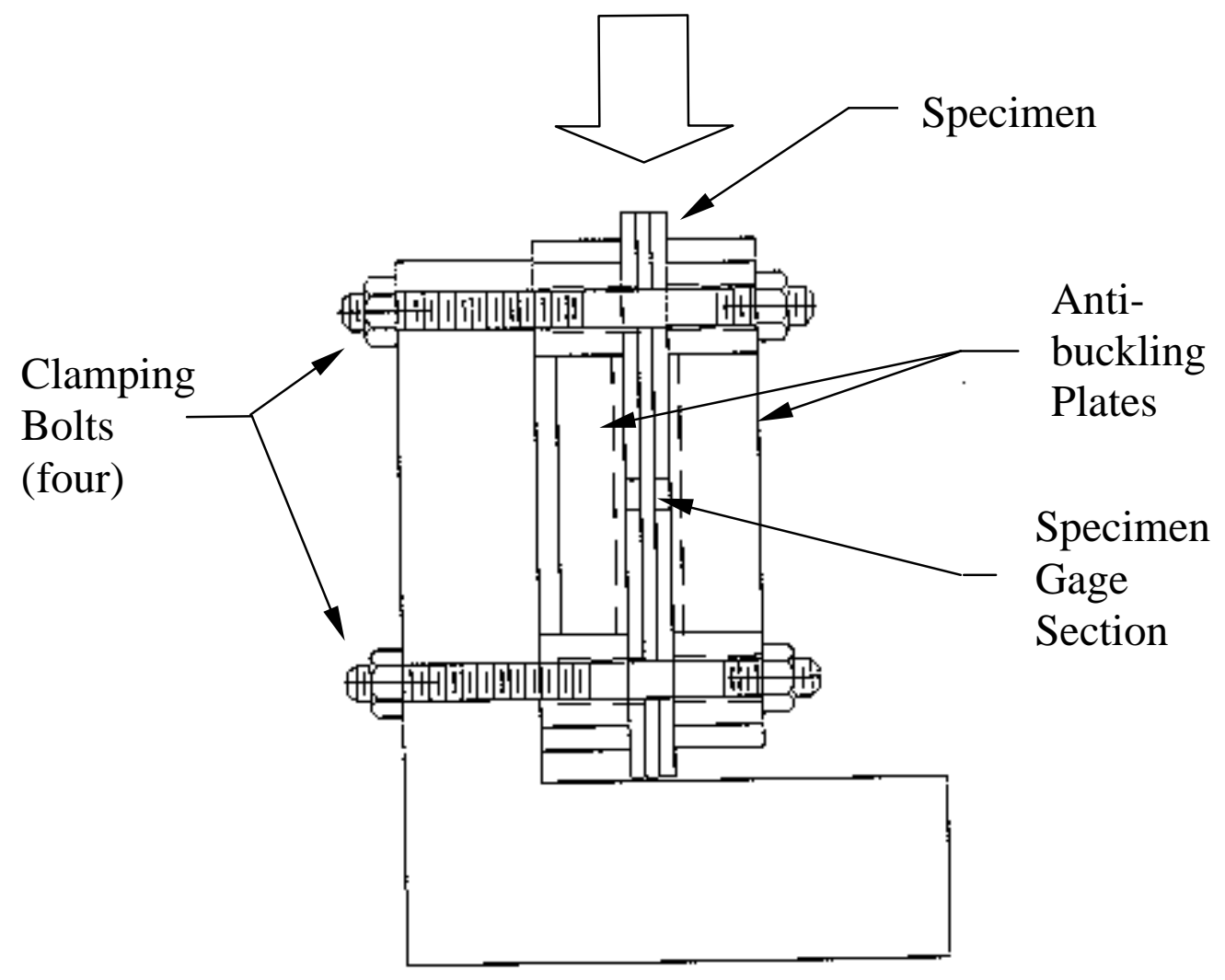

Figure 3.3 SACMA Compression Test Set-Up 


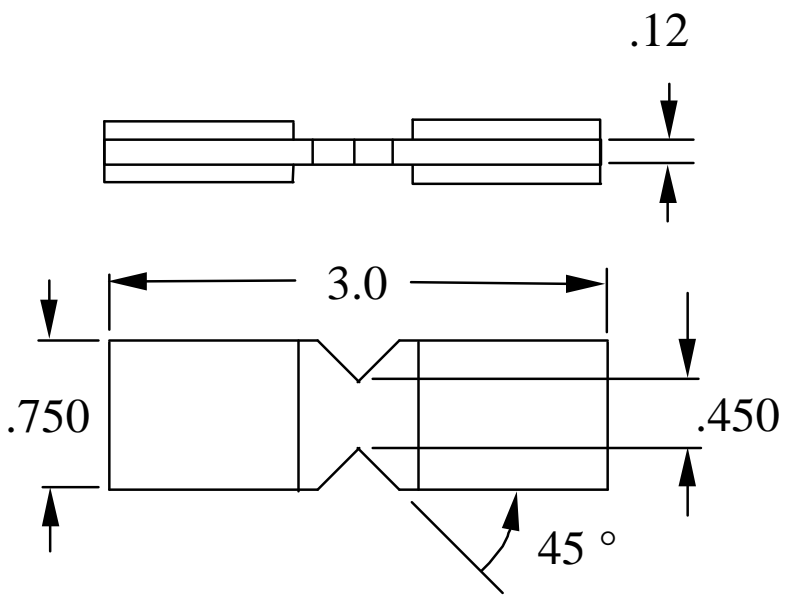

Notes: 1. All dimensions in inches

2. Tolerance as follows

$\begin{array}{lll}0 . X & 0 . X X & 0 . X X X \\ +/-0.1 & +/-0.03 & +/-0.01\end{array}$

3. All angles have atolerance of $+/-0.5$ degree.

4. Ply orientation $+/-0.5$ degree.

Figure 3.4 Shear Specimen Dimensions

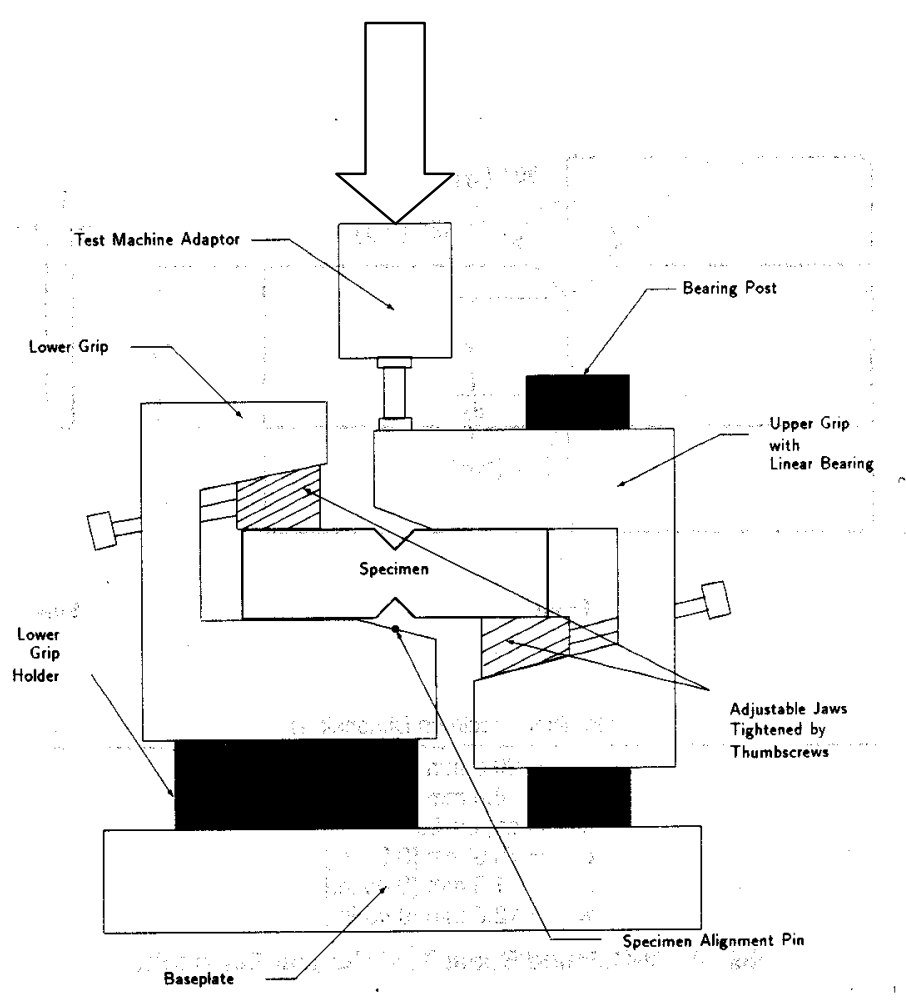

Figure 3.5 Shear Test Set-Up 


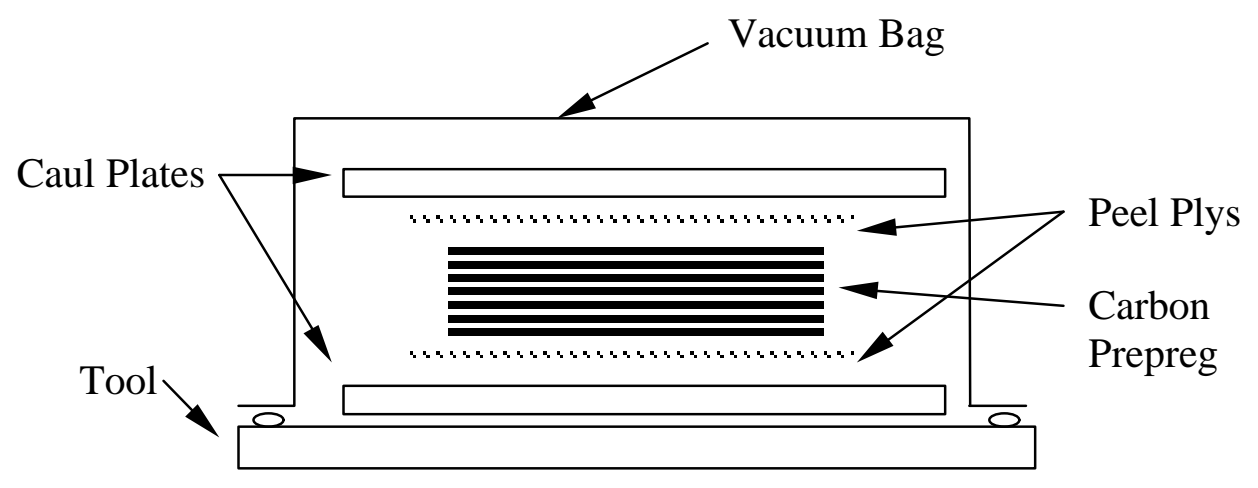

Figure 3.6 Lay-Up Sequence

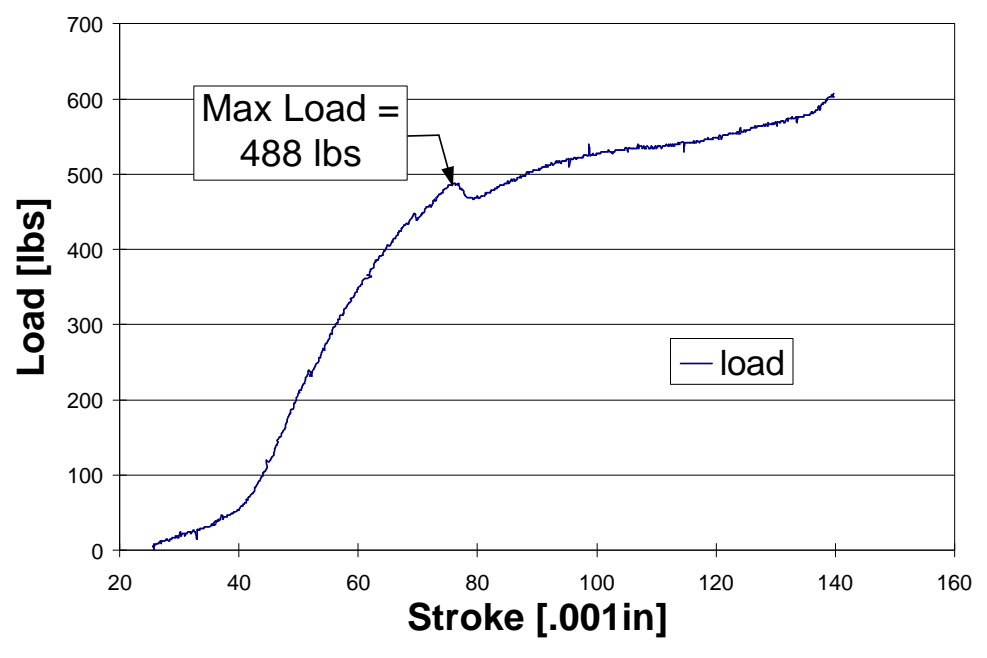

Figure 3.7 Significant Change in Slope at Max. Shear Load

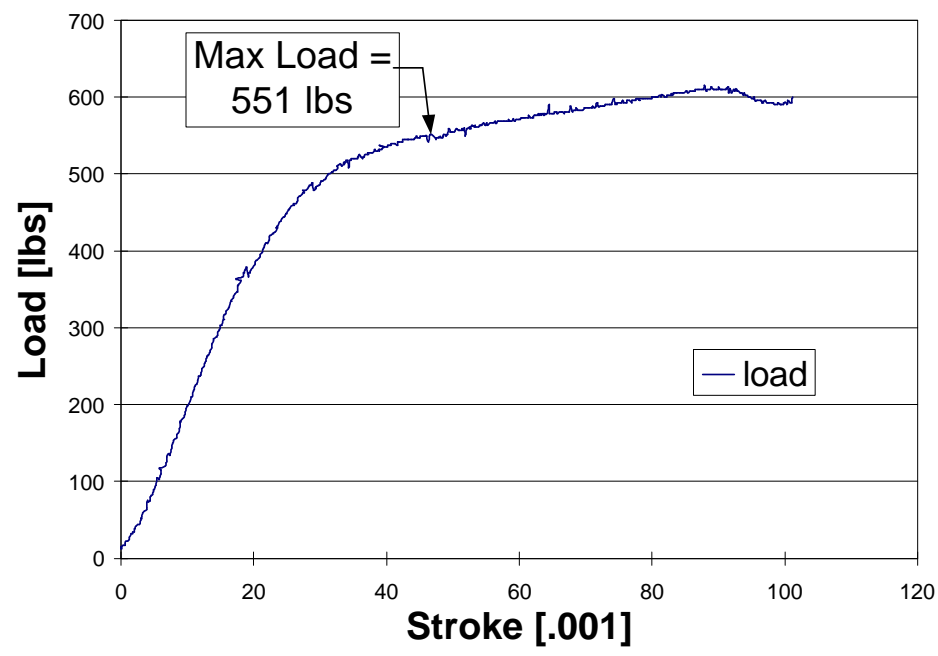

Figure 3.8 No Significant Change in Slope at Max. Shear Load 


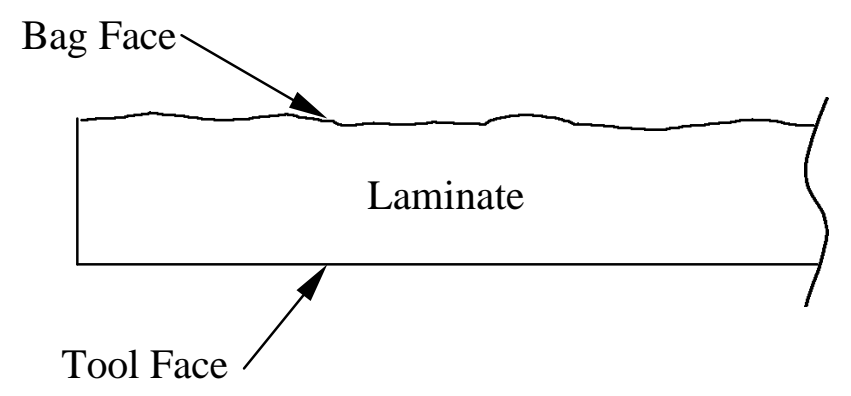

Figure 3.9 Bag Face vs. Tool Face
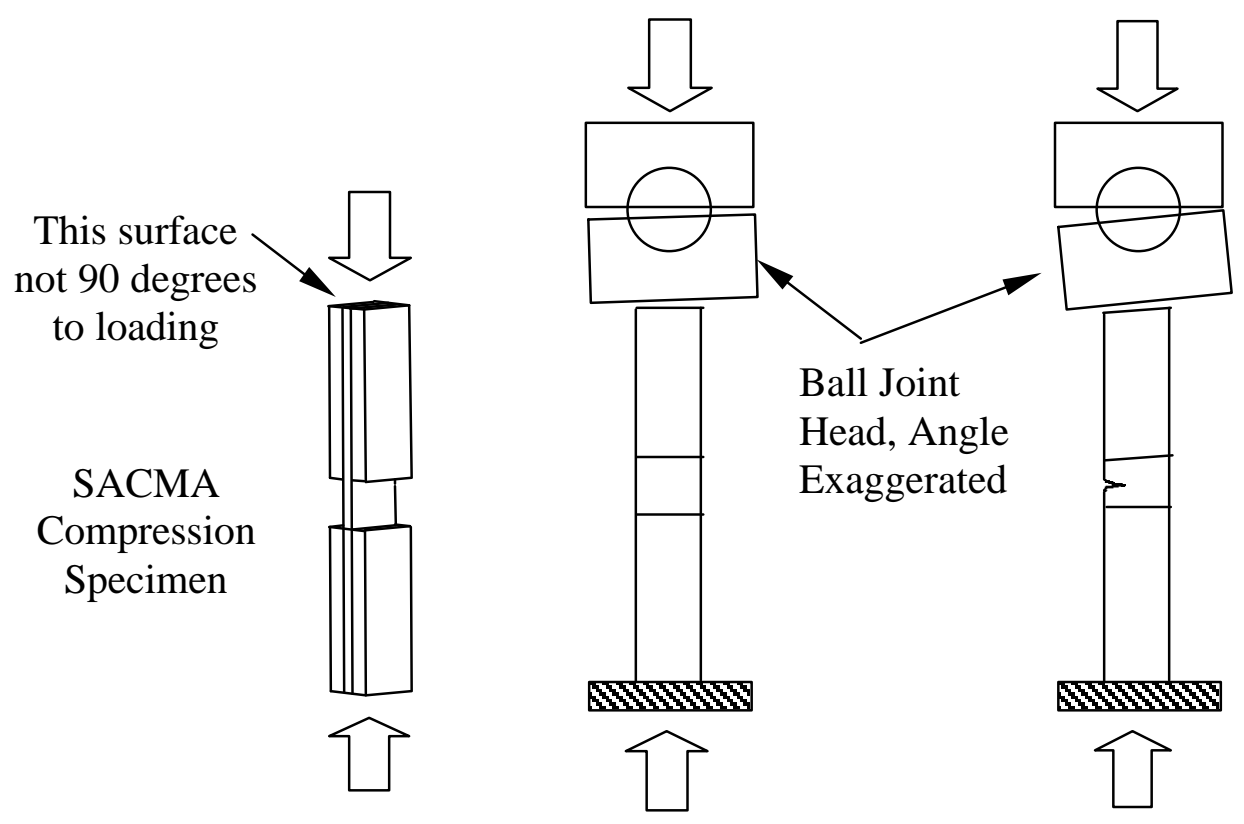

Figure 3.10 Effects of Ball Joint Head 

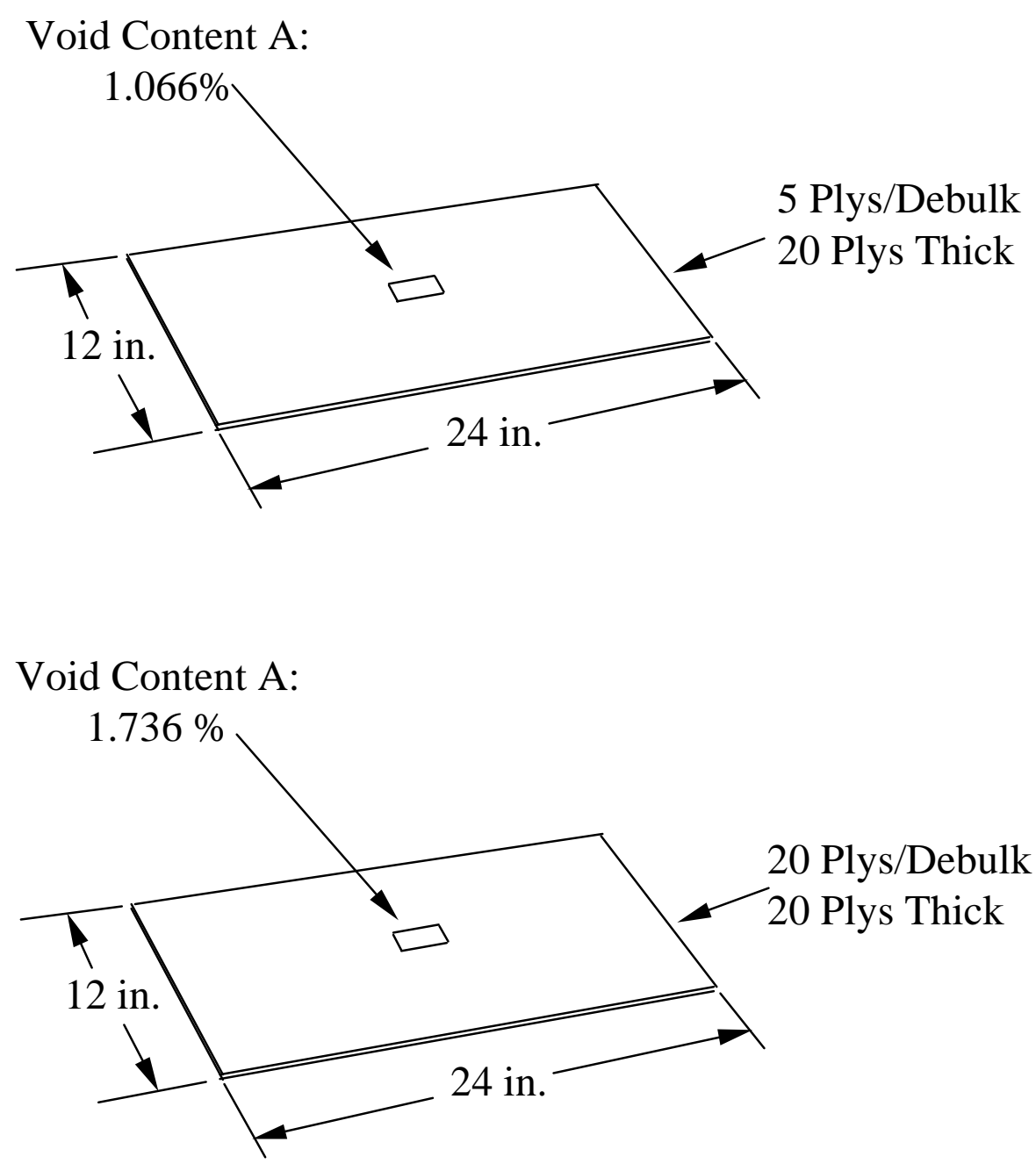

Figure 3.11 Void Content Increase with Ply/Debulk Increase. 


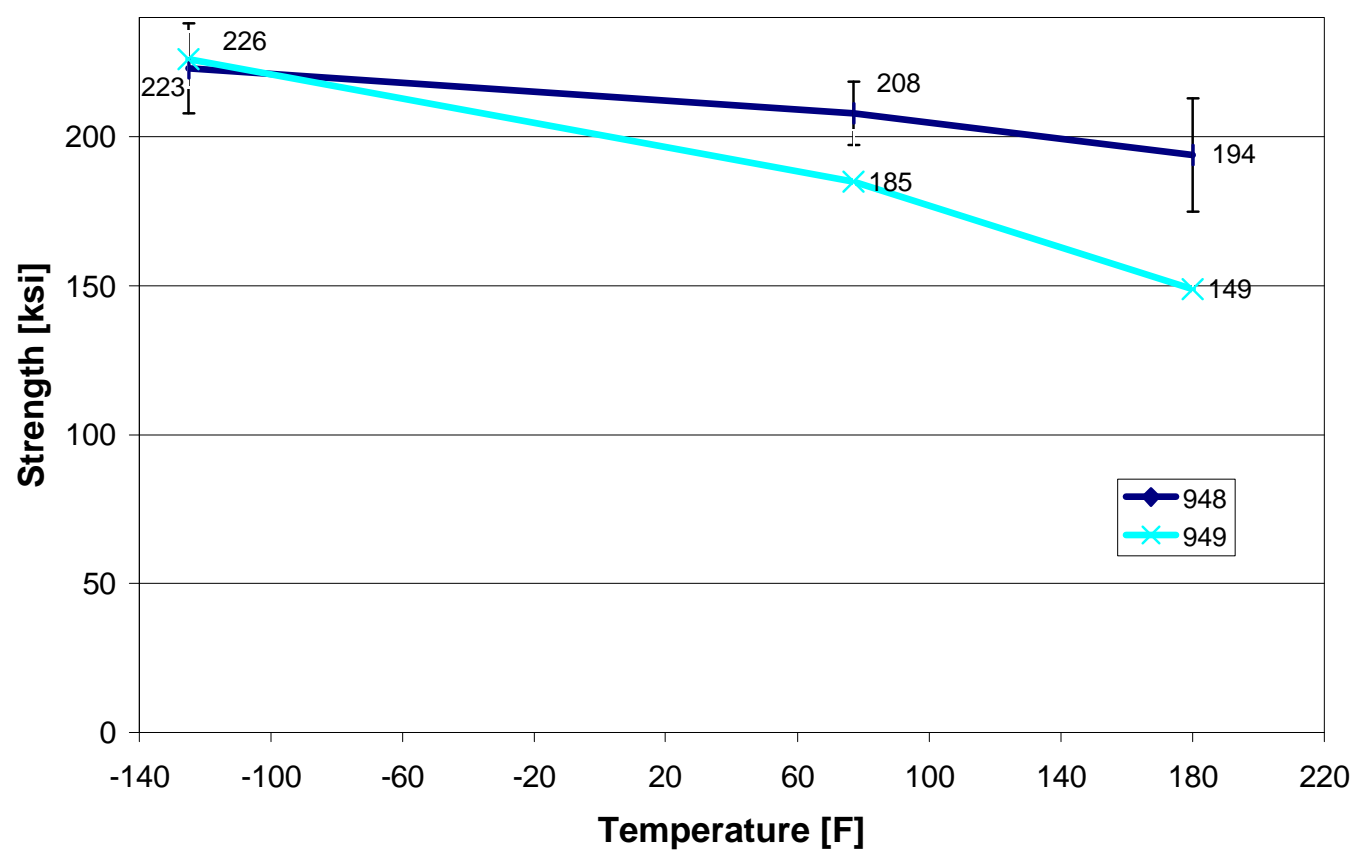

Figure 3.12 Longitudinal Compressive Strength vs. Temperature

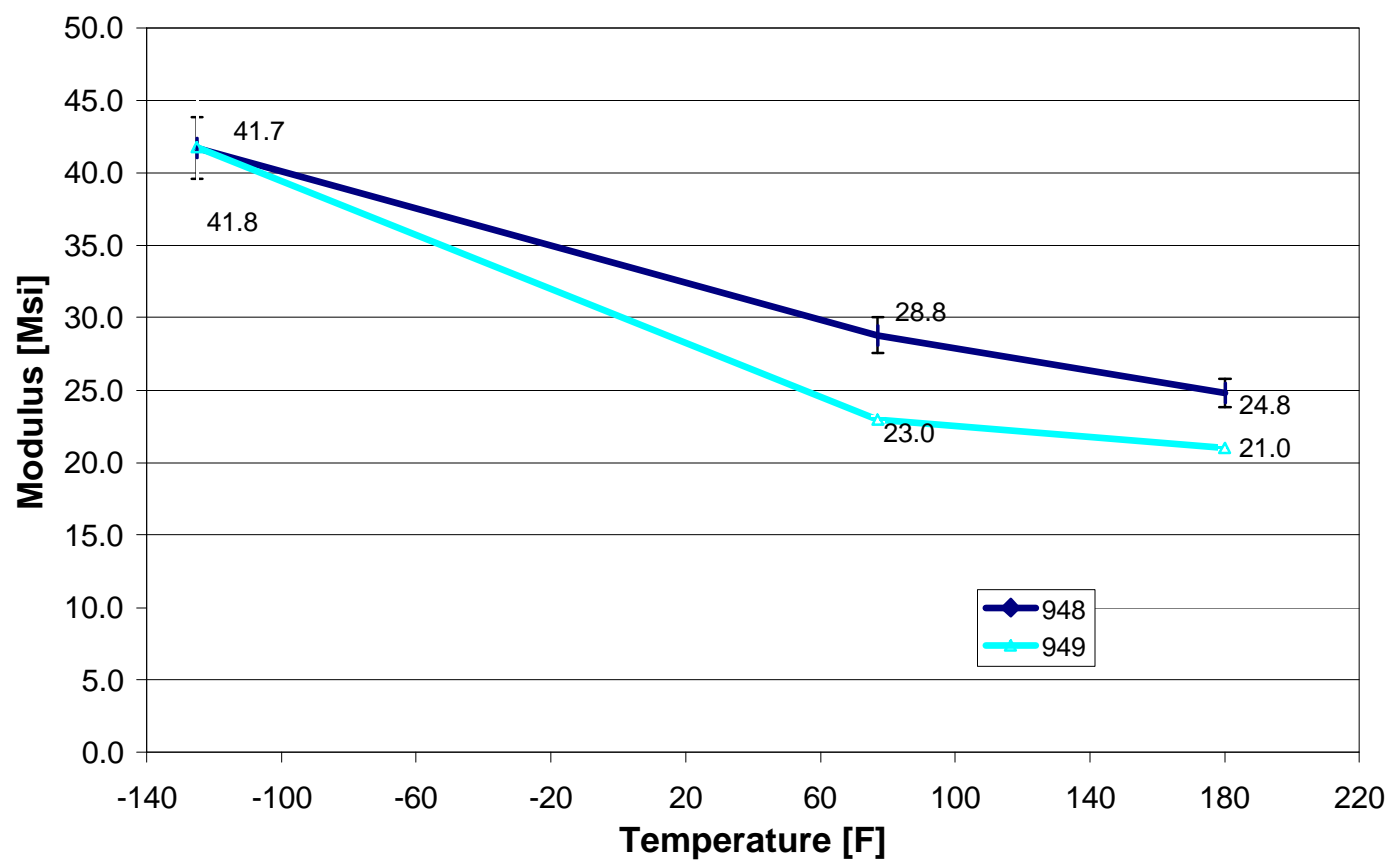

Figure 3.13 Longitudinal Compressive Modulus vs. Temperature 


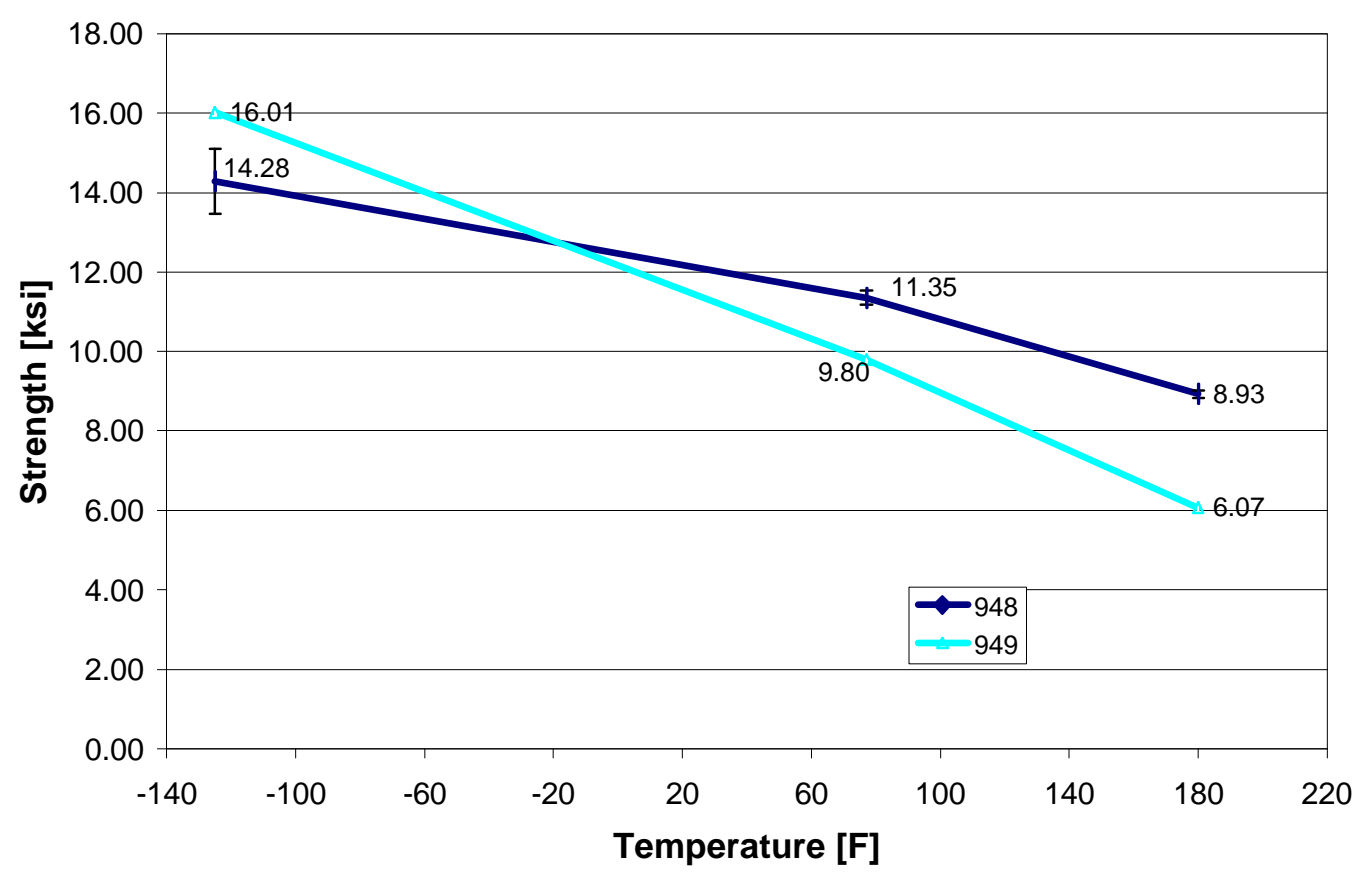

Figure 3.14 In-Plane Shear Strength vs. Temperature

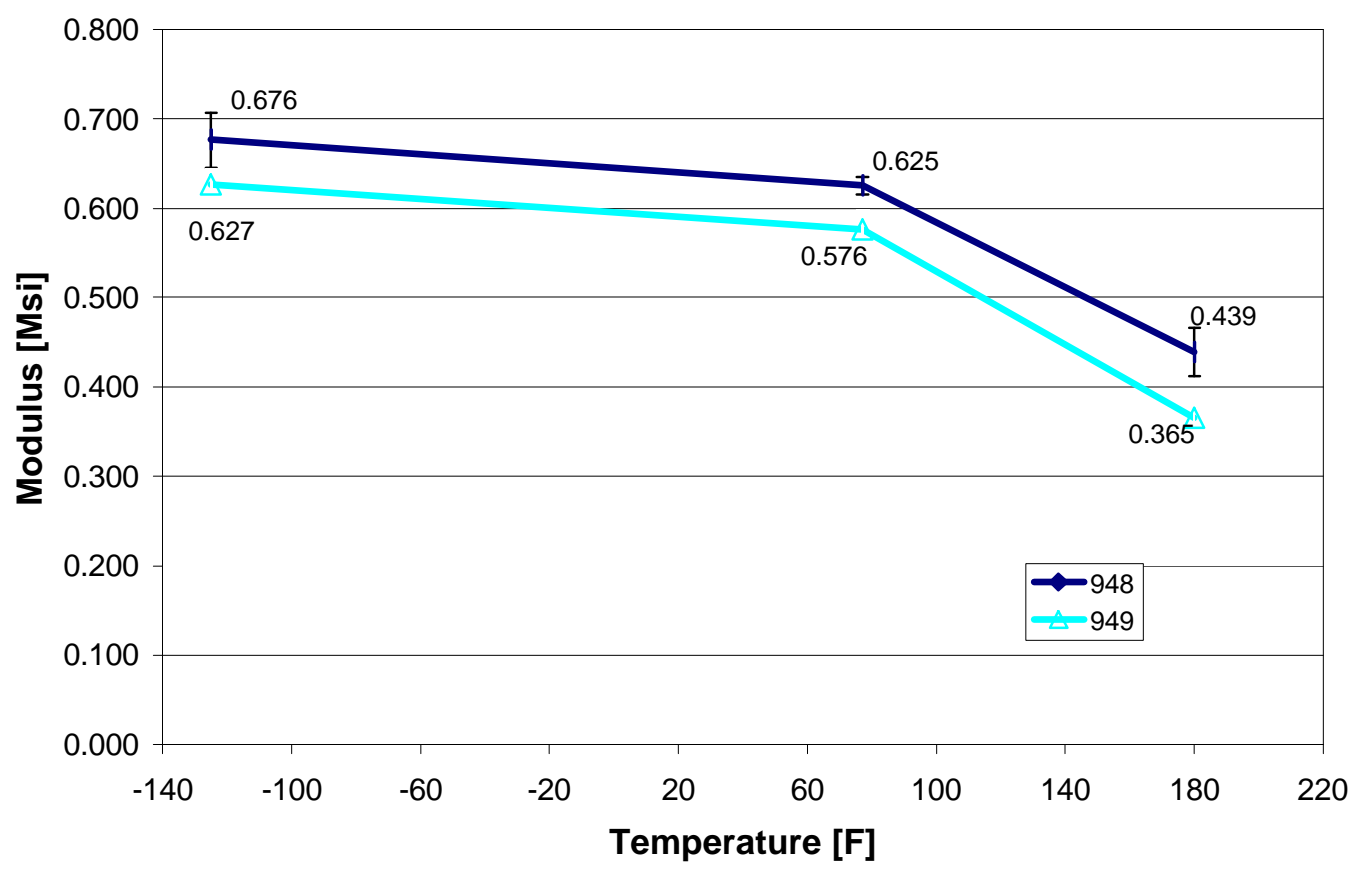

Figure 3.15 In-Plane Shear Modulus vs. Temperature 


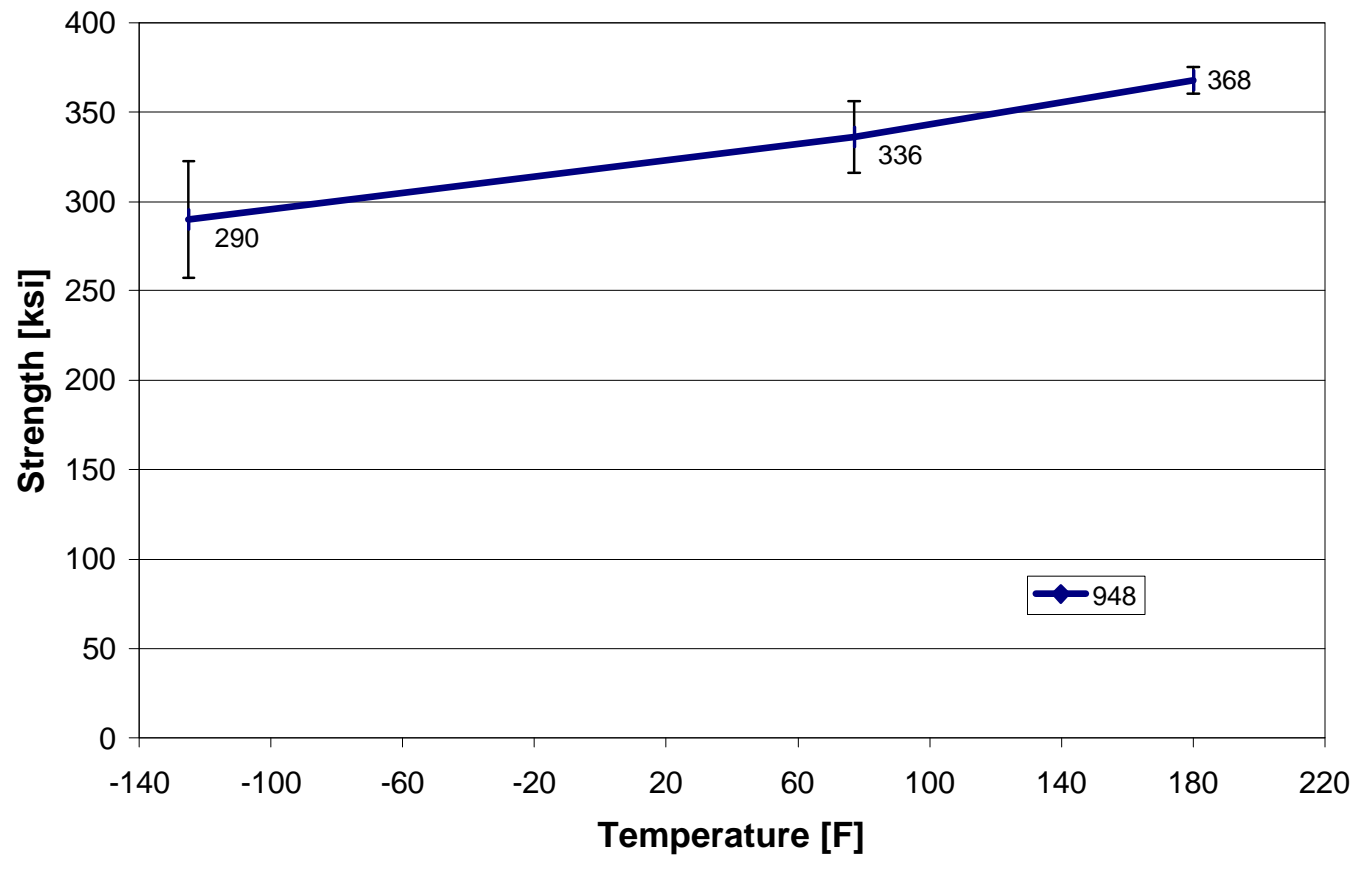

Figure 3.16 Longitudinal Tensile Strength vs. Temperature

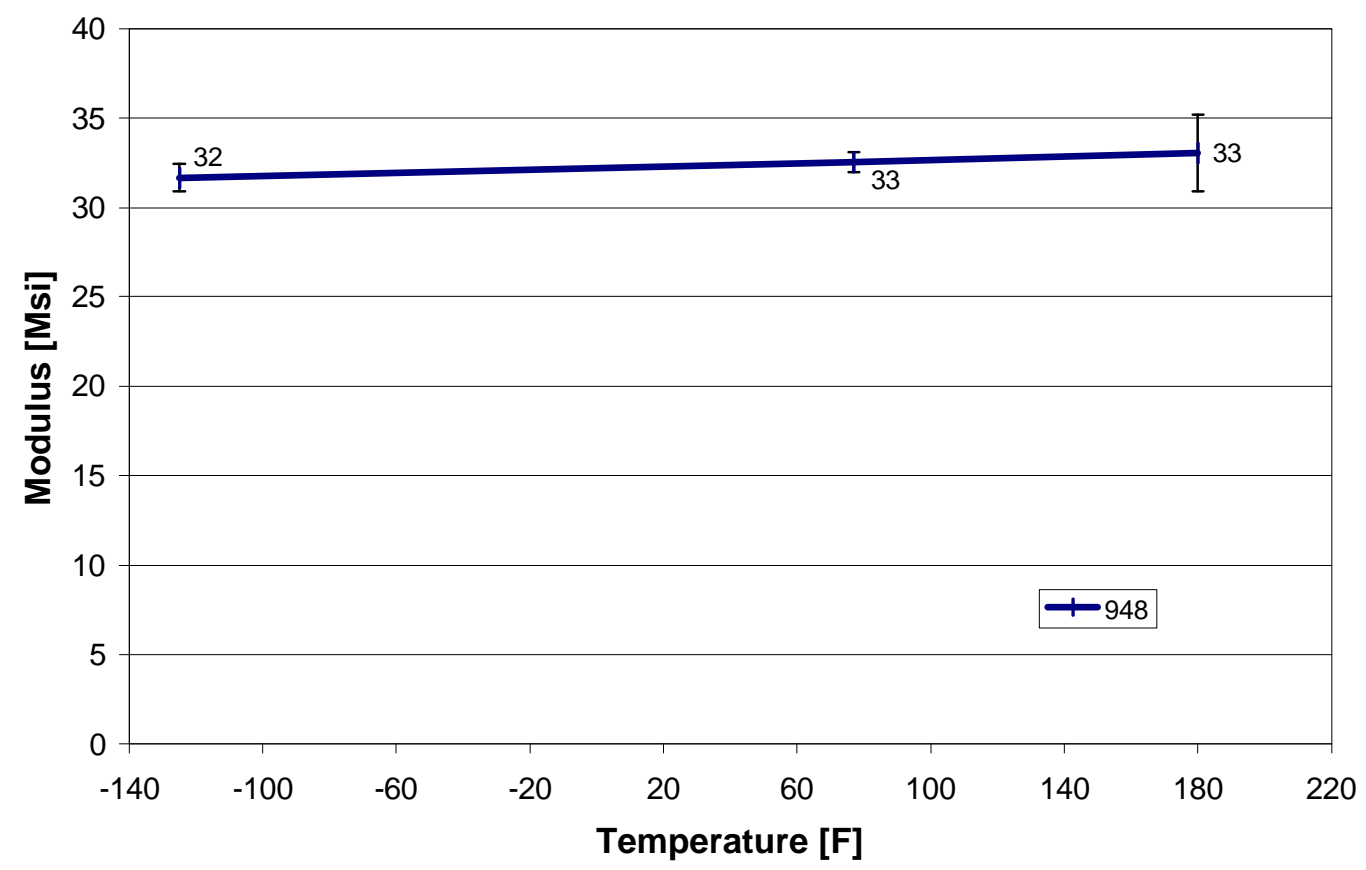

Figure 3.17 Longitudinal Tensile Modulus vs. Temperature 


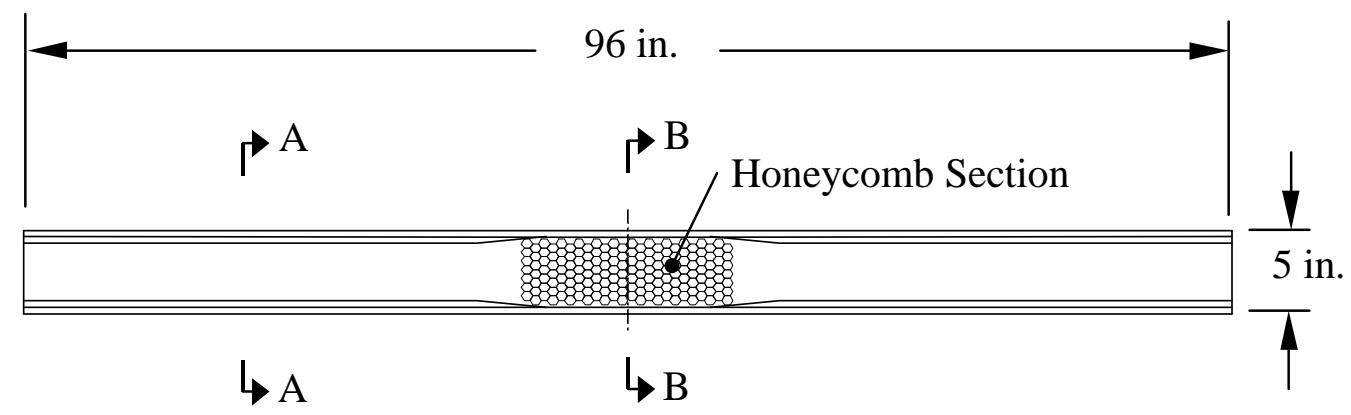

Figure 3.18 C-Beam Dimensions

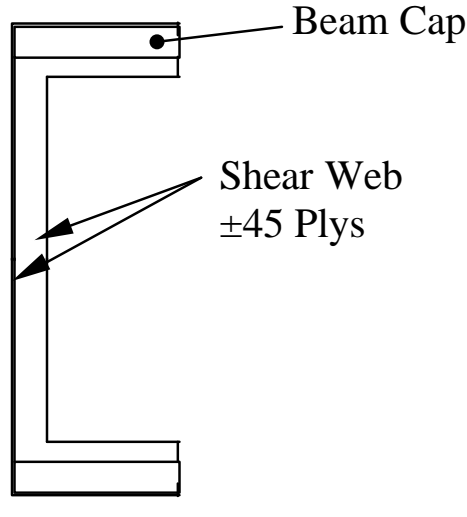

A-A

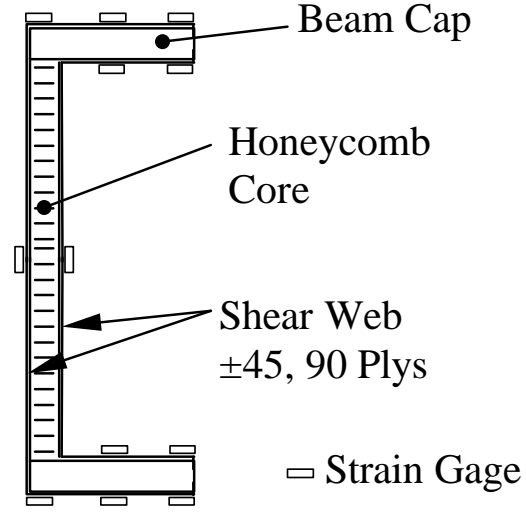

B-B

Test Section

Figure 3.19 C-Beam Cross Sectional Views 


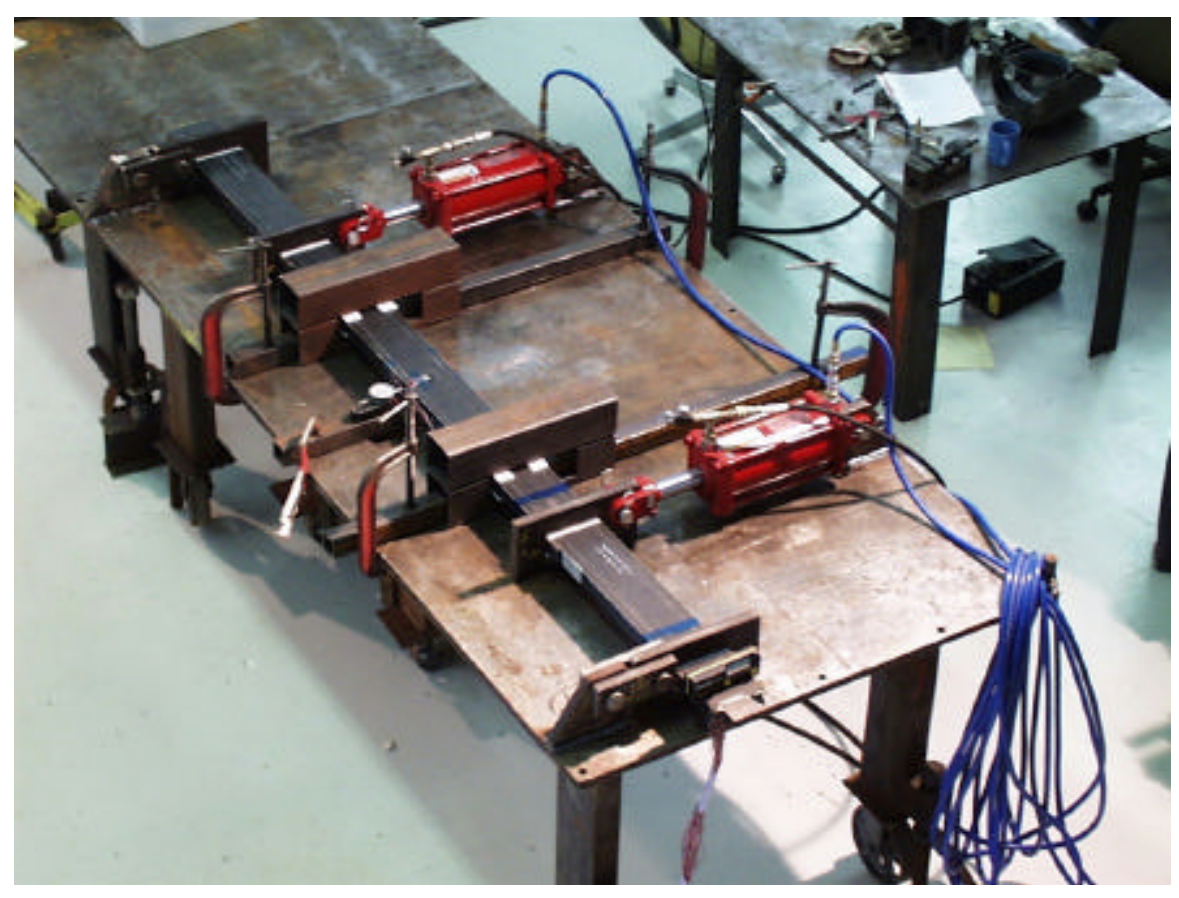

Figure 3.20 Four Point Bending Test

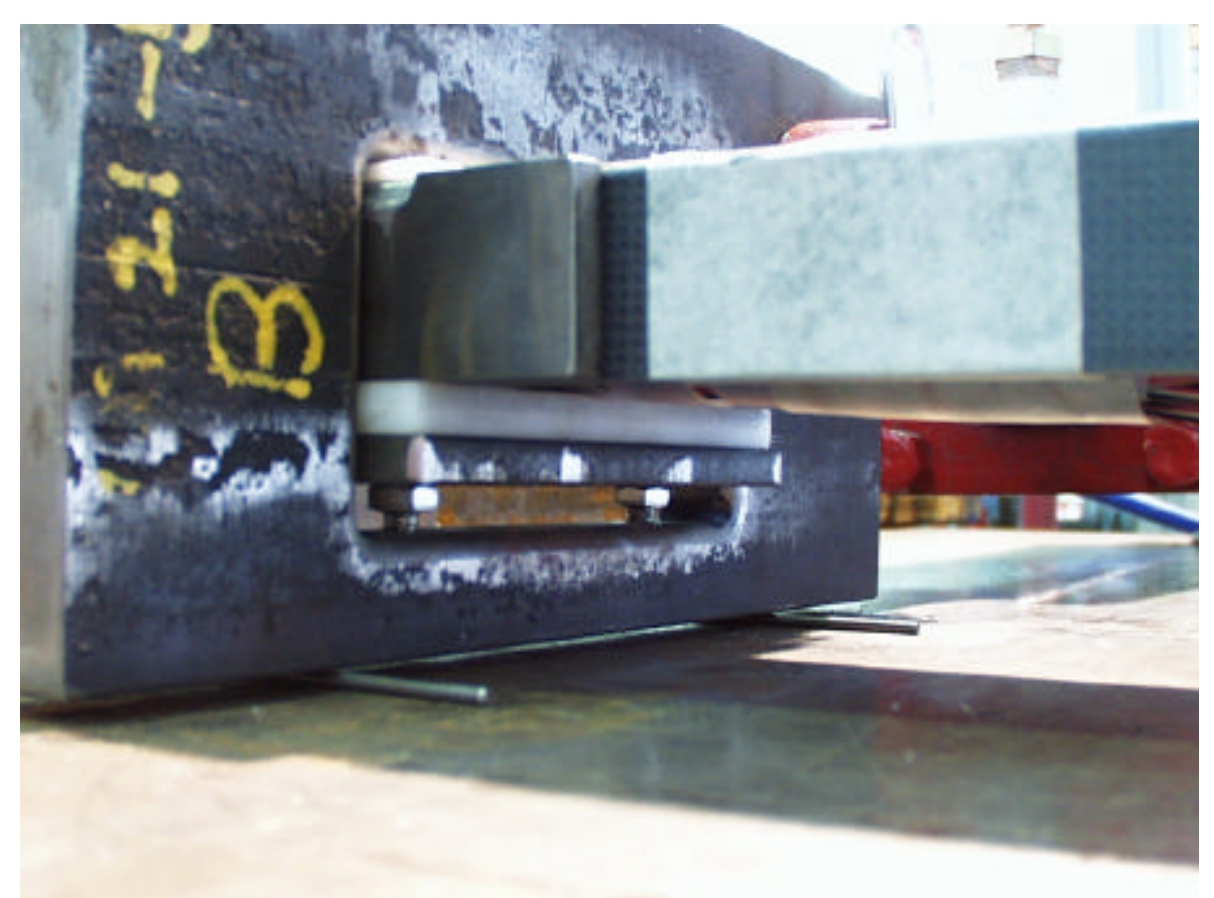

Figure 3.21 Teflon Spacers to Allow Deflection 


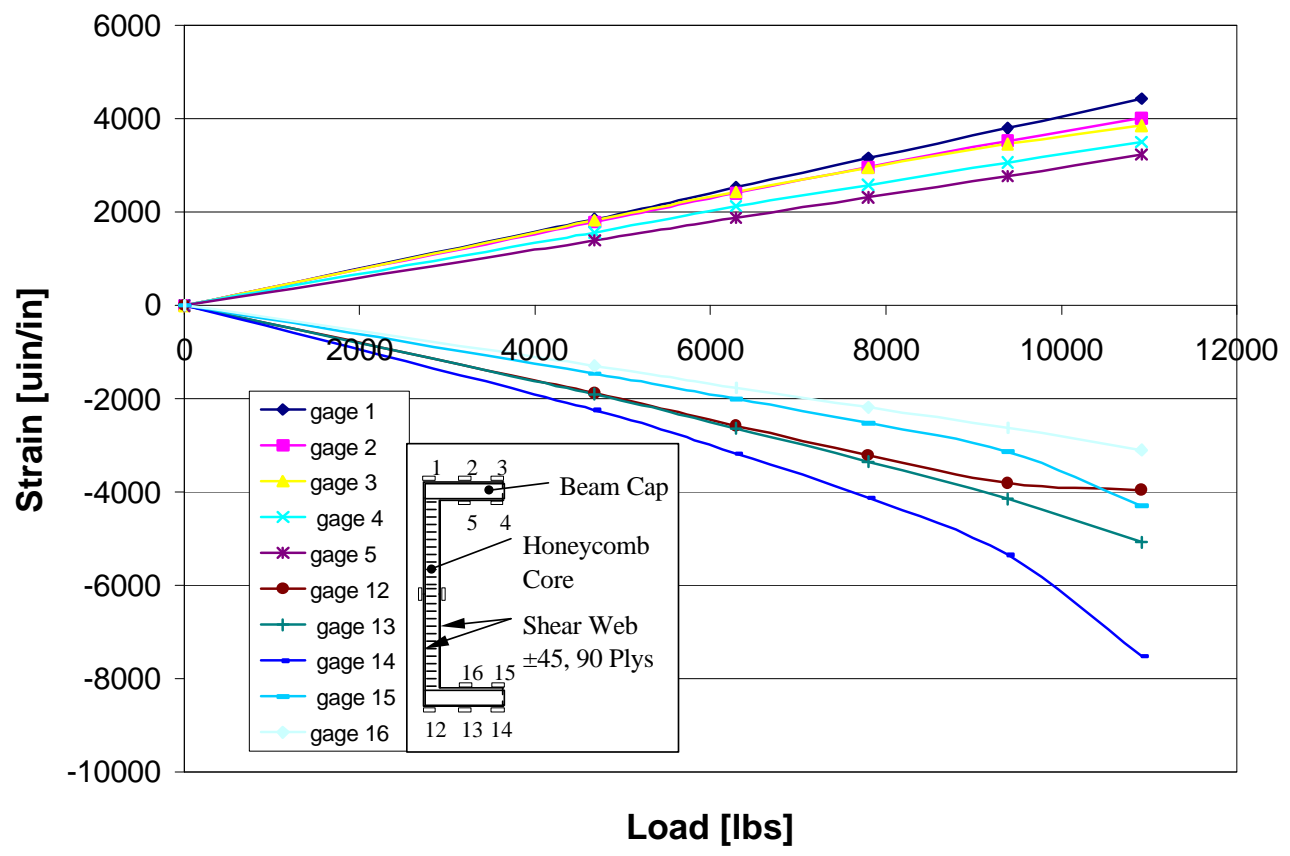

Figure 3.22 Beam 1 Test Results

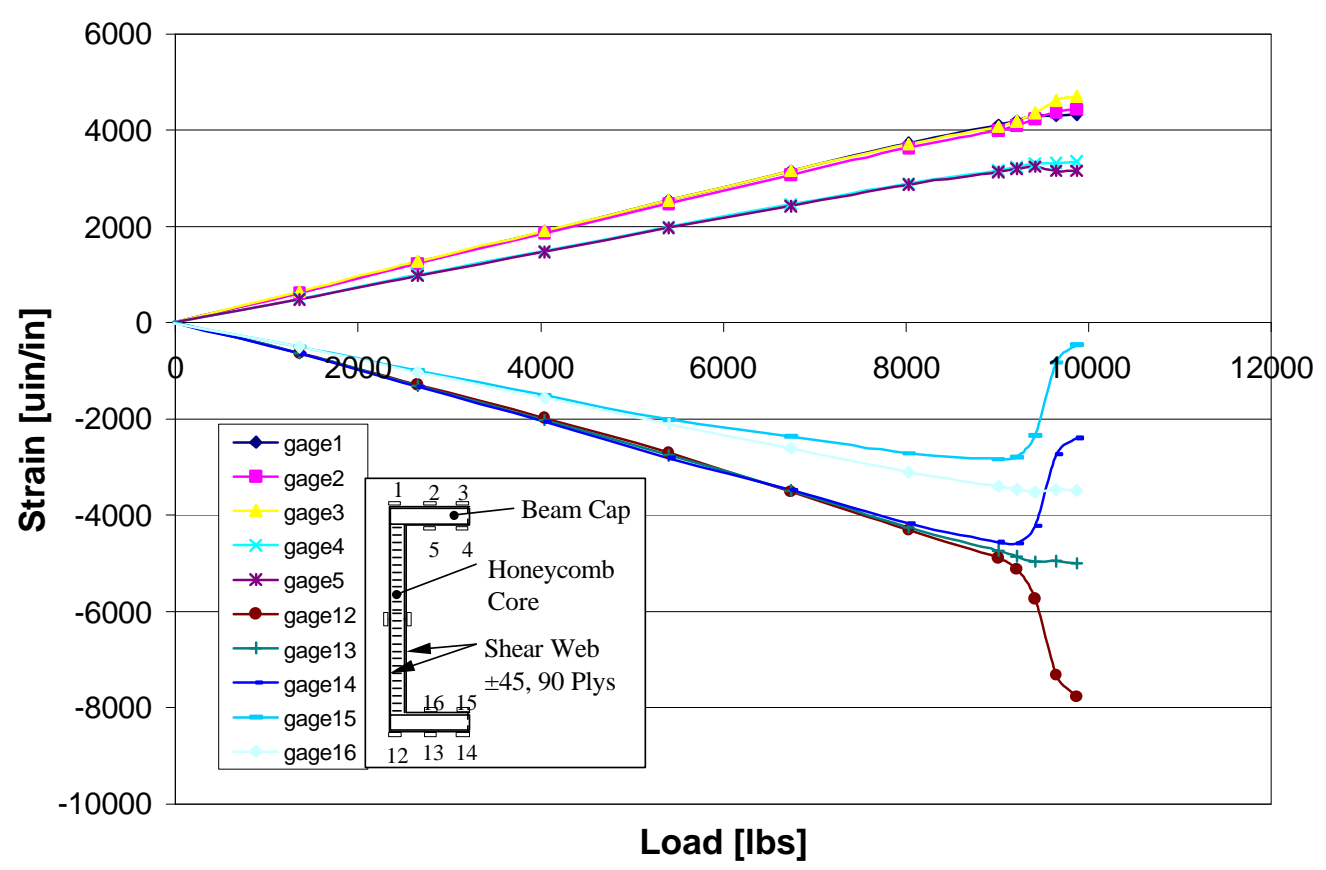

Figure 3.23 Beam 2 Test Results 


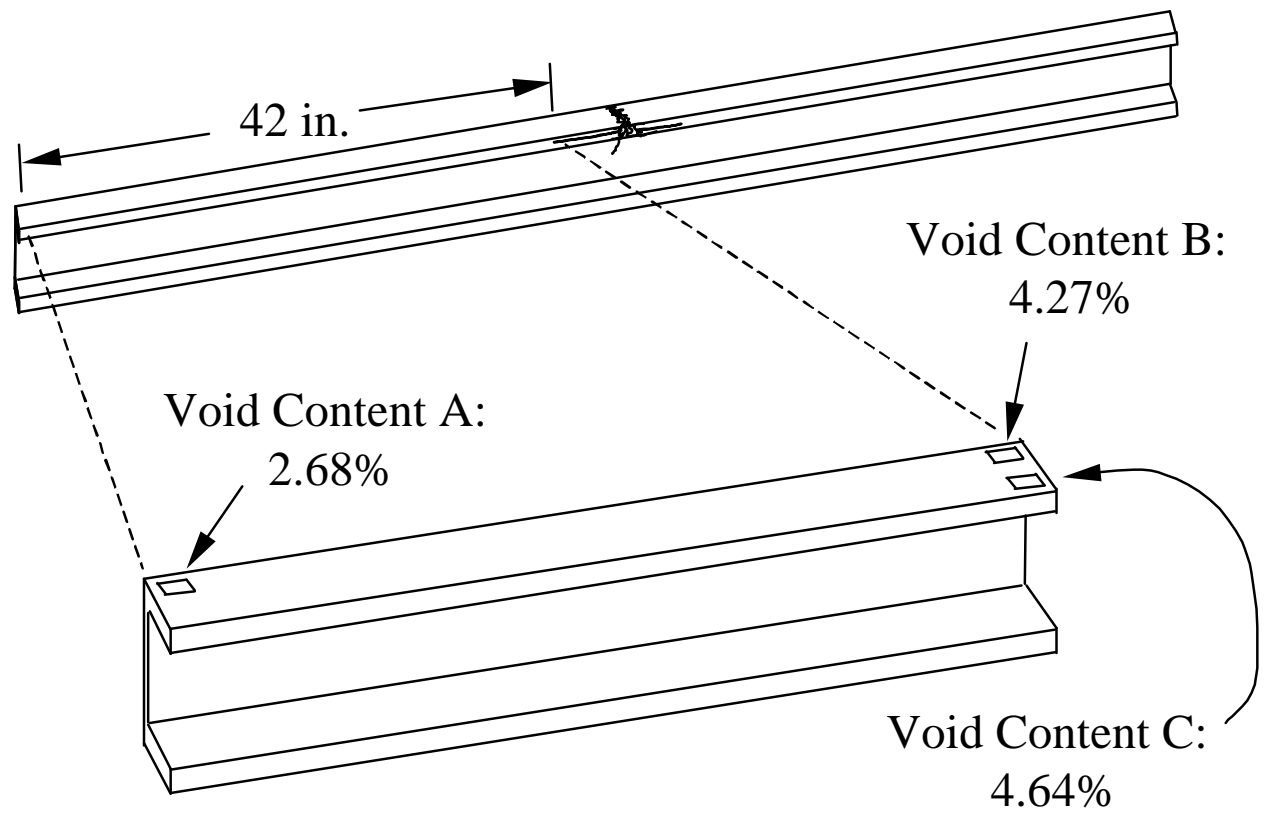

Figure 3.24 Beam Void Content Increase with Location 


\section{Chapter 4: Prediction of Compression Strength}

With the material characterization and beam compression tests complete, the work turned to predicting the compression strengths. Two of the three parameters required, shear strength and modulus, were already captured in the experimental portion of the program. The only remaining parameter was the standard deviation of the fiber misalignment, $\Omega$.

\subsection{Optical Technique}

An optical technique first proposed by Yurgartis [3] can be used to measure the misalignment angle of each fiber in the cross section. The technique consist of cutting the composite at a known angle and measuring under microscope the major axis of the ellipse formed by the intersection of a cylindrical fiber with the cutting plane. The misalignment angle is computed from the major axis length, $l$, the fiber diameter, $d$, and the angle of the cutting plane $\phi$, as shown in Figure 4.1.

This technique assumes that (1) fibers are straight over short sections and that (2) fibers have equal diameters. The first assumption has been shown to be reasonable in [1], [3]. The fiber diameters were roughly equal and were averaged for each material system. The fiber diameters for both materials were found to be lower than those reported by the manufacturer, Toray. Approximately forty points of data were taken on each specimen and the coefficient of variation is about $10 \%$ as shown in the Table 4.1. As in [1], [21], the effect of fiber diameter variation was not included in the study. 
The angle of the sectioning plane should be chosen so that most of the misaligned fibers can be captured. At the same time, the angle should not be set such that the ellipse formed at the plane of intersection is very long since the assumption of straight segments is less likely to be fulfilled. Practically speaking, a low viewing magnification would be required to measure long ellipses. This would reduce accuracy when taking measurements manually. The angle to cut the composite was chosen at 5 deg since [1], [3] obtained good results with carbon/epoxy at this angle. Later, the results would show it was a good choice.

When laying down the unidirectional prepreg at 0 degrees, it was assumed that the global misalignment tolerance was \pm 0.25 degrees for the compression specimen panels and \pm 0.5 degree for the prototype production beams. A \pm 0.25 degree tolerance was assumed when cutting and polishing the specimens and beam samples. Summing the tolerances, a \pm 0.50 degree total tolerance was expected on the angles produced from the compression specimen samples and a \pm 0.75 degree total tolerance was expected on the beam samples.

It is reasonable to expect a symmetric distribution of fiber angles but this technique typically shows a distribution of angles that is skewed as shown in Figure 4.2. This shows more fibers counted with positive angles. Statistically, skew can be quantified as,

$$
\text { skewness }=\frac{n}{(n-1)(n-2)} \sum_{j=1}^{n}\left(\frac{x_{j}-\bar{x}}{s}\right)^{3}
$$


where

$$
\begin{aligned}
& n=\text { number of data points } \\
& s=\text { sample standard deviation } \\
& \overline{\mathrm{x}}=\text { sample average } \\
& \mathrm{x}_{\mathrm{j}}=j \text { th sampled data point. }
\end{aligned}
$$

Positive skewness indicates a distribution with an asymmetric tail extending toward more positive values. Negative skewness indicates a distribution with an asymmetric tail extending toward more negative values [24].

One explanation of why there is a skew is that fibers that have angles less than -5 degrees get "flipped" back into the distribution [1], [21]. For example, if $\alpha=-6 \mathrm{deg}$, it would be recorded as $\alpha=-4 \operatorname{deg}, \alpha=-7 \operatorname{deg}$ as $\alpha=-3 \operatorname{deg}$, etc. However, this does not explain the phenomenon that was observed in this study. The technique had a tendency to show more frequency on the side of the distribution where the fiber lengths are shorter. Also, it seems unlikely that fibers with angles greater than -5 degrees are getting "flipped" back into the distribution because most of the fibers never went beyond -4 degrees. One would have expected more frequency leading up to -5 degrees in order to believe significant frequency beyond -5 degrees.

\subsection{Modifications to Optical Technique}

Because there is inherent skew in this technique, researchers have proposed different methods of adjusting the curve to make it a normal or Gaussian distribution. In [21], the negative side of the curve was discarded and assumed to be a mirror image of the positive side. In [1], the values were first shifted to make the mean equal 0 degrees, 
and then the positive values were added to the negative values to get a "folded" distribution.

In this investigation, another method is proposed with the intent of changing the original data as little as possible. Data was taken on a +5 and -5 degree cut surface so that two oppositely skewed distributions would be obtained. If the average angles of the distributions were within the tolerances caused by cutting/polishing and global misalignment, then it was judged to be reasonable to shift the distributions to have an average of zero degrees. The distributions were then added to get a single distribution with skewness closer to zero (Figure 4.3).

\section{3 Preparation}

After the compression specimens were broken, the two halves of the specimens were carefully ground to regain parallel edges. This is possible since the damage from the compression failure is around the gage section and the end of the specimen can still be used to establish a reference surface. A 5 degree cut was made on each of the compression specimen halves so that one side would have +5 degree cut and the other side would have a -5 degree cut as shown in Figure 4.4. Each side was cut into three pieces so that they could be potted in small circular acrylic cylinders with the \pm 5 degree surfaces on top. These cylinders were installed in a carousel that could handle 3 or 6 cylinders at one time and the carousel was installed in the Buehler Ecomet 2 polishing machine. These surfaces were then polished at 240, 400, 600, 800 grit sandpaper and with 1 micron alumina polishing compound. 
In the case of the beams, a piece was cut from the compression caps as near as possible to the location of the failure as shown in Figure 4.5. A piece cut in this manner had two faces that were against the tool and therefore could be taken as reference surfaces when performing the subsequent grinding to square up the specimen. Again, the pieces were sectioned into thirds and then potted in acrylic

To quantify fiber misalignment, the major and minor axes of the fiber ellipse were measured with a conventional microscope and a graphics software program, OPTIMAS. The major axis was measured at 200X magnification for 1512 fibers on each specimen and the minor axis of the fiber was measured at 500X magnification for 40 points on each specimen.

As pointed out in [1], [3], there is a tendency to pick the fibers with a major axis of smaller length and neglect the fibers with a longer length. To make the selection as random as possible, a line was drawn on the screen as shown in Figure 4.6 and all fibers crossing the line were measured. The line was kept so that it started from the top of the specimen and ended at the bottom. Additional lines of data were taken until the required number of points had been achieved.

\subsection{Data Reduction and Interpretation}

Tables 4.2, 4.3, 4.4, 4.5 show the average angle before shifting to zero and the skew for all the specimens. (Note the "Left Side" was cut at -5 degrees and the "Right Side" was cut at +5 degrees.) The average angle is very small - less than \pm 0.5 deg with only a few exceptions. As mentioned before, this is caused by cutting, polishing and 
global misalignment errors. Hence, it is reasonable to disregard these average angles and shift to zero degrees in each case. As expected, the combined skew is reduced by adding the "Left Side" and "Right Side" angles.

\subsection{Fiber Volume Correction}

As noted in Chapter 3.3, the material properties were reported at the fiber volumes in which they were tested and not normalized as in Table 4.6 and 4.7. In order to make the compressive strength comparisons, the data for F6 and G12 was normalized to the same fiber volume fraction of F1c by the following equations.

$$
\begin{gathered}
G_{12} \cong \frac{v_{f} \bar{G}_{12}}{\bar{v}_{f}} \\
F_{6} \cong \frac{v_{f} \bar{F}_{6}}{\bar{v}_{f}}
\end{gathered}
$$

For the 949/M30GC material, G12 and F6 were reported at 54.13\% and F1c at $61.45 \%$. For the 948A1/M40J material, G12 and F6 were reported at 52.02\% and F1c at $59.41 \%$. Therefore the correction factor was 1.135 for $949 / \mathrm{M} 30 \mathrm{GC}$ and 1.142 for $948 \mathrm{~A} 1 / \mathrm{M} 40 \mathrm{~J}$.

It should be noted that these are approximate equations and the relationships could be more refined. From the inverse rule of mixtures, G12 does not have a linear relationship with fiber volume. However, in the range of fiber volumes of this study, $52 \%$ to $61 \%$, the relationship is essentially linear and can be written as above.

$$
G_{12}=\bar{G}_{12}\left(\frac{1-\bar{v}_{f}}{1-v_{f}}\right) \cong \frac{v_{f} \bar{G}_{12}}{\bar{v}_{f}}
$$




\subsection{Confidence Intervals on Measured Data}

The confidence interval on the mean of a normal distribution with the population variance unknown, is given by [25],

$$
\bar{x}-\frac{t_{\alpha / 2, n-1} s}{\sqrt{n}} \leq \mu \leq \bar{x}+\frac{t_{\alpha / 2, n-1} s}{\sqrt{n}}
$$

where

$$
\begin{aligned}
& \mu=\text { population mean for } \mathrm{G}_{12}, \mathrm{~F}_{6}, \mathrm{~F}_{1 \mathrm{c}} \\
& \overline{\mathrm{x}}=\text { sample mean } \\
& \mathrm{s}=\text { sample standard deviation } \\
& \alpha=\text { probability } \\
& \mathrm{n}=\text { number of data points } \\
& \mathrm{t}_{\alpha / 2, \mathrm{n}-1}=\mathrm{t} \text { distribution at } \alpha / 2, \mathrm{n}-1 .
\end{aligned}
$$

Thus, there is a $100(1-\alpha)$ percent confidence that the population mean, $\mu$, lies between the above two values, which form the confidence interval. This equation was used for F6, G12, and the experimental values of F1c. The confidence intervals are shown in Table 4.6 and 4.7 .

The confidence interval on the standard deviation of a normal distribution with the population variance unknown, is given by [25],

$$
\sqrt{\frac{(n-1) s^{2}}{\chi_{\alpha / 2, n-1}^{2}}} \leq \Omega \leq \sqrt{\frac{(n-1) s^{2}}{\chi^{2}{ }_{1-\alpha / 2, n-1}}}
$$

where 


$$
\begin{aligned}
& \Omega=\text { population standard deviation } \\
& \mathrm{s}=\text { sample standard deviation } \\
& \mathrm{s}^{2}=\text { sample variance } \\
& \alpha=\text { probability } \\
& \mathrm{n}=\text { number of data points } \\
& \chi^{2}{ }_{\alpha / 2, \mathrm{n}-1}=\mathrm{chi}^{2} \text { distribution at } \alpha / 2, \mathrm{n}-1 \\
& \chi^{2}{ }_{1-\alpha / 2, \mathrm{n}-1}=\mathrm{chi}^{2} \text { distribution at } 1-\alpha / 2, \mathrm{n}-1 .
\end{aligned}
$$

The results of the confidence interval on $\Omega$ are shown in the "chi-squared" column of Table 4.8 and 4.9 with $\alpha=0.05$, or a $95 \%$ confidence level. Since 1512 fibers per sample were measured $(n=1512)$, the confidence intervals were very narrow. However, as can be seen for the samples with identification NTP-15-XX, the confidence intervals of the four samples do not overlap. The same is true of the other three types of samples. This means that $\Omega$ changes from point to point in the same panel (i.e. NTP-11XX) or from panel to panel. Because of this, the values of $\Omega$ were treated as point estimates, or samplings, of the standard deviation of the misalignment angle at different locations in the panels instead representing the population standard deviation of the misalignment angle. The standard deviation was then calculated as

$$
\Omega=\sqrt{\frac{s_{1}^{2}+s_{2}^{2}+s_{3}^{2}+\cdots+s_{n}^{2}}{n}}
$$

where

$$
\begin{aligned}
& \Omega=\text { population standard deviation } \\
& \mathrm{s}=\text { sample standard deviation } \\
& \mathrm{s}^{2}=\text { sample variance } \\
& \mathrm{n}=\text { number of data points }=4 .
\end{aligned}
$$

The confidence interval was calculated as 


$$
\sqrt{V-\frac{t_{\alpha / 2, n-1} S V}{\sqrt{n}}} \leq \Omega \leq \sqrt{V+\frac{t_{\alpha / 2, n-1} S V}{\sqrt{n}}}
$$

where

$$
\begin{aligned}
& \Omega=\text { population standard deviation } \\
& \mathrm{V}=\text { sample variance } \\
& \mathrm{SV}=\text { standard deviation of sample variance } \\
& \alpha=\text { probability } \\
& \mathrm{n}=\text { number of data points } \\
& \mathrm{t}_{\alpha / 2, \mathrm{n}-1}=\mathrm{t} \text { distribution at } \alpha / 2, \mathrm{n}-1 .
\end{aligned}
$$

The values of $\Omega$ and the confidence intervals are shown in the "t-dist." column of Tables 4.8 and 4.9 .

\subsection{Confidence Intervals on Predicted Data}

Because the three terms in the compression formula (2.20) all have their own confidence interval, the predicted compression strength will have its associated confidence interval. Using a binomial expansion for the terms in compression formula, it shows that the highest value of F1c occurs when G12 and F6 are at their highest value and $\Omega$ is at its lowest. The lowest values of F1c occur when the values take the opposite extremes, which is consistent with intuition.

$$
F_{1 C}=G_{12}\left(\frac{\chi}{a}+1\right)^{b}\left(1+\frac{ \pm \frac{\chi}{a} \frac{\Delta F_{6}}{F_{6}} \pm \frac{1}{a F_{6}}\left(\Omega \Delta G_{12} \pm G_{12} \Delta \Omega\right)}{\frac{\chi}{a}+1}\right)
$$




\begin{tabular}{lcc} 
& $\begin{array}{c}\text { 949/M30GC } \\
\text { Fiber Diameter } \\
\text { [microns] }\end{array}$ & $\begin{array}{c}\text { 948A1/M40J } \\
\text { Fiber Diameter } \\
\text { [microns] }\end{array}$ \\
\hline Average & 5.02 & 4.85 \\
Standard Dev. & 0.41 & 0.52 \\
Cv & 8.16 & 10.67 \\
\hline
\end{tabular}

No. of pts $n$

238

320

Table 4.1 Fiber Diameters

Left Side

\begin{tabular}{|l|cc|}
\hline 949/M30GC & $\alpha^{1}$ & Skew \\
Specimen & {$[\mathrm{deg}]$} & {[]} \\
\hline NTP-15-1 & -1.22 & 0.424 \\
NTP-15-84 & -0.47 & -0.167 \\
NTP-15-86 & -0.36 & 0.413 \\
NTP-15-21 & 0.26 & -0.118 \\
\hline Average & -0.45 & 0.138 \\
\hline Standard Dev. & 0.61 & 0.32 \\
\hline
\end{tabular}

Note 1: Angles before shifting to zero.
Right Side

\begin{tabular}{|cc|}
\hline$\alpha^{1}$ & Skew \\
{$[\mathrm{deg}]$} & {[]} \\
\hline-0.12 & -0.168 \\
-0.02 & -0.064 \\
0.02 & -0.328 \\
0.10 & -0.173 \\
\hline 0.00 & -0.183 \\
\hline 0.09 & 0.11 \\
\hline
\end{tabular}

Combined

\begin{tabular}{|cc|}
\hline $\begin{array}{c}\alpha^{1} \\
{[\mathrm{deg}]}\end{array}$ & $\begin{array}{c}\text { Skew } \\
{[]}\end{array}$ \\
\hline-0.67 & -0.022 \\
-0.24 & -0.113 \\
-0.17 & -0.010 \\
0.18 & -0.145 \\
\hline-0.23 & -0.072 \\
\hline 0.35 & 0.07 \\
\hline
\end{tabular}

Table 4.2 Average Angle and Skew, 949/M30GC compression specimens

\begin{tabular}{|l|cc|}
\multicolumn{2}{c}{ Left Side } \\
\hline 948A1/M40J & $\alpha^{1}$ & Skew \\
Specimen & {$[\mathrm{deg}]$} & {$[\mathrm{]}$} \\
\hline NTP-11-1 & -0.14 & 0.328 \\
NTP-17-7 & 0.35 & 0.405 \\
NTP-16-5 & 0.78 & 0.750 \\
NTP-11-21 & 0.37 & -0.064 \\
\hline Average & 0.34 & 0.355 \\
\hline Standard Dev. & 0.38 & 0.33 \\
\hline
\end{tabular}

Right Side

\begin{tabular}{|cc|}
\hline$\alpha^{1}$ & Skew \\
{$[\mathrm{deg}]$} & {$[\mathrm{]}$} \\
\hline 0.18 & -0.100 \\
-0.41 & -0.193 \\
-0.50 & -0.259 \\
0.26 & -0.332 \\
\hline-0.12 & -0.221 \\
\hline 0.39 & 0.10 \\
\hline
\end{tabular}

Combined

\begin{tabular}{|cc|}
\hline$\alpha^{1}$ & Skew \\
{$[\mathrm{deg}]$} & []$]$ \\
\hline 0.02 & 0.105 \\
-0.03 & 0.099 \\
0.14 & 0.221 \\
0.32 & -0.218 \\
\hline 0.11 & 0.052 \\
\hline 0.15 & 0.19 \\
\hline
\end{tabular}

Table 4.3 Average Angle and Skew , 948A1/M40J compression specimens 
Left Side

\begin{tabular}{|l|cc|}
\hline 949/M30GC & $\alpha^{1}$ & $\begin{array}{c}\text { Skew } \\
\text { Beam 1 Sample }\end{array}$ \\
{$[\mathrm{deg}]$} & {[]} \\
\hline B1-1 & 0.31 & 0.346 \\
B1-L1R1 & -0.02 & 0.176 \\
B1-L2R2 & -0.38 & 0.429 \\
B1-L3R3 & -0.01 & -0.086 \\
\hline Average & -0.03 & 0.216 \\
\hline Standard Dev. & 0.28 & 0.23 \\
\hline
\end{tabular}

Note 1: Angles before shifting to zero.
Right Side

\begin{tabular}{|cc|}
\hline $\begin{array}{c}\alpha^{1} \\
{[\mathrm{deg}]}\end{array}$ & $\begin{array}{c}\text { Skew } \\
{[]}\end{array}$ \\
\hline 0.14 & -0.133 \\
-0.12 & -0.470 \\
-0.28 & -0.264 \\
-0.13 & -0.017 \\
\hline-0.10 & -0.221 \\
\hline 0.17 & 0.19 \\
\hline
\end{tabular}

Combined

\begin{tabular}{|cc|}
\hline $\begin{array}{c}\alpha^{1} \\
{[\mathrm{deg}]}\end{array}$ & $\begin{array}{c}\text { Skew } \\
{[]}\end{array}$ \\
\hline 0.23 & 0.035 \\
-0.07 & -0.207 \\
-0.33 & 0.113 \\
-0.07 & -0.046 \\
\hline-0.06 & -0.026 \\
\hline 0.23 & 0.14 \\
\hline
\end{tabular}

Table 4.4 Average Angle and Skew, 949/M30GC Beam 1 Samples

Left Side

\begin{tabular}{|l|cc|}
\hline 949/M30GC & $\alpha^{1}$ & $\begin{array}{c}\text { Skew } \\
\text { Beam 2 Sample }\end{array}$ \\
\hline $\mathrm{deg}]$ & {[]} \\
\hline B2-1 & 0.30 & 0.082 \\
B2-L1R1 & 0.30 & 0.082 \\
B2-L2R2 & -0.38 & 0.388 \\
B2-L3R3 & 0.25 & 0.835 \\
\hline Average & 0.12 & 0.347 \\
\hline Standard Dev. & 0.33 & 0.36 \\
\hline
\end{tabular}

Note 1: Angles before shifting to zero.
Right Side

\begin{tabular}{|cc|}
\hline$\alpha^{1}$ & Skew \\
{$[\mathrm{deg}]$} & {[]} \\
\hline-0.07 & -0.585 \\
-0.01 & -0.728 \\
-0.29 & -0.253 \\
-0.95 & -0.325 \\
\hline-0.33 & -0.473 \\
\hline 0.43 & 0.22 \\
\hline
\end{tabular}

Combined

\begin{tabular}{|cc|}
\hline$\alpha^{1}$ & Skew \\
{$[\mathrm{deg}]$} & {[]} \\
\hline 0.12 & -0.260 \\
0.15 & -0.310 \\
-0.34 & -0.022 \\
-0.35 & 0.306 \\
\hline-0.11 & -0.072 \\
\hline 0.27 & 0.28 \\
\hline
\end{tabular}

Table 4.5 Average Angle and Skew, 949/M30GC Beam 2 Samples

\begin{tabular}{|c|c|c|c|}
\hline Material & Temp. & $\begin{array}{c}\text { G12 } \\
\text { (Fib. Vol. } \\
54.13 \% \text { ) } \\
\\
\text { [Msi] }\end{array}$ & $\begin{array}{c}95 \% \\
\text { Confidence } \\
\text { Interval } \\
\text { (t-dist.) } \\
\text { [Msi] }\end{array}$ \\
\hline \multirow{3}{*}{ 949/M30GC } & 180 & 0.365 & $\begin{array}{l}+.026 \\
-.026 \\
\end{array}$ \\
\hline & RTA & 0.576 & $\begin{array}{l}+.026 \\
-.026\end{array}$ \\
\hline & -125 & 0.627 & $\begin{array}{l}+.020 \\
-.020\end{array}$ \\
\hline
\end{tabular}

\begin{tabular}{|cc|}
\hline $\begin{array}{c}\text { F6 } \\
\text { (Fib. Vol. } \\
54.13 \%)\end{array}$ & $\begin{array}{c}95 \% \\
\text { Confidence } \\
\text { Interval } \\
\text { (t-dist.) } \\
{[\mathrm{ksi}]}\end{array}$ \\
\hline 6.07 & +.410 \\
& -.410 \\
\hline 9.80 & +.621 \\
& -.621 \\
\hline 16.01 & +.906 \\
& -.906 \\
\hline
\end{tabular}

\begin{tabular}{|cc|}
\hline $\begin{array}{c}\text { F1c } \\
\text { (Fib. Vol. } \\
61.45 \%)\end{array}$ & $\begin{array}{c}95 \% \\
\text { Confidence } \\
\text { Interval } \\
\text { (t-dist.) } \\
{[\mathrm{ksi}]}\end{array}$ \\
\hline ksi] & +5.41 \\
\hline 149 & -5.41 \\
\hline 185 & +21.4 \\
& -21.4 \\
\hline 226 & +11.6 \\
& -11.6 \\
\hline
\end{tabular}

Table 4.6 $\mathrm{G}_{12}, \mathrm{~F}_{6}, \mathrm{~F}_{1 \mathrm{c}}$ Confidence Intervals, 949/M30GC 


\begin{tabular}{|c|c|c|c|}
\hline Material & {$[F]$} & $\begin{array}{c}\text { G12 } \\
\text { (Fib. Vol. } \\
52.02 \% \text { ) } \\
\text { [Msi] }\end{array}$ & $\begin{array}{c}95 \% \\
\text { Confidence } \\
\text { Interval } \\
\text { (t-dist.) } \\
\text { [Msi] }\end{array}$ \\
\hline \multirow{3}{*}{ 948A1/M40J } & 180 & 0.439 & $\begin{array}{r}+.034 \\
-.034 \\
\end{array}$ \\
\hline & RTA & 0.625 & $\begin{array}{l}+.012 \\
-.012\end{array}$ \\
\hline & -125 & 0.676 & $\begin{array}{l}+.039 \\
-.039\end{array}$ \\
\hline
\end{tabular}

\begin{tabular}{|cc|}
\hline $\begin{array}{c}\text { F6 } \\
\text { (Fib. Vol. } \\
52.02 \%)\end{array}$ & $\begin{array}{c}95 \% \\
\text { Confidence } \\
\text { Interval } \\
\text { (t-dist.) } \\
{[\mathrm{ksi}]}\end{array}$ \\
\hline $\mathrm{ksi}]$ & +.124 \\
\hline 8.93 & -.124 \\
\hline 11.40 & +.223 \\
& -.223 \\
\hline 14.30 & +1.02 \\
& -1.02 \\
\hline
\end{tabular}

\begin{tabular}{|cc|}
\hline $\begin{array}{c}\text { F1c } \\
\text { (Fib. Vol. } \\
59.41 \%)\end{array}$ & $\begin{array}{c}95 \% \\
\text { Confidence } \\
\text { Interval } \\
\text { (t-dist.) } \\
{[\mathrm{ksi}]}\end{array}$ \\
\hline $1 \mathrm{ksi}]$ & +13.6 \\
& -13.6 \\
\hline 208 & +5.68 \\
& -5.68 \\
\hline 223 & +18.6 \\
& -18.6 \\
\hline
\end{tabular}

Table $4.7 G_{12}, F_{6}, F_{1 c}$ Confidence Intervals, 948A1/M40J

\begin{tabular}{|c|c|c|c|c|c|}
\hline \multirow[t]{2}{*}{$\begin{array}{c}\text { Type } \\
\text { of } \\
\text { Sample }\end{array}$} & I.D. & $\begin{array}{l}\text { Standard } \\
\text { Deviation }\end{array}$ & $\begin{array}{c}95 \% \\
\text { Confidence } \\
\text { Interval } \\
\text { (Chi }{ }^{2} \text { dist.) }\end{array}$ & $\begin{array}{c}\text { Modified } \\
\text { Standard } \\
\text { Deviation } \\
\Omega \\
\mathrm{n}=4\end{array}$ & $\begin{array}{c}95 \% \\
\text { Confidence } \\
\text { Interval } \\
\text { (t - dist.) }\end{array}$ \\
\hline & & [deg] & [deg] & [deg] & [deg] \\
\hline \multirow{4}{*}{$\begin{array}{c}\text { 948A1/M40J } \\
\text { SACMA } \\
\text { Compression } \\
\text { Specimen }\end{array}$} & NTP-11-1 & 1.129 & $\begin{array}{l}+.040 \\
-.039\end{array}$ & \multirow{4}{*}{1.205} & \multirow{4}{*}{$\begin{array}{l}+.157 \\
-.181\end{array}$} \\
\hline & NTP-17-7 & 1.164 & $\begin{array}{l}+.041 \\
-.040\end{array}$ & & \\
\hline & NTP-16-5 & 1.163 & $\begin{array}{l}+.041 \\
-.040\end{array}$ & & \\
\hline & NTP-11-21 & 1.352 & $\begin{array}{l}+.048 \\
-.047\end{array}$ & & \\
\hline
\end{tabular}

Table 4.8 Standard Deviation of Misalignment Angle Confidence Intervals, 948A1/M40J 


\begin{tabular}{|c|c|c|c|c|c|}
\hline \multirow[t]{2}{*}{$\begin{array}{c}\text { Type } \\
\text { of } \\
\text { Sample }\end{array}$} & I.D. & $\begin{array}{l}\text { Standard } \\
\text { Deviation }\end{array}$ & $\begin{array}{c}95 \% \\
\text { Confidence } \\
\text { Interval } \\
\text { (Chi }{ }^{2} \text { dist.) }\end{array}$ & $\begin{array}{c}\text { Modified } \\
\text { Standard } \\
\text { Deviation } \\
\Omega \\
\mathrm{n}=4 \\
\end{array}$ & $\begin{array}{c}95 \% \\
\text { Confidence } \\
\text { Interval } \\
\text { (t - dist.) }\end{array}$ \\
\hline & & [deg] & [deg] & [deg] & [deg] \\
\hline \multirow{4}{*}{$\begin{array}{c}\text { 949/M30GC } \\
\text { SACMA } \\
\text { Compression } \\
\text { Specimen }\end{array}$} & NTP-15-1 & 1.236 & $\begin{array}{l}+.046 \\
-.043\end{array}$ & \multirow{4}{*}{1.150} & \multirow{4}{*}{$\begin{array}{l}+.091 \\
-.099\end{array}$} \\
\hline & NTP-15-84 & 1.123 & $\begin{array}{l}+.042 \\
-.039\end{array}$ & & \\
\hline & NTP-15-86 & 1.129 & $\begin{array}{l}+.042 \\
-.039\end{array}$ & & \\
\hline & NTP-15-21 & 1.109 & $\begin{array}{l}+.041 \\
-.038\end{array}$ & & \\
\hline \multirow{4}{*}{$\begin{array}{c}\text { 949/M30GC } \\
\text { Beam } 1\end{array}$} & B1-1 & 1.342 & $\begin{array}{c}+.0500 \\
-.046\end{array}$ & \multirow{4}{*}{1.313} & \multirow{4}{*}{$\begin{array}{l}+.091 \\
-.097\end{array}$} \\
\hline & B1-L1R1 & 1.328 & $\begin{array}{l}+.049 \\
-.046\end{array}$ & & \\
\hline & B1-L2R2 & 1.223 & $\begin{array}{l}+.045 \\
-.042\end{array}$ & & \\
\hline & B1-L3R3 & 1.355 & $\begin{array}{l}+.050 \\
-.047 \\
\end{array}$ & & \\
\hline \multirow{4}{*}{$\begin{array}{c}\text { 949/M30GC } \\
\text { Beam } 2\end{array}$} & B2-1 & 1.158 & $\begin{array}{l}+.043 \\
-.040\end{array}$ & \multirow{4}{*}{1.125} & \multirow{4}{*}{$\begin{array}{l}+.055 \\
-.058\end{array}$} \\
\hline & B2-L1R1 & 1.134 & $\begin{array}{l}+.042 \\
-.039\end{array}$ & & \\
\hline & B2-L2R2 & 1.074 & $\begin{array}{l}+.040 \\
-.370\end{array}$ & & \\
\hline & B2-L3R3 & 1.133 & $\begin{array}{l}+.042 \\
-.039\end{array}$ & & \\
\hline
\end{tabular}

Table 4.9 Standard Deviation of Misalignment Angle Confidence Intervals, 949/M30GC 


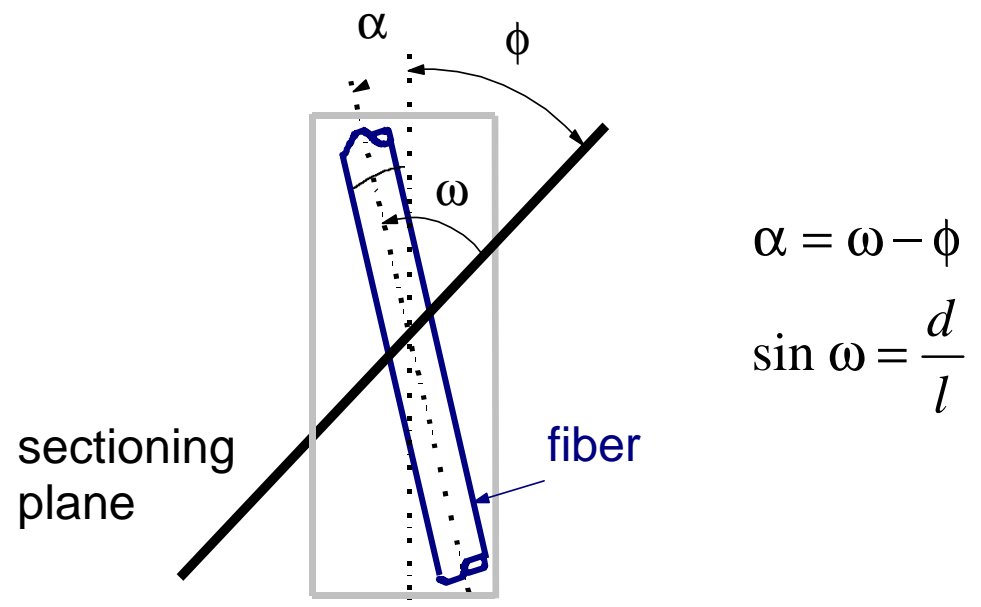

Figure 4.1 Calculation of Fiber Angle

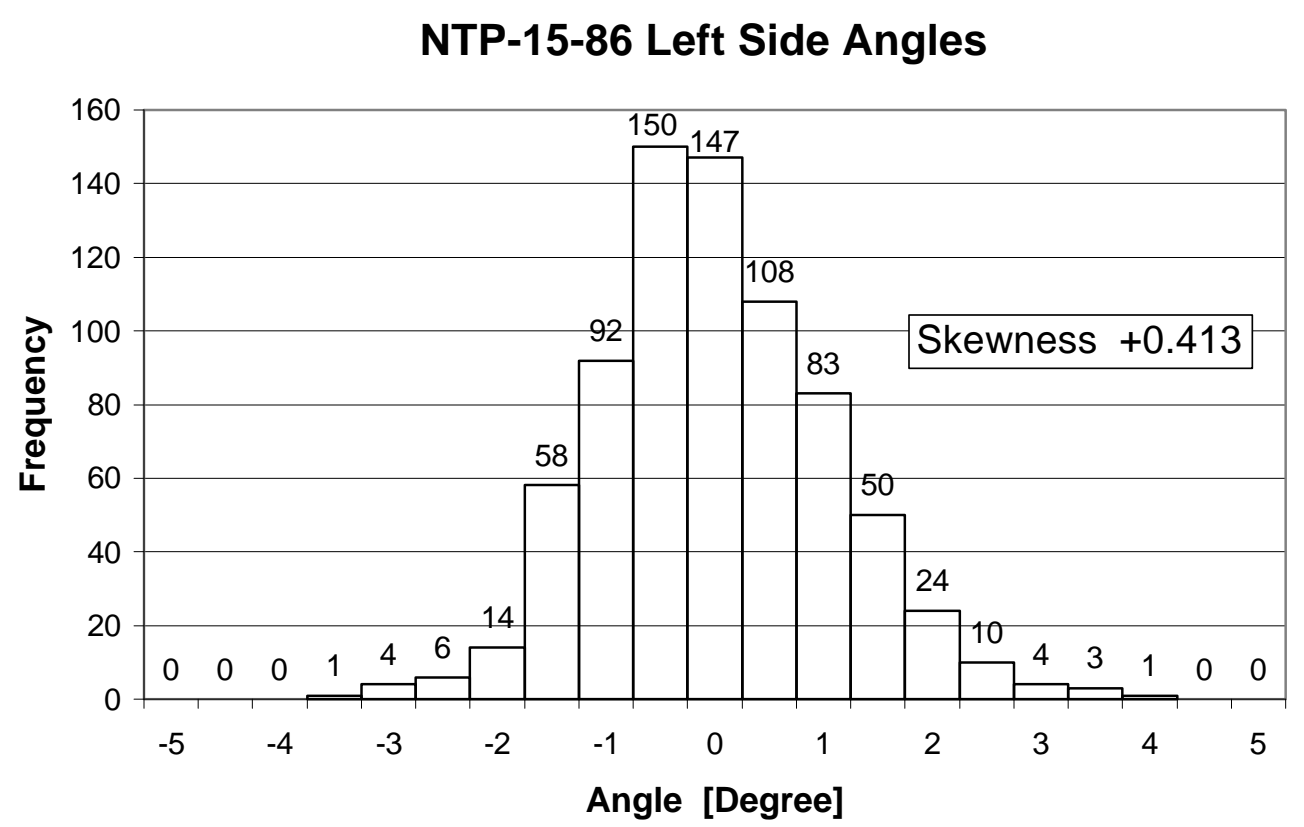

Figure 4.2 Specimen Skew Example 


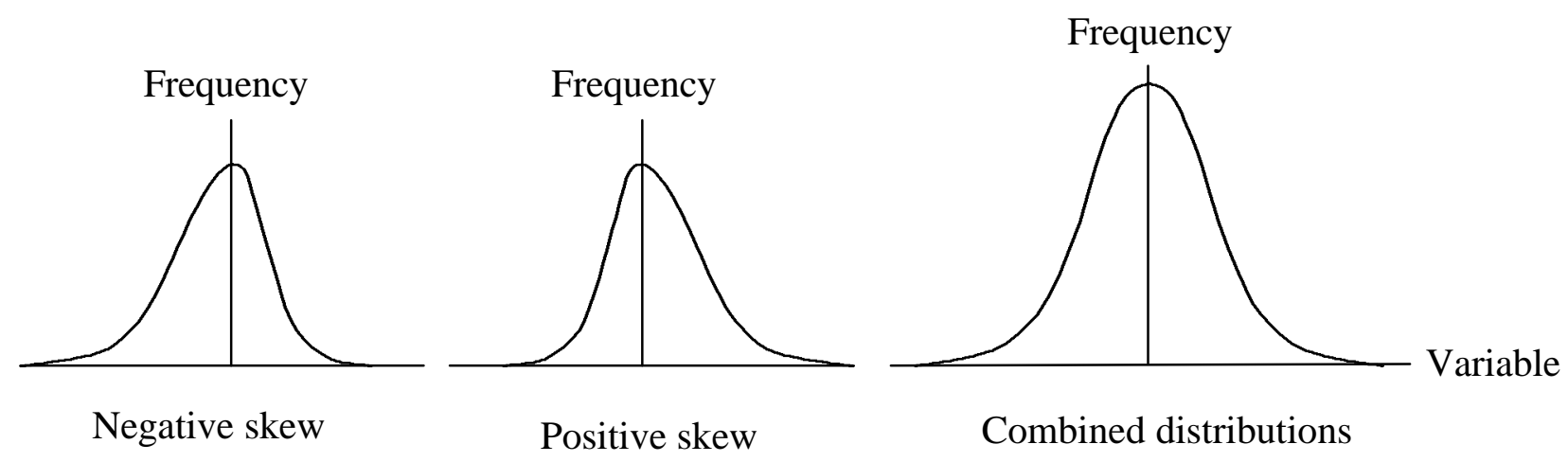

Figure 4.3 Reducing Skew by Combination of Distributions

1.

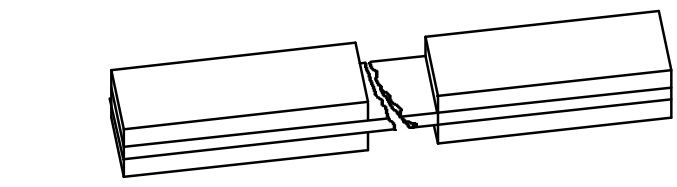

2.

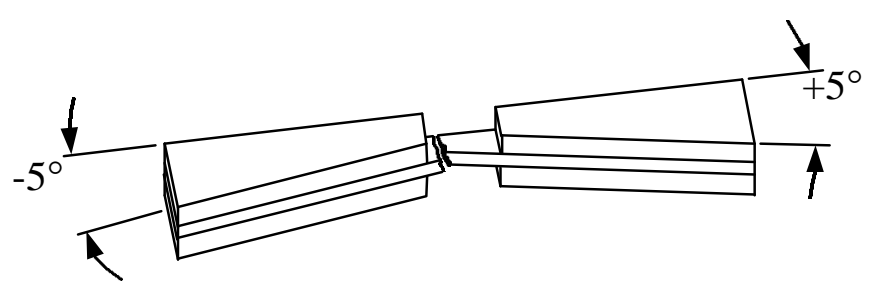

3.

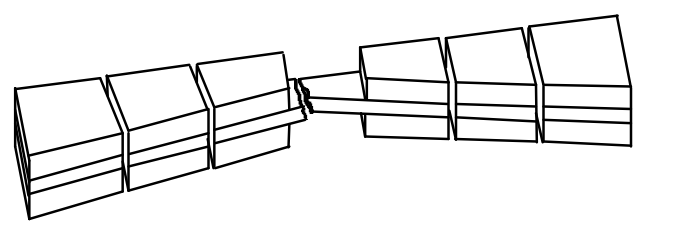

4.

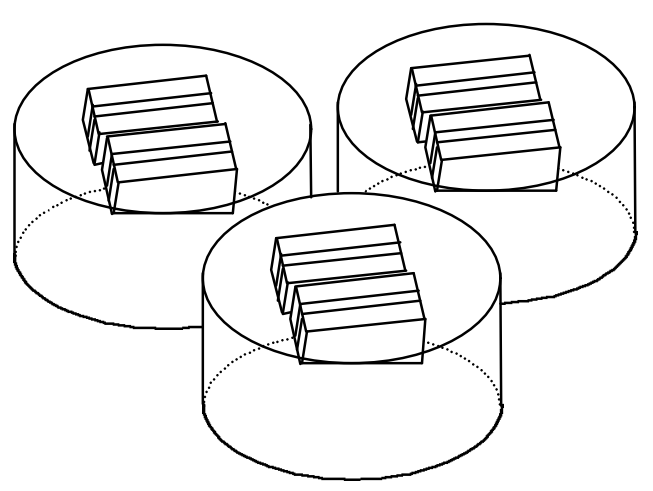

Figure 4.4 Specimen Polishing Procedure 

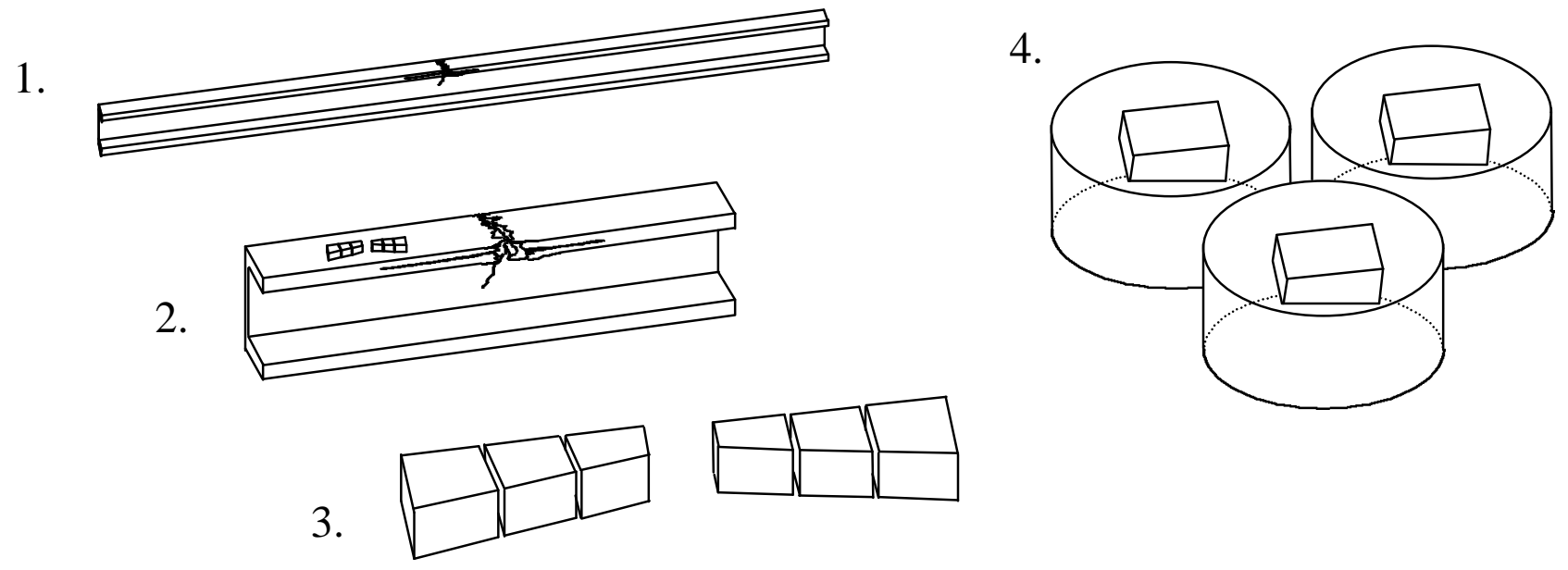

Figure 4.5 Beam Sample Polishing Procedure

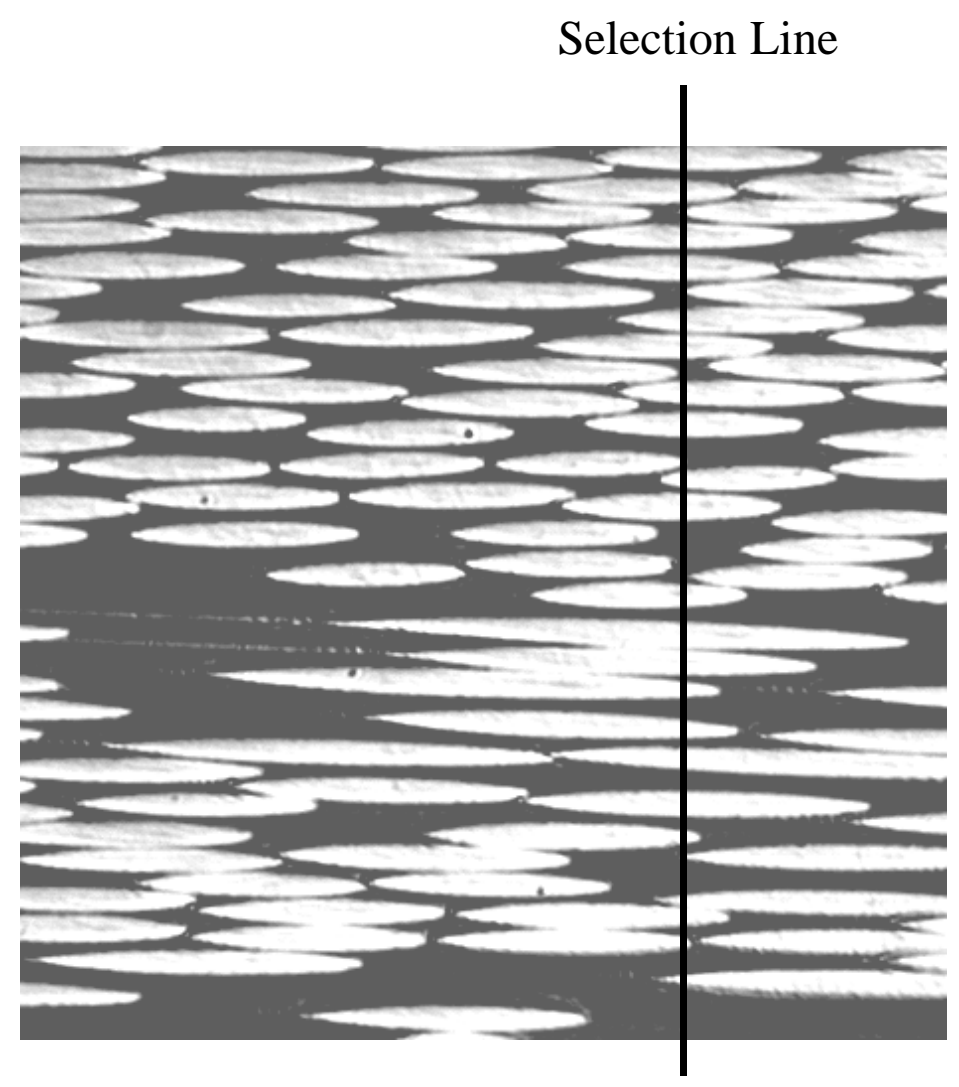

Figure 4.6 Measurement of Ellipses That Intersect Selection Line 


\section{Chapter 5: Prediction Results}

\subsection{Normal Distribution}

The plots of cumulative distribution show that they are very close to a normal cumulative distribution. The lowest and highest skew for all the specimens was in 949/M30GC samples and is shown in Figures 5.1 and 5.2. Figure 5.3 shows a typical one-sided skew for the 948A1M40J material. These figures compare the analytical normal cumulative distribution function $(\mathrm{CDF})$ with the experimental CDF. Hence, it was reasonable to use the normal distribution in the derivation of the compressive strength.

\subsection{Predicted Strength}

Actual vs. predicted compressive strengths of the SACMA specimens and fourpoint beam bending specimens are shown in Figure 5.4 for the 949/M30GC, Figure 5.5 for the 948/M40J and Figure 5.6 for the 949/M30GC Beam 1 and 2. For a full breakdown of the data, see Table 5.1. The formula predicted the compressive strength of the RTA and $-125 \mathrm{~F}$ compression specimens very well. The averages are within $8 \%$. However, the $180 \mathrm{~F}$ specimen strength predictions were low even when using the full extent of the confidence interval. The predictions at this temperature are conservative by a $25 \%$ margin. The discrepancy is believed to be due in part to the large changes in shear modulus that occur at high temperature. One can see from Figure 3.11 and Figure 3.12, shear strength is almost linear in the $-125 \mathrm{~F}$ to $180 \mathrm{~F}$ temperature range while shear 
modulus has a large decrease between RTA and 180F. Residual stresses from curing the part in manufacturing may also play a role in the discrepancy.

Actual vs. predicted strengths on the beam data was also very good as can be seen in Figure 5.6. On beam 2, the value was within a percentage point of the experimental values. Plotted against other data from the literature [1], [21] in Figure 5.7, the experimental data falls along the line of predicted values vs. the non-dimensional parameter, $\chi$.

The sensitivity plot for 949/M30GC at room temperature in Figure 5.8 confirms the trends expected by intuition. Increases in G12 and F6 increase compressive strength F1c, and increases in $\Omega$ decrease F1c. On a percentage basis, F6 is most powerful in reducing F1c and $\Omega$ is the most powerful in increasing F1c.

In Figure 5.9, the combined buckling/misalignment plot for 949/M30GC at room temperature shows the maximum strength of $177 \mathrm{ksi}$ at the point of zero slope on the $\sigma$ applied curve. This point corresponds to a misalignment of approximately 1.75 degrees which means that fibers with angles greater than 1.75 degrees have already buckled by the time compression failure occurs. The percentage of fibers that had not buckled before compression failure was approximately $87 \%$. A normalized version of this data in Figure 5.10, shows that the failure occurs at only $27 \%$ of the theoretical maximum $(\mathrm{F} 1 \mathrm{c}=\mathrm{G} 12)$ and at 1.5 times the standard deviation, $\Omega$. Interestingly, other than the different absolute values of compressive strength, similar values were obtained in the normalized version for 948A1/M40J as shown in Figure 5.11, 5.12.

The strength values for global misalignment of 949/M30C and 948A1/M40J at room temperature are shown in Figures 5.13 and 5.14 using the method of shifted 
distributions described in section 2.6. As can been seen, this method shows that the drop in strength caused by global misalignment occurs much faster than the stress transformation factor of cosine squared $\alpha_{\mathrm{G}}$. "Carpet plots" of compressive strength vs. $\Omega$ and average global misalignment, $\alpha_{\mathrm{G}}$, are shown on Figures 5.15 and 5.16. According to this, composites with high misalignment $\Omega$ (i.e. fiberglass $\Omega=3-4$ degrees), are quite insensitive to global misalignment. 


\begin{tabular}{|c|c|c|c|c|c|c|}
\hline $\begin{array}{l}\text { Type } \\
\text { of } \\
\text { Sample }\end{array}$ & Temperature & $\begin{array}{c}\text { Predicted } \\
\text { Compressive } \\
\text { Strength } \\
\text { F1c } \\
\text { [ksi] }\end{array}$ & $\begin{array}{c}95 \% \\
\text { Confidence } \\
\text { Interval } \\
\\
{[\mathrm{ksi}]} \\
\end{array}$ & $\begin{array}{c}\text { Actual } \\
\text { Compressive } \\
\text { Strength } \\
\text { F1c } \\
\text { [ksi] }\end{array}$ & $\begin{array}{c}95 \% \\
\text { Confidence } \\
\text { Interval } \\
\text { (t-dist.) } \\
\text { [ksi] }\end{array}$ & $\begin{array}{c}\% \text { Diff. } \\
\text { (Actual } \\
\text { Base) } \\
\\
{[\%]}\end{array}$ \\
\hline \multirow{3}{*}{$\begin{array}{l}\text { 949/M30GC } \\
\text { SACMA } \\
\text { Compression } \\
\text { Specimens }\end{array}$} & 180 & 111 & $\begin{array}{l}+14 \\
-12\end{array}$ & 149 & $\begin{array}{l}+5 \\
-5\end{array}$ & $-26 \%$ \\
\hline & RTA & 177 & $\begin{array}{l}+20 \\
-17\end{array}$ & 185 & $\begin{array}{l}+21 \\
-21\end{array}$ & $-4 \%$ \\
\hline & -125 & 243 & $\begin{array}{l}+24 \\
-21 \\
\end{array}$ & 226 & $\begin{array}{l}+12 \\
-12 \\
\end{array}$ & $8 \%$ \\
\hline $\begin{array}{c}\text { 949/M30GC } \\
\text { Beam } 1\end{array}$ & RTA & 160 & $\begin{array}{l}+17 \\
-15\end{array}$ & 169 & $\mathrm{~N} / \mathrm{A}$ & $-5 \%$ \\
\hline $\begin{array}{c}\text { 949/M30GC } \\
\text { Beam } 2\end{array}$ & RTA & 176 & $\begin{array}{l}+16 \\
-14\end{array}$ & 175 & $\mathrm{~N} / \mathrm{A}$ & $1 \%$ \\
\hline \multirow{3}{*}{$\begin{array}{l}\text { 948A1/M40J } \\
\text { SACMA } \\
\text { Compression } \\
\text { Specimens }\end{array}$} & 180 & 147 & $\begin{array}{l}+21 \\
-16\end{array}$ & 194 & $\begin{array}{l}+14 \\
-14\end{array}$ & $-24 \%$ \\
\hline & RTA & 196 & $\begin{array}{l}+23 \\
-17\end{array}$ & 208 & $\begin{array}{l}+6 \\
-6\end{array}$ & $-6 \%$ \\
\hline & -125 & 231 & $\begin{array}{l}+39 \\
-30 \\
\end{array}$ & 223 & $\begin{array}{l}+19 \\
-19 \\
\end{array}$ & $4 \%$ \\
\hline
\end{tabular}

Table 5.1 Actual vs. Predicted Compressive Strength 


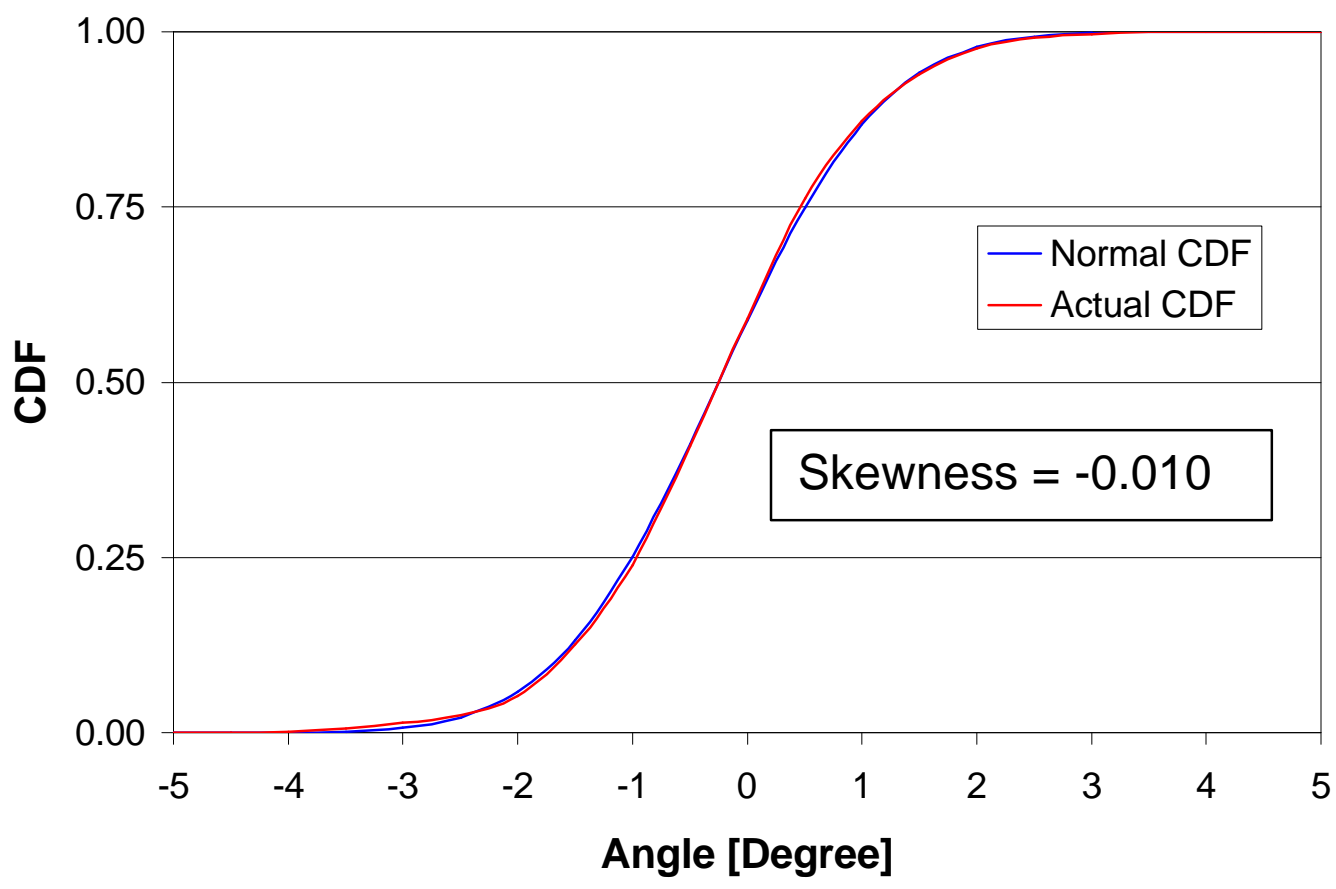

Figure 5.1 Cumulative Distribution Function for Specimen with lowest skew.

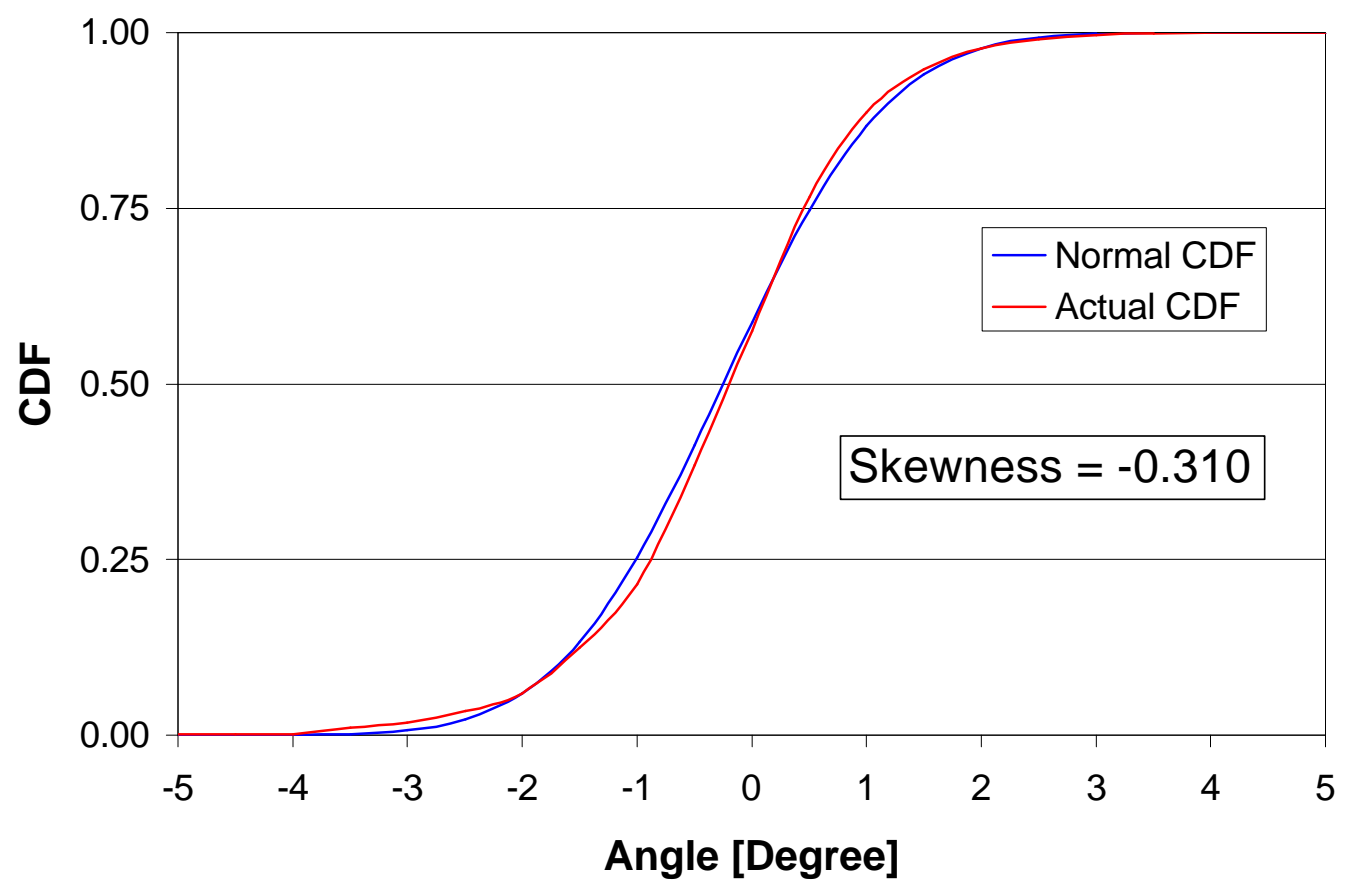

Figure 5.2 Cumulative Distribution for Specimen with highest skew. 


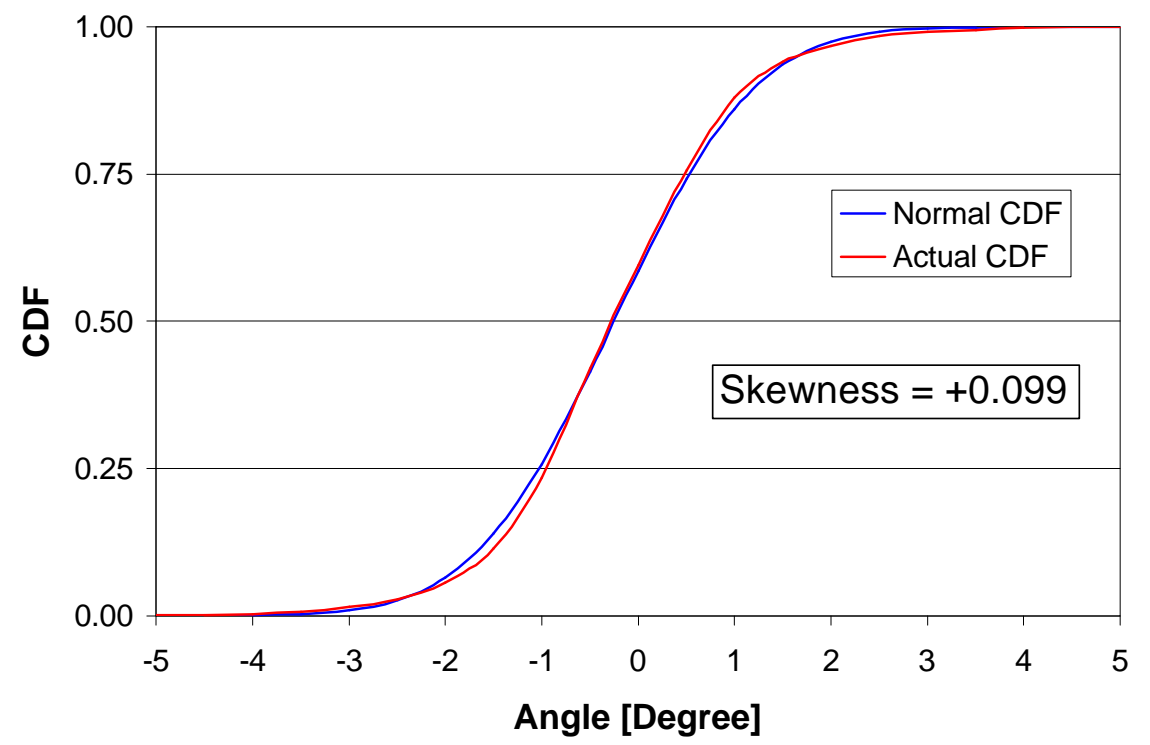

Figure 5.3 Cumulative Distribution Function of 948A1/M40J specimen.

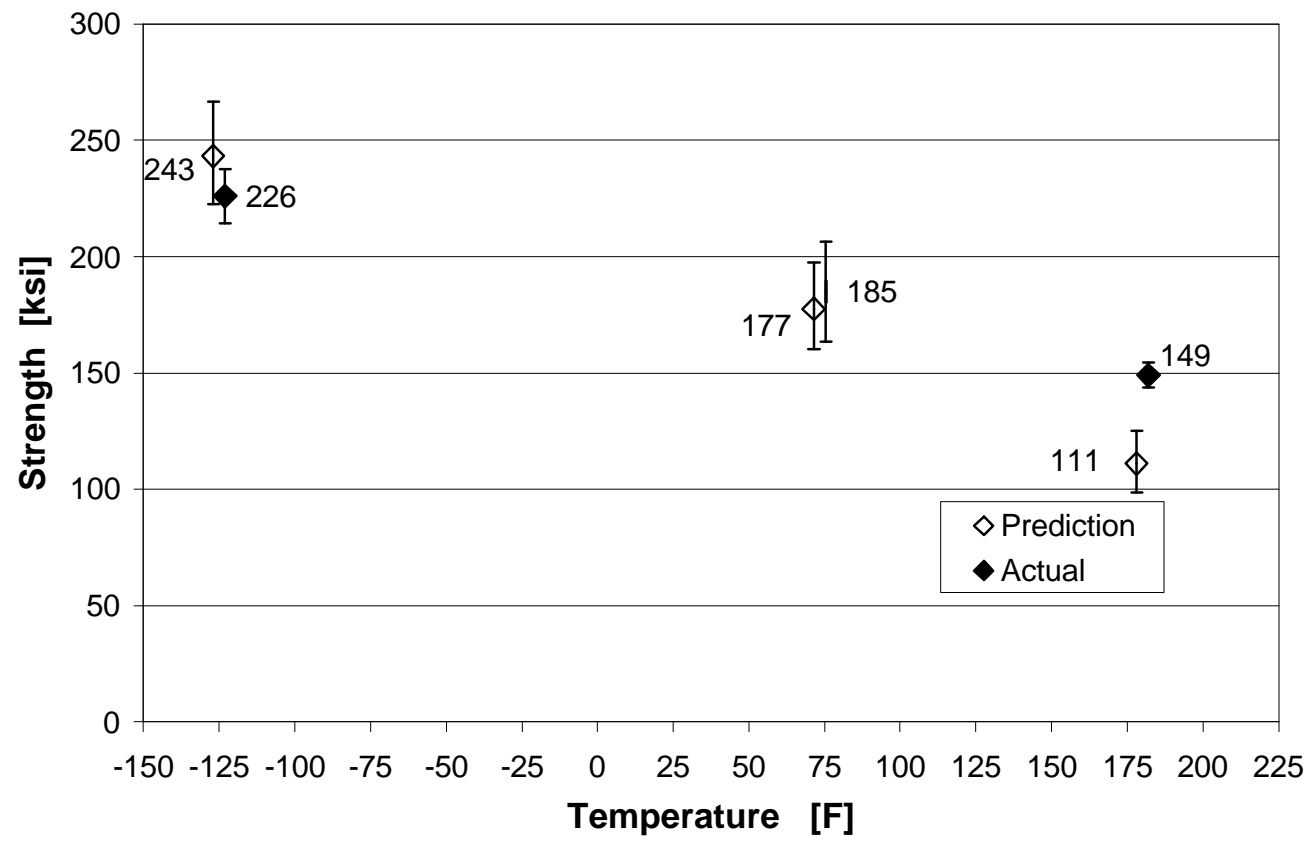

Figure 5.4 949/M30GC Actual vs. Predicted Compressive Strength 


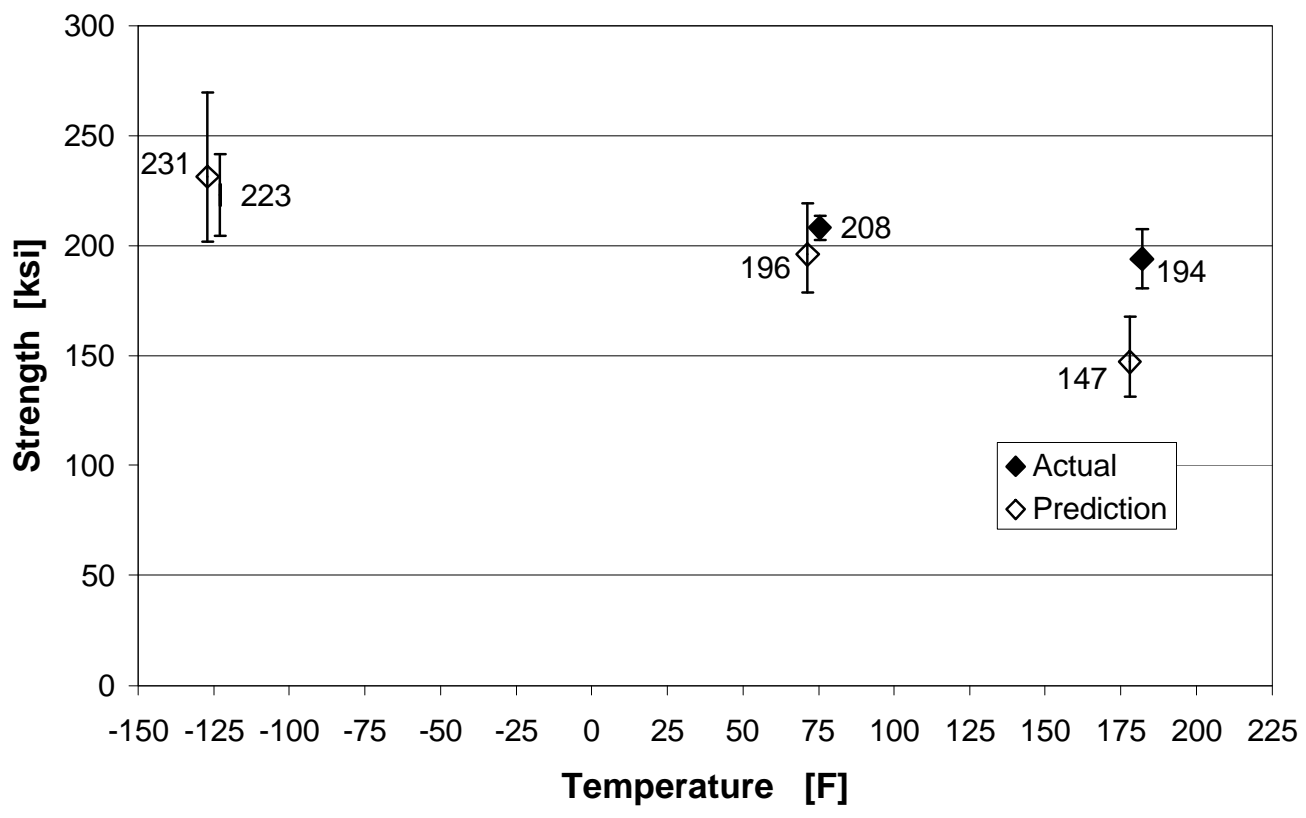

Figure 5.5 948A1/M40J Actual vs. Predicted Compressive Strength

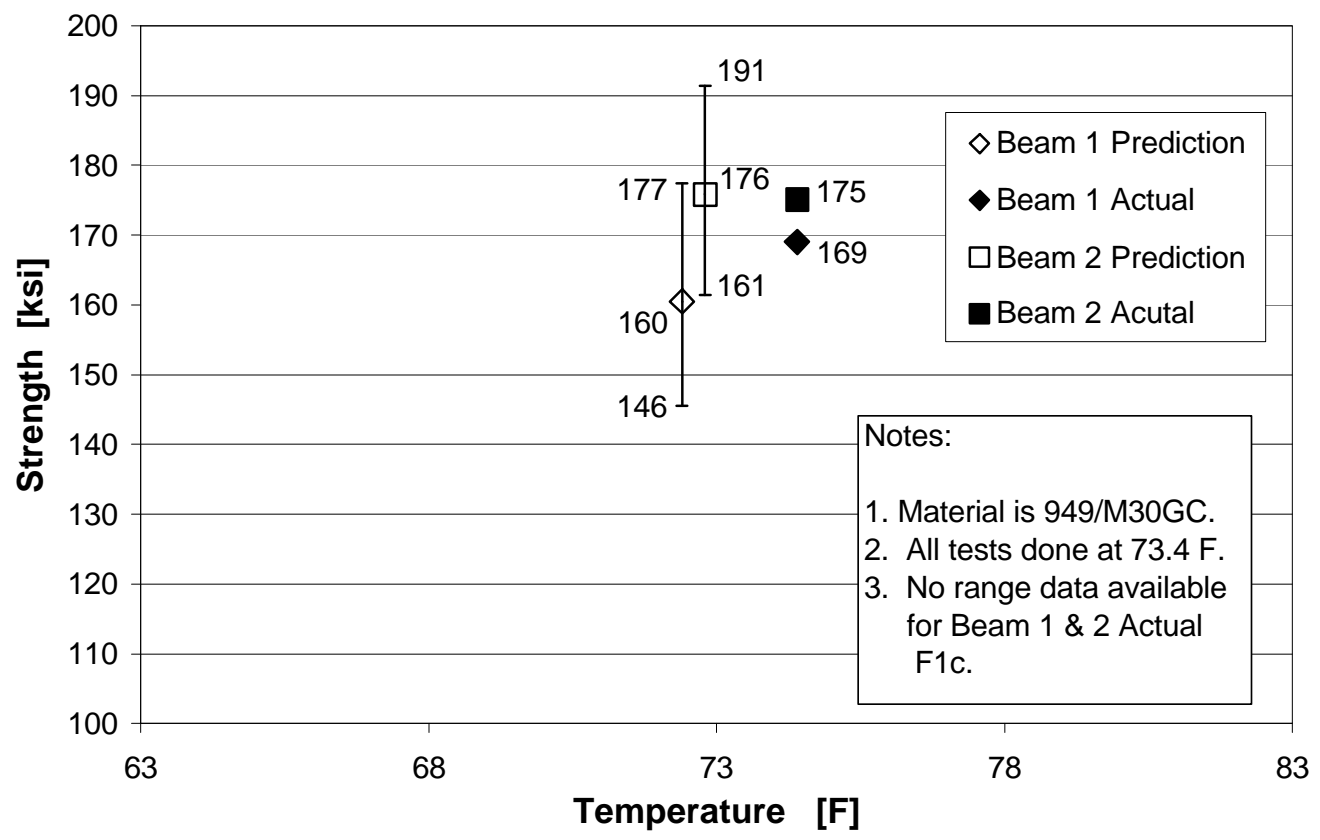

Figure 5.6 949/M30GC Beam 1\&2 Actual vs. Compressive Strength 


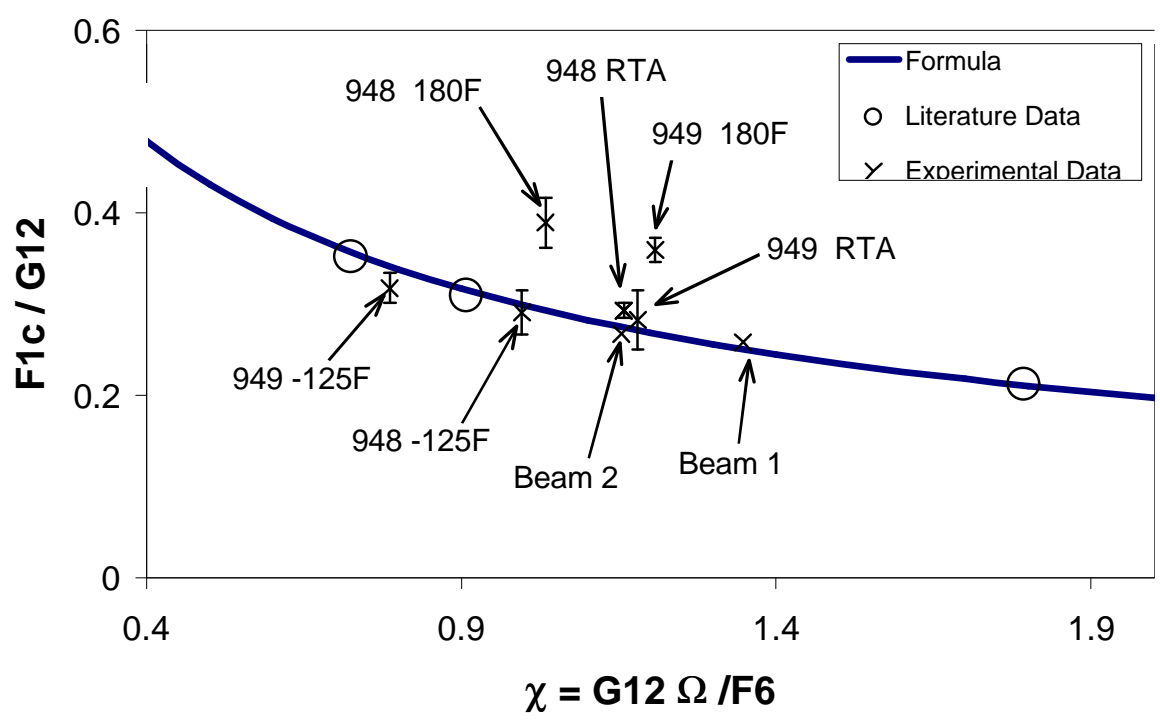

Figure 5.7 Formula vs. Experimental, Literature Data

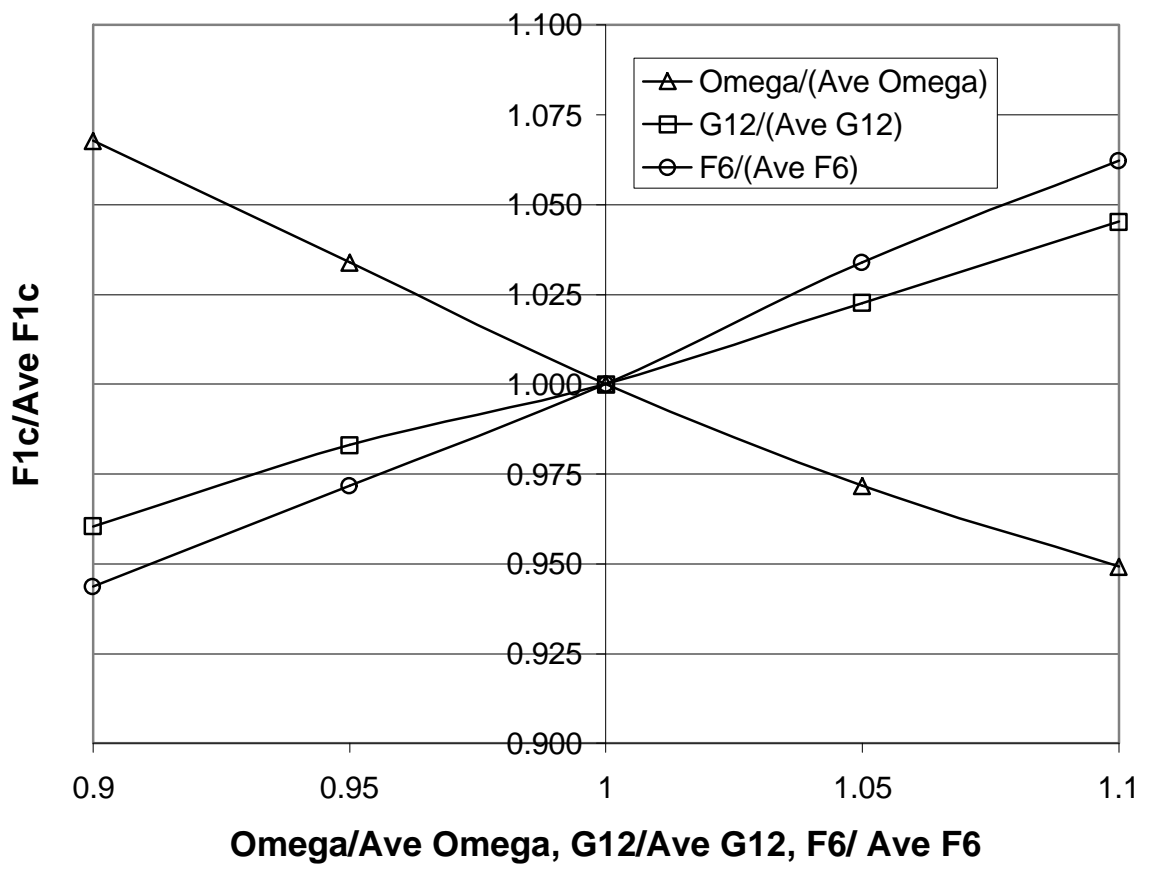

Figure 5.8 949/M30GC RTA Sensitivity to $\Omega$, G12, F6 


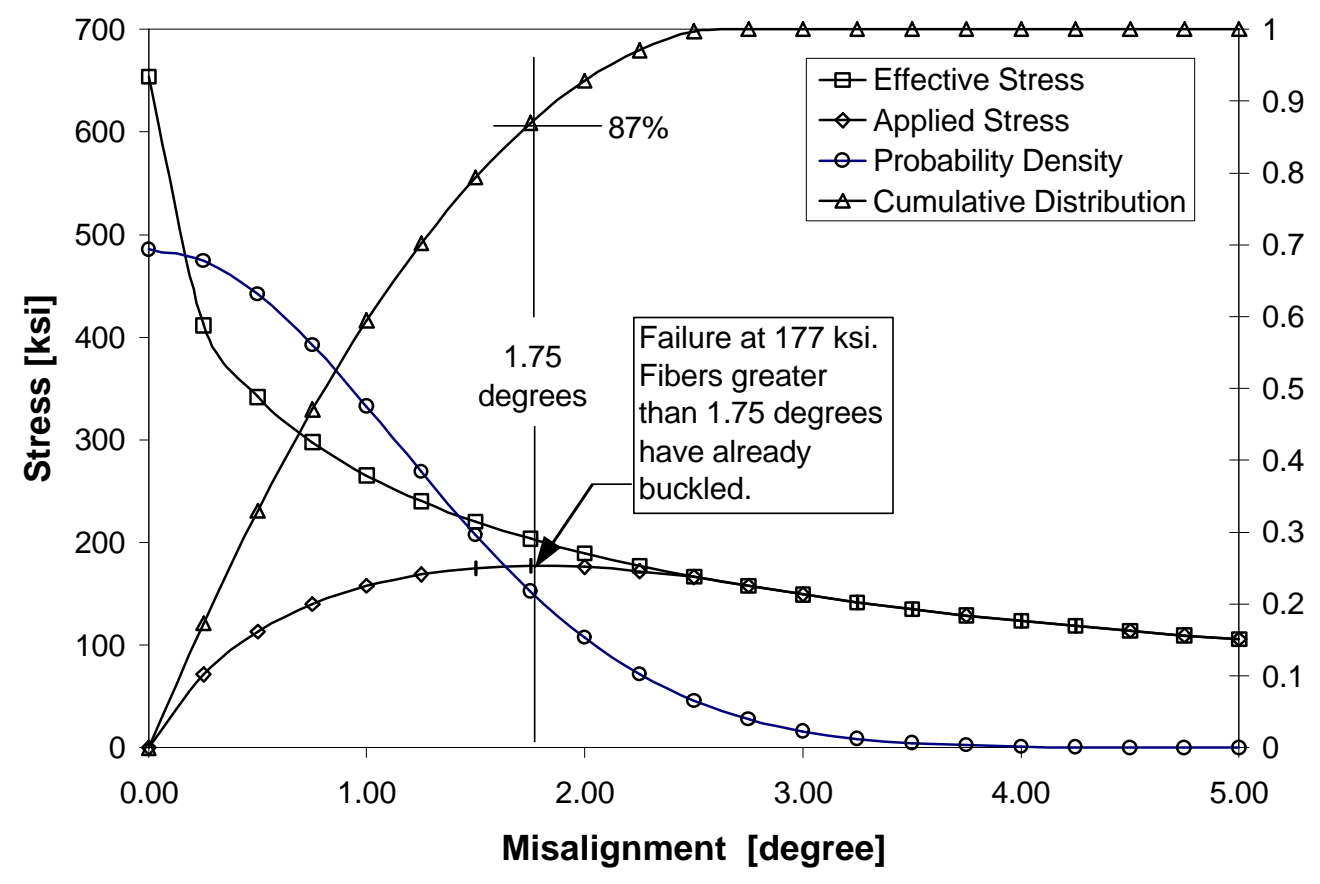

Figure 5.9 949/M30GC RTA Maximum Compressive Strength

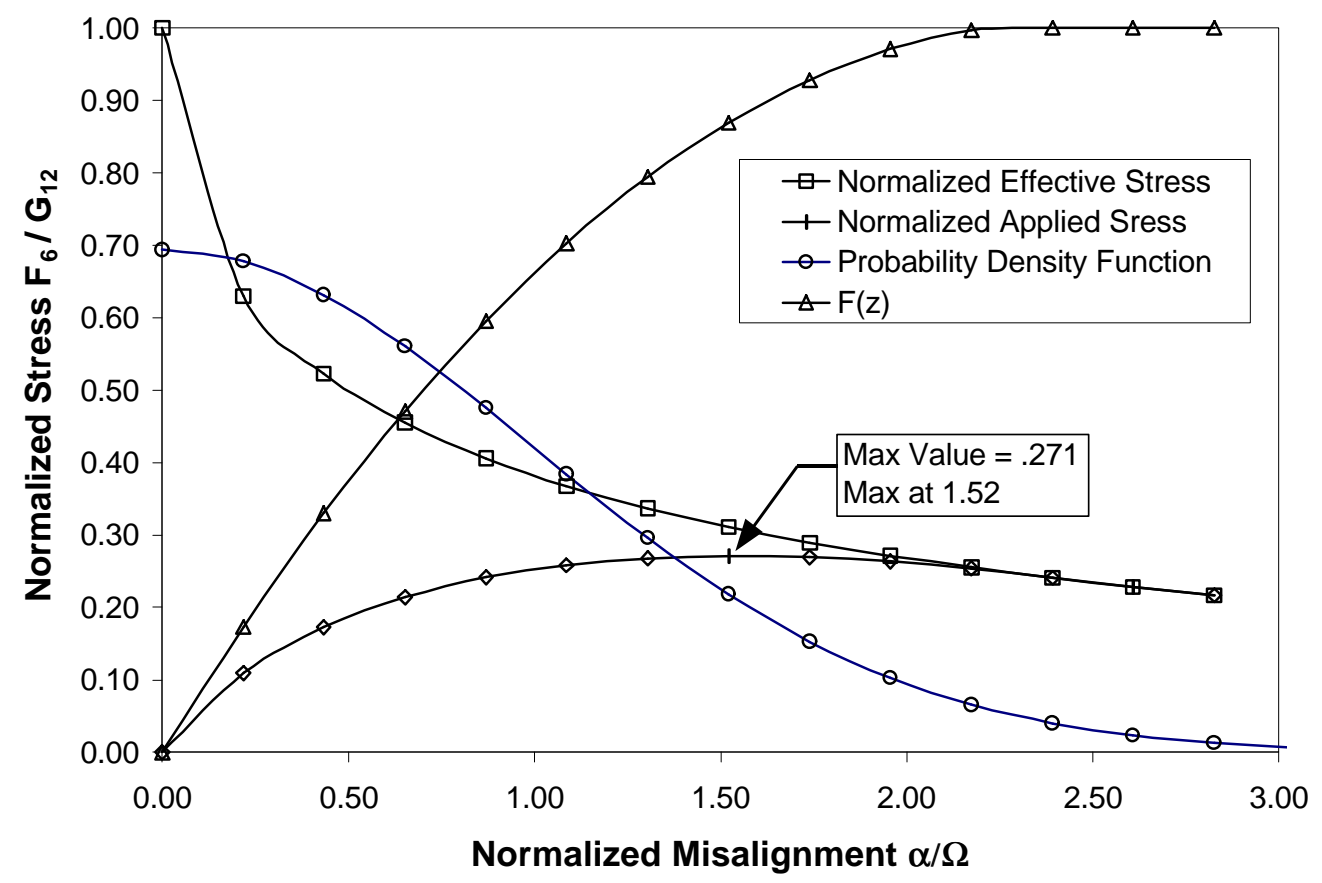

Figure 5.10 949/M30GC RTA Normalized Maximum Compressive Strength 


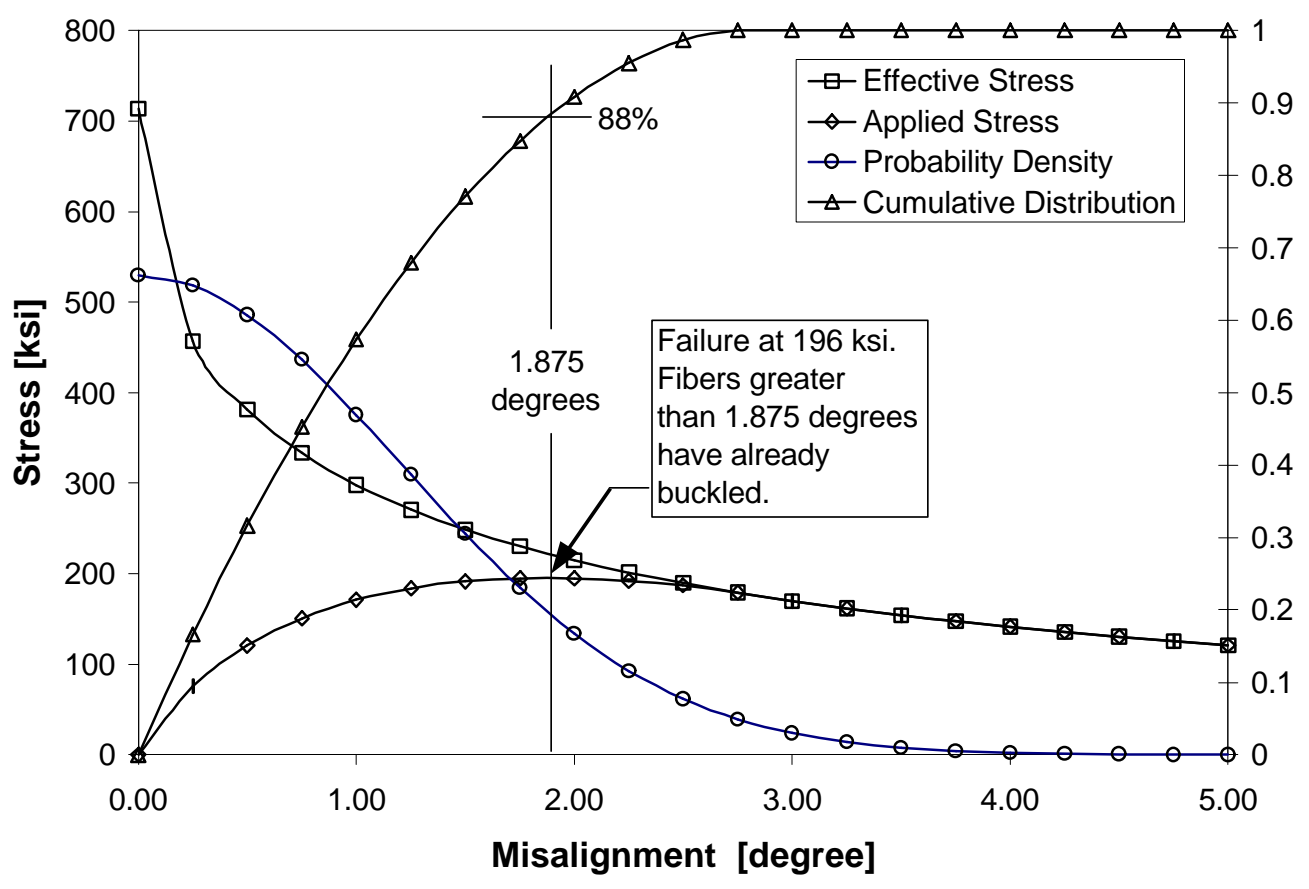

Figure 5.11 948A1/M40J RTA Maximum Compressive Strength

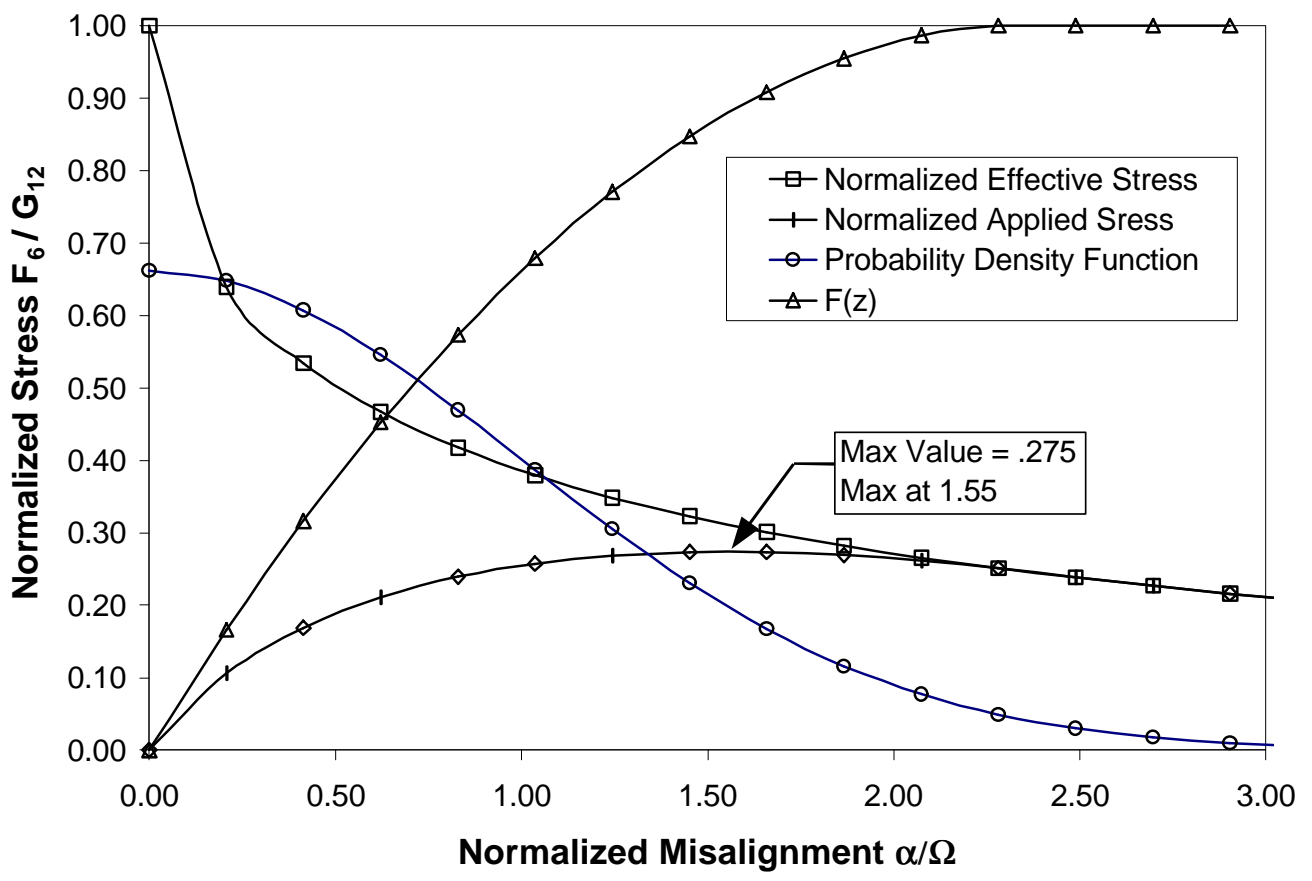

Figure 5.12 948A1/M40J Normalized RTA Maximum Compressive Strength 


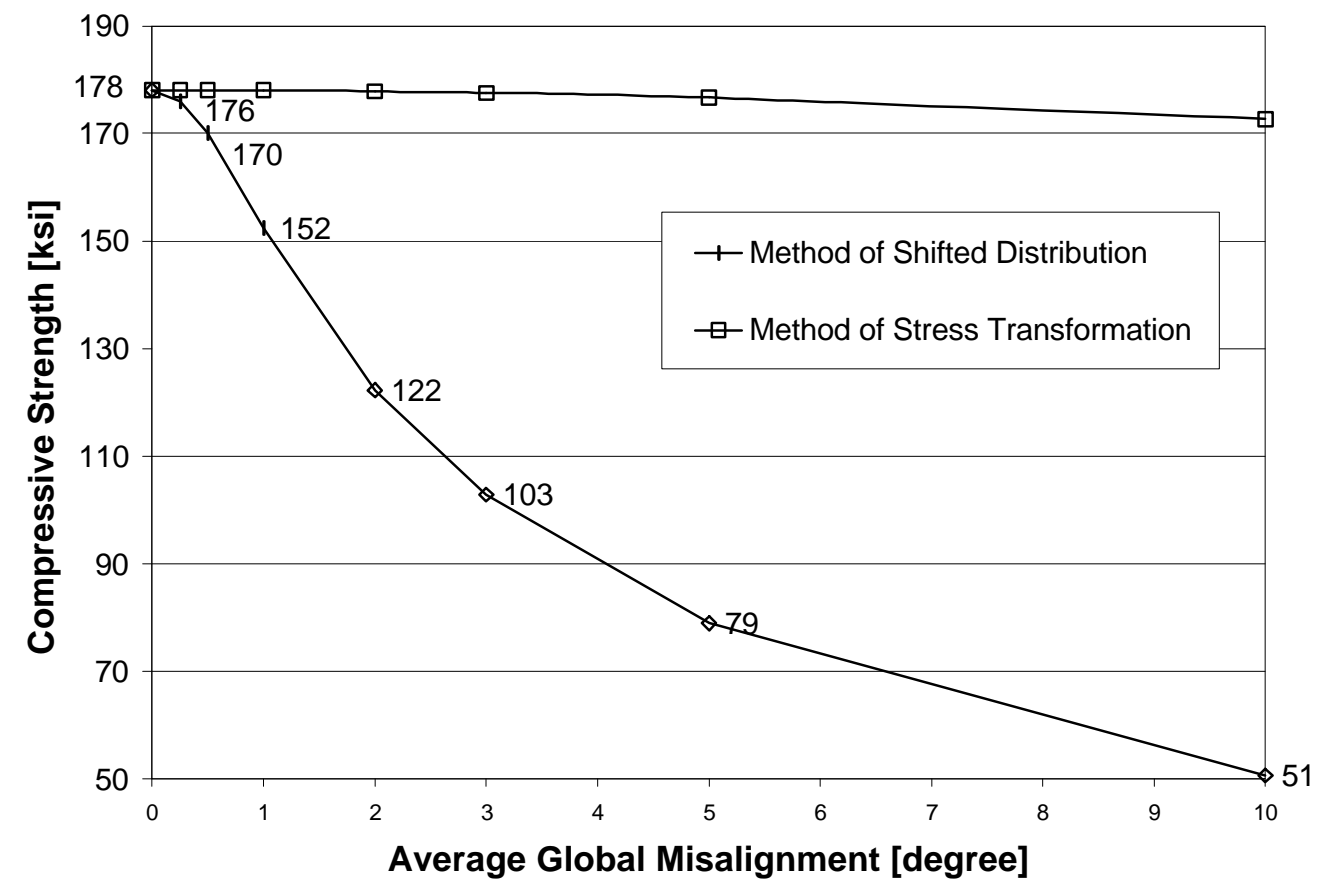

Figure 5.13 949/M30GC RTA Compressive Strength vs. Ave. Global Misalignment

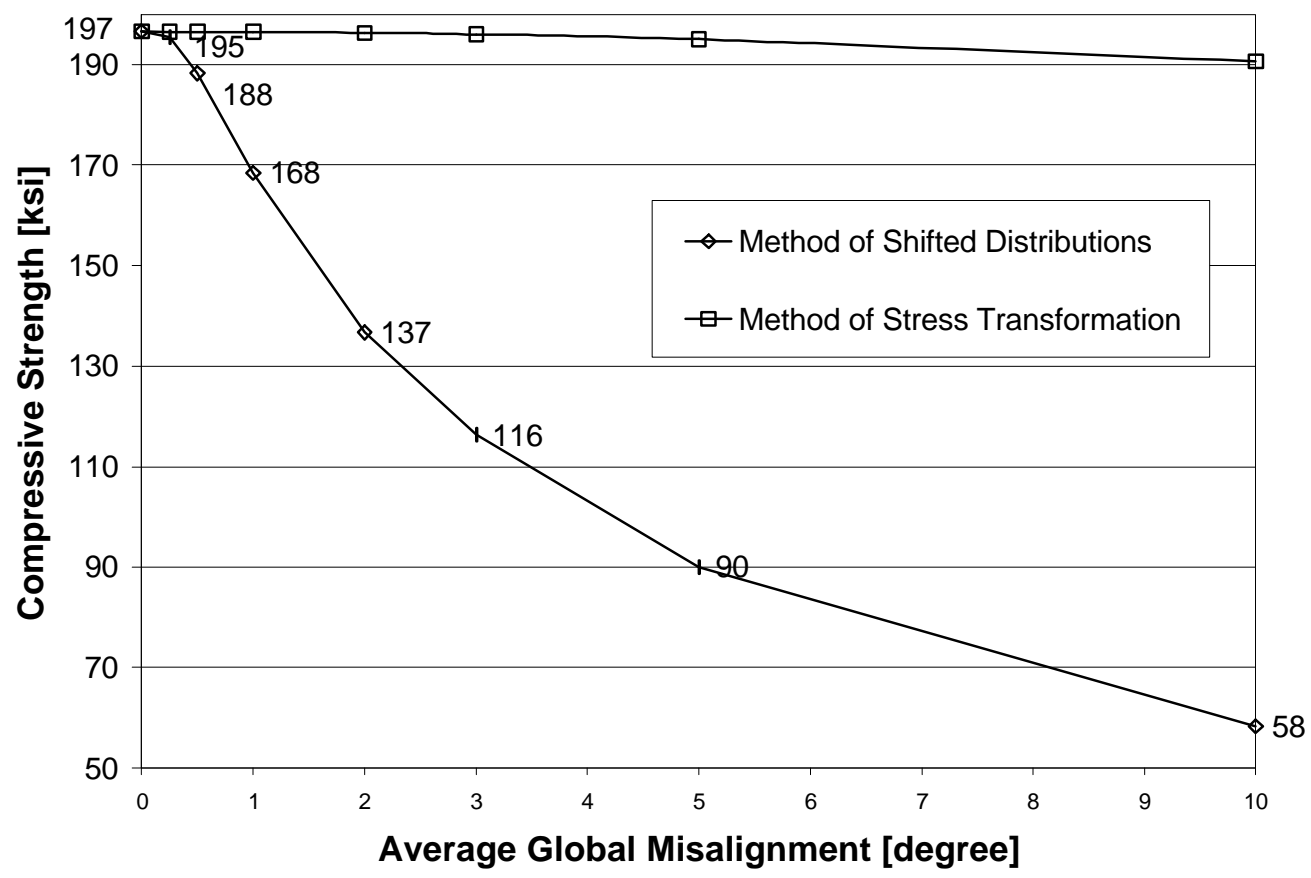

Figure 5.14 948/M40J RTA Compressive Strength vs. Ave. Global Misalignment 


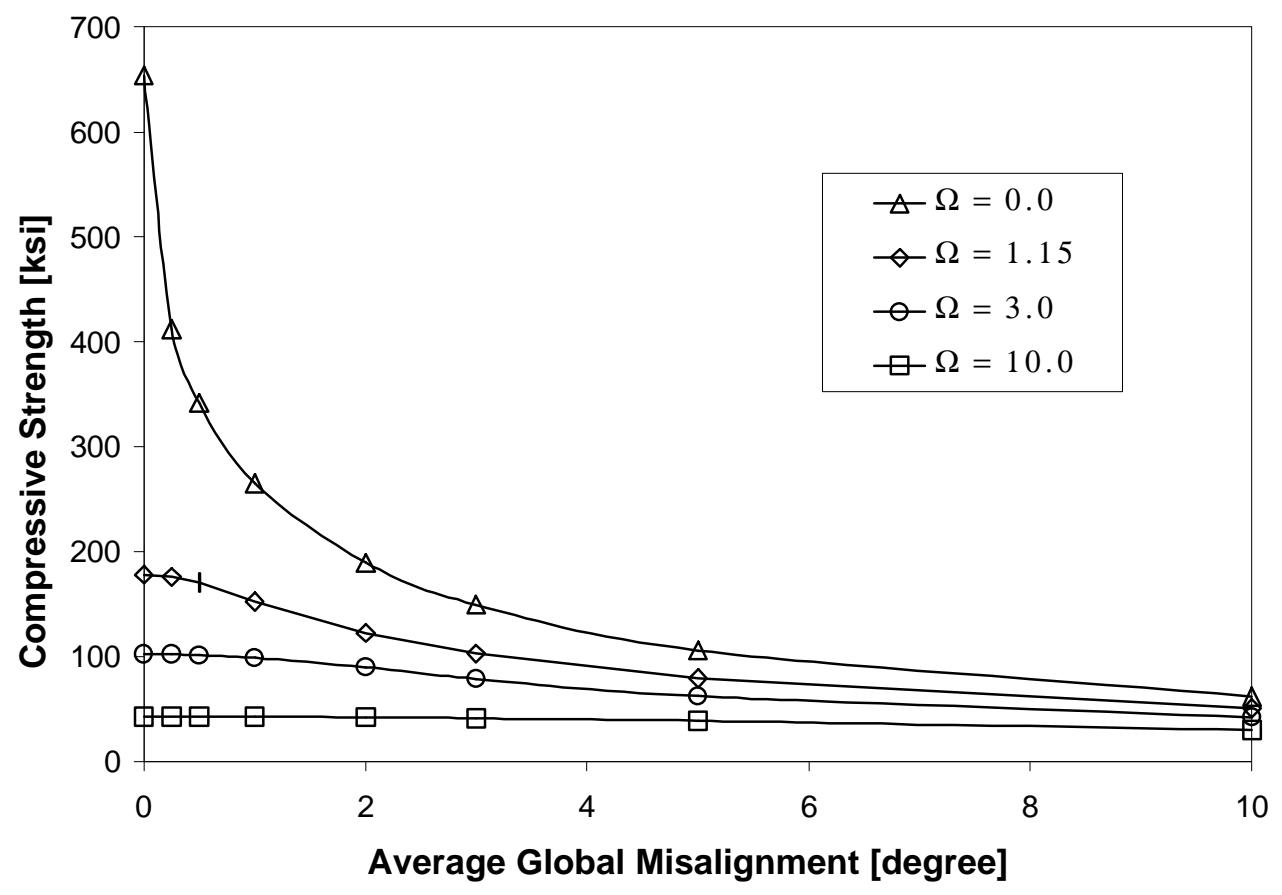

Figure 5.15 949/M30GC RTA F1c vs. Ave. Global Misalignment, $\Omega$

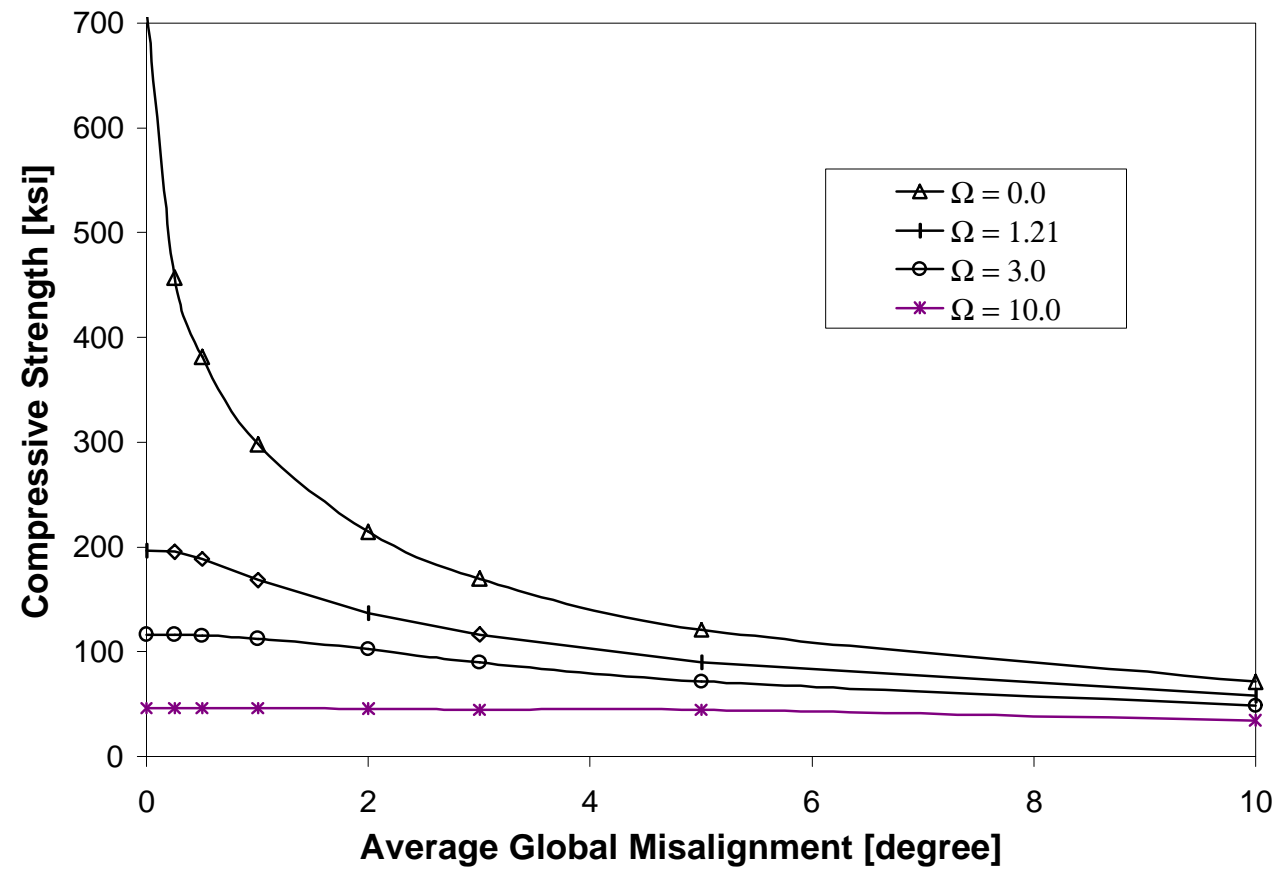

Figure 5.16 948A1/M40J RTA F1c vs. Ave. Global Misalignment, $\Omega$ 


\section{Chapter 6: Summary and Conclusions}

This study has shown very good agreement between actual and predicted values of compressive strength in compression specimens. At the higher temperatures, the prediction method is conservative which suggests that there are other effects that may not have been considered. These include errors in reading the shear stiffness and strength in the shear test because of the significant increase in temperatures.

The prototype-beam actual strengths were also very close to the predicted.

Interestingly, the misalignment $\Omega$ of beam 1 was the highest and beam 2 the lowest of all samples tested. While it is expected that production parts would have higher misalignment $\Omega$ than test specimens, beam 2 shows that Aurora Flight Sciences can make production parts with very low misalignment and, when doing so, will gain a benefit in ultimate compressive strength capability.

Void content was very low on the specimen panels (1-2\%) and thus did not effect material properties in Phase I. The void content on the beams was considerably higher (2-4\%) but did not seem to be a factor affecting compressive strength since the predictions were very close. This agrees with the results from [11].

Despite some conservatism, the technique outlined here could be practical in some production environments. Already there are some production parts that are made slightly longer so that the excess can be cut for density and void content tests. Likewise, if a segment of the compression portion of the part could be lengthened, it too could be cut and polished to take fiber misalignment data. The measurement of fiber 
misalignment does not have to be done manually. Commercial equipment is available that automate the polishing and the acquisition of the fiber data [26]. This would greatly reduce the time required for this process.

Undoubtedly, this technique has application to "post-mortem" investigation. For example, a part that failed (i.e. wing spar) could be examined to find the fiber misalignment $\Omega$ and, with shear properties, a compressive strength capability could be determined. The investigators could then deduce if the reason for failure was lower than expected strength capability. The alternative is much more difficult. Cutting the damaged part to get a specimen for compression tests causes micro-defects in the material that greatly reduce strength.

Lastly, the technique proposed to predict the compression strength of composites with average global misalignment in a $\left[+\alpha_{G}\right]_{n}$ or $\left[-\alpha_{G}\right]_{n}$ stacking schedule also holds promise. Test fixtures will need to be devised to stabilize this type of laminate up to compressive failure stress in order to confirm the predictions. 


\section{Chapter 7: Recommendations}

Due to the time and budget restraints of this study, there are some areas that could not be explored and would be excellent candidates for future investigations.

- Determine the mechanism that allows compressive strength to be higher than predicted at $180 \mathrm{~F}$ and incorporate into explicit equation.

- Test commercially available software [26] that measures fiber misalignment in an actual case to predict compressive strength of a production part.

- Determine the minimum number of data points necessary to get $\Omega$ on a production part by checking variation in $\Omega$ at different points in the production part.

- Generalize the explicit equation by incorporating effects of global misalignment and void content.

- Demonstrate effectiveness of this technique on an actual Quality Control and "PostMortem" studies. 


\section{References}

1. Haberle, J.G. 1991. "Strength and Failure Mechanisms of Unidirectional Carbon Fibre-Reinforced Plastics Under Axial Compression," Ph.D. Thesis, Imperial College, London, U.K.

2. Barbero, E.J. 1998.'Prediction of Compression Strength Of Unidirectional Polymer Matrix Composites," Journal of Composite Materials, 32(5):483-502.

3. Yurgartis, S.W. 1987. "Measurement of Small Angle Fiber Misalignment In Continuous Fiber Composites," Composite Science and Technology, 30:279-293.

4. Rosen, B.W. 1965. Chapter 3 in "Fiber Composite Materials," Metals Park, OH: American Society for Metals.

5. Wang, A.S.D. 1978. "A Non-Linear Microbuckling Model Predicting the Compressive Strength of Unidirectional Composites," ASME Winter Annual Meeting. ASME Paper 78-WA/Aero-I.

6. Maewal, A. 1981. "Post Buckling Behavior of a Periodically Laminated Medium in Compression," International Journal of Solids and Structures. 17:335-344.

7. Martinez, G.M., M.R. Piggott, D.M.R. Bainbridge and B. Harris. 1981. "The Compression Strength of Composites with Kinked, Misaligned and Poorly Adhering Fibres," Journal of Materials Science. 16: 2831-2836.

8. Barbero, E.J. 1999. "Introduction to Composite Materials Design," Taylor and Francis, Philadelphia, PA.

9. Piggot, M.R. 1981. "A theoretical framework for the compressive properties of aligned fibre composite," Journal of Materials Science. 16: 2837-2845.

10. Budiansky, B. 1983. "Micromechanics," Computers and Structures. 16: 3-12.

11. Tang, J.M., W.I. Lee and G.S. Springer. 1987. "Effects of Cure Pressure on Resin Flow, Voids, and Mechanical Properties," Journal of Composite Materials. 21:421440.

12. Mrse, A. and Piggott. 1990. "Relation between Fibre Divagation and Compressive Properties of Fibre Composites," $35^{\text {th }}$ International SAMPE Symposium, April 2-5, pp. 2236-2244.

13. Yurgartis, S. W. and S.S. Sternstein. 1992. "Experiments to reveal the role of matrix properties and Composite Microstructure in Longitudinal Compression Strength," 
ASTM Symposium on Compression Response of Composite Structures. November 16-17.

14. Barbero, E.J. and J.S. Tomblin, 1996. "A Damage Mechanics Model for Compression Strength of Composites,” Int. J. Solid Structures. 33(29):4379-4393.

15. Lagoudas, D.C. and A.M. Saleh. 1993. "Compressive Failure Due to Kinking of Fibrous Composites," Journal of Composite Materials,” 27:83-106.

16. Crasto, A.S. and R.Y. Kim, 1992. "The Effects of Constituent Properties on the Compression Strength of Advanced Composites," ASTM Symposium on Compression Response of Composite Structures. November 16-17.

17. Steif, P.S. 1990. "A Model for Kinking in Fiber Composites-Part I Fiber Breakage via Micro-buckling," 26:549-561, and "II Kink Band Formation,” Int. JJ. Solid Structures. 26:563-569.

18. Shuart, M.J. 1989.'Failure of Compression-Loaded Multidirectional Composite Laminates," AIAA Journal. 27:1274-1279.

19. Tomblin, J.S., L.A. Godoy, and E.J. Barbero. 1997. "Imperfection Sensitivity of Fiber Micro-buckling in Elastic-Nonlinear Polymer Matrix Composites," Int. J. Solid Structures. 34(13):1667-1679.

20. Kachanov, L.M. 1990. "Introduction to Continuum Damage Mechanics," Kluwer Academic Publishers, Hingham, MA.

21. Tomblin, J.S. 1994. "Compressive Strength Models for Pultruded Glass Fiber Reinforced Composites,” Ph.D. Thesis, West Virginia University, Morgantown, WV.

22. Dobyns, A., B. Barr, and J. Adelmann. 1999. "RAH-66 Comanche Building Block Structural Qualification Program," ASTM Symposium on Composite Structures: Theory And Practice, May 17-18.

23. Anderson, T.C. 1999. "The Interaction Between CAI and BVID as It Applies to the Development of a Thermoplastic Tailboom," ASTM Symposium on Composite Structures: Theory And Practice, May 17-18.

24. Sachs, L. 1982. “Applied Statistics: A Handbook of Techniques,” Springer-Verlag, New York, New York.

25. Montgomery, D.C. and G.C. Runger. 1994. “Applied Statistics and Probability for Engineers," John Wiley and Sons, New York, New York.

26. Buehler Enterprises. 41 Waukegan Rd, Lake Bluff, IL. 


\section{Appendix A:}

\section{Testing Methods/Panel History}


Longitudinal Compressive Strength Longitudinal Compressive Modulus Transverse Compressive Strength

Transverse Compressive Modulus

Tested by: $\quad$ Touchstone Research Laboratories

Test Specification: ASTM D3410-95

Method: $\quad$ Procedure B, "IITRI", with tabs

Specimen Materia Cytech Fiberite Carbon Tape

Product Code: HYE 949/M30GC, HYE948A1/M40J

Length: $\quad 6.0$ in

Width: $\quad 0.5$ in

Depth: $\quad .110-.115$ in

Tab Material: E-glass, plain weave

Tab Depth: $\quad .062$ in

Adhesive: $\quad 275$ deg F, 90 min. cure

Rate of Cross-hear $\sim 1.5 \mathrm{~mm} / \mathrm{min}$

Strain Measureme none

Test Humidity: Ambient

Test Environment: Lab Air

Test Temperature: $~ 65$ deg F

Notes:

1. Tabs protruded .1" from end of grips.

2. 3-4 samples tested of each material type.
Tested by: $\quad$ Touchstone Research Laboratories, WVU, OCM

Test Specification: SACMA SRM 1R-94

Method: Standard

Specimen Material Cytech Fiberite Carbon Tape

Product Code: HYE 949/M30GC, HYE948A1/M40J

Length: $\quad 3.18$ in

Width: $\quad 0.5$ in

Depth: $\quad .037-.044$ and $.110-.115$

Tab Material: $\quad$ Alternating carbon/E-glass panel, McMaster-Carr

Tab Depth: $\quad .090$ in

Adhesive: $\quad$ AF163, 250 deg F, 60 min. cure, Magnabond 6380

Rate of Cross-hear $1.0 \mathrm{~mm} / \mathrm{min}$

Strain Measureme extensometer, EA-06-125AC-350,-120 strain gages

Test Humidity: Ambient

Test Environment: Lab Air

Test Temperature: $\sim 65$ deg $\mathrm{F}$

Notes:

1. Touchstone used extensometer and found modulus in 1000-3000 microstrain range.

2. WVU used strain gages and found modulus in 0-1000 microstrain range. This was because specimens buckled 1500 microstrain and above.

3. WVU used surface grinder to square off four of six faces of specimens. 
Property: In-Plane Shear Strength

In-Plane Shear Modulus

Tested by: $\quad$ WVU, OCM

Test Specification: ASTM D5379-93

Method: With tabs

Specimen Materia Cytech Fiberite Carbon Tape

Product Code: HYE 949/M30GC, HYE948A1/M40J

Length: $\quad 3.0$ in

Width: $\quad .75$ in

Depth:

Tab Material: $\quad$ Alternating carbon/E-glass panel, McMaster-Carr

Tab Depth:

Adhesive:

.062 in DP460,

Rate of Cross-hear. $05 \mathrm{in} / \mathrm{min}$

Strain Measureme MicroMeasurements Shear Gages

Test Humidity: $\quad 50 \%$ Relative Humidity

Test Environment: Lab Air

Test Temperature: 23 deg $C$

Notes: $\quad$ 1. Back-to-back shear gages used.

2. Over $3 \%$ twist occured in some tests, cause unknown, values are averaged from both gages

3. Shear Chord Modulus taken over 1000-6000 microstrains.
Property: $\quad$ Longitudinal Tensile Strength

Longitudinal Tensile Modulus

Transverse Tensile Strength

Transverse Tensile Modulus

Tested by: $\quad$ WVU

Test Specification: ASTM D3039-95a

Method: With tabs

Specimen Material Cytech Fiberite Carbon Tape

Product Code: $\quad$ HYE 949/M30GC, HYE948A1/M40J

Length: $\quad 10.0$ in., 7.0 in

Width: $\quad 0.5$ in., 1.0 in

Depth: $\quad .041 \mathrm{in}, .110-.115 \mathrm{in}$

Tab Material: $\quad$ Alternating carbon/E-glass panel, McMaster-Carr

Tab Depth: $\quad .062$ in

d Adhesive:

DP460, EPIBOND 1559A/B, Magnabond 6380

Rate of Cross-hear.05 in/min

Strain Measuremel EA-06-125TM-120 strain gages

Test Humidity: $\quad 45 \%$ Relative Humidity

Test Environment: Lab Air

Test Temperature: 24 deg C

Notes:

1. Transverse Chord Modulus taken over 1000-2500 microstrains. Longitudinal Chord Modulus taken over 1000-3000 microstrains.

2. MTS 810 material system used for modulus tests.

3. Instron 1000 with manually tightened, self-aligning grips, used for Transverse strength testing. 4. Transverse strength specimens taken from modulus specimens with tabs removed. Specimen

length $=5.0$ in .

5. Emery cloth used at grips. 
Property: $\quad$ Apparent Density

Tested by: WVU

Test Specification: ASTM D 792-91, Helium Pycnometer Method

Method: Method B for D792-91

Specimen Materia Cytech Fiberite Carbon Tape

Product Code: HYE 949/M30GC, HYE 948A!/M40J

Length:

$38 \mathrm{~mm}$

Width:

$11 \mathrm{~mm}$

Depth: $\quad .110-.115$ in

Tab Material: none

Tab Depth: none

Adhesive: none

Rate of Cross-heaınone

Strain Measureme none

Test Humidity: $\quad 50 \%$ Relative Humidity

Test Environment: Lab Air

Test Temperature: $20 \operatorname{deg} \mathrm{C}$

Notes: $\quad$ 1. Both liquid displacement and helium pycnometer used for tests.

2. 4 samples for each material type

used with $D$ 792-91.

3. 5 samples used for each material type with pyncometer.
Property: $\quad$ Theoretical Density

Void Content

Tested by: $\quad$ WVU

Test Specification: Procedure from Micromeritics

Method: Micromeitics Accu Pyc 1330 Standard

Specimen Material Cytech Fiberite Carbon Tape, Intermediate Modulus

Product Code: HYE 949/M30GC, HYE 948A1/M40J

Length: $\quad 2.75-5.25 \mathrm{cc}$, ground to pass 30 mesh sieve

Width: $\quad 2.75-5.25 \mathrm{cc}$, ground to pass 30 mesh sieve

Depth: $\quad 2.75-5.25 \mathrm{cc}$, ground to pass 30 mesh sieve

Tab Material: none

Tab Depth: none

Adhesive: none

Rate of Cross-heacnone

Strain Measureme none

Test Humidity: $\quad 45 \%$ Relative Humidity

Test Environment: Lab Air

Test Temperature: $20 \operatorname{deg} \mathrm{C}$

Notes: $\quad 1$. Differences in theoretical density most likely caused by variations in grinding. 
Property:

Glass Transition Temperature

Tested by:

WVU

Test Specification: Cytech Fiberite Test Method T16

Method: Max Value of $\tan (\delta)$

Specimen Materia Cytech Fiberite Carbon Tape

Product Code: HYE 949/M30GC, HYE 948/M40J

Length:

$5.5 \mathrm{~mm}$

Width:

$1.1 \mathrm{~mm}$

Depth:

$.042 "-.043 "$

Tab Material:

none

Tab Depth:

none

Adhesive:

none

Rate of Cross-hea none

Strain Measureme none

Test Humidity: $\quad 50 \%$ Relative Humidity

Test Environment: Lab Air

Test Temperature: 20 deg $C$

Notes:

\author{
Tested by: \\ OCM \\ Test Specification: ASTM E-831 \\ Method: \\ TMA \\ Specimen Material Cytech Fiberite Carbon Tape \\ Product Code: HYE 949/M30GC \\ Length: $\quad$.25" \\ Width: $\quad .25^{\prime \prime}$ \\ Depth: $\quad .120 "-.127 "$ \\ Tab Material: none \\ Tab Depth: $\quad$ none \\ Adhesive: none \\ Rate of Cross-hear none \\ Strain Measureme none \\ Test Humidity: $\quad 45 \%$ Relative Humidity \\ Test Environment: Lab Air \\ Test Temperature: 20 deg $\mathrm{C}$
}

Property: $\quad$ Longitudinal Coefficient of Thermal Expansion Transverse Coefficient of Thermal Expansion

Notes:

1. Tested in temperature range $-125 \mathrm{~F}$ to $180 \mathrm{~F}$. 


\begin{tabular}{|c|c|c|c|c|c|c|c|c|c|c|c|}
\hline \multirow{2}{*}{$\begin{array}{c}\text { Panel } \\
\text { ID } \\
\text { NTP- } \\
\end{array}$} & \multirow[t]{2}{*}{ Material } & \multirow{2}{*}{$\begin{array}{l}\text { Len } \\
\text { [in] }\end{array}$} & \multirow{2}{*}{$\begin{array}{l}\text { Wid } \\
\text { [in] }\end{array}$} & \multirow{2}{*}{\begin{tabular}{|} 
Approx Thich \\
Unsanded \\
[in]
\end{tabular}} & \multirow{2}{*}{ \# Plys } & \multirow{2}{*}{$\begin{array}{c}\text { Plys/ } \\
\text { Debulk }\end{array}$} & \multicolumn{4}{|c|}{ Manufacturing Method } & \multirow[t]{2}{*}{ Notes } \\
\hline & & & & & & & $\begin{array}{c}\text { Caul } \\
\text { Plates }\end{array}$ & $\begin{array}{l}\text { Peel } \\
\text { Ply }\end{array}$ & $\begin{array}{l}\text { Perf. } \\
\text { Ply }\end{array}$ & $\begin{array}{l}\text { Bleeder/ } \\
\text { Breather }\end{array}$ & \\
\hline 1 & 949/M30GC & 22 & 12 & 0.120 & 20 & 5 & --- & --- & $\mathrm{P} 7$ & Yes & Cured to $240 \mathrm{~F}$,post cured to $275 \mathrm{~F}$. \\
\hline 2 & 949/M30GC & 22 & 12 & 0.120 & 20 & 10 & --- & --- & $\mathrm{P} 7$ & Yes & Cured to $240 \mathrm{~F}$,post cured to $275 \mathrm{~F}$. \\
\hline 3 & 949/M30GC & 22 & 12 & 0.120 & 20 & 20 & --- & --- & $\mathrm{P} 7$ & Yes & Cured to $240 \mathrm{~F}$,post cured to $275 \mathrm{~F}$. \\
\hline 4 & 949/M30GC & 22 & 12 & 0.124 & 20 & 5 & --- & --- & CT & Yes & \\
\hline 5 & 949/M30GC & 20 & 4 & CT & 20 & 5 & --- & --- & $\mathrm{CT}$ & Yes & \\
\hline 6 & 949/M30GC & 20 & 4 & CT & 20 & 10 & --- & --- & P3 & Yes & \\
\hline 7 & 949/M30GC & 12 & 24 & 0.046 & 7 & 7 & --- & --- & $\mathrm{P} 7$ & Yes & \\
\hline 8 & 948A1/M40」 & 12 & 24 & 0.046 & 7 & 7 & --- & --- & P7 & Yes & \\
\hline 9 & 948A1/M40」 & 18 & 12 & 0.124 & 20 & 20 & --- & --- & $\mathrm{P} 7$ & Yes & Cracked when removed from tool. \\
\hline 10 & 948A1/M40J & 23.5 & 12 & 0.042 & 7 & 7 & $.5 "$ Alum & Yes & --- & --- & Discarded, suspected lint contamination \\
\hline 11 & 948A1/M40」 & 23.5 & 12 & 0.042 & 7 & 7 & $.5 "$ Alum & Yes & --- & --- & \\
\hline 12 & 948A1/M40 & 22 & 12 & 0.127 & 20 & 20 & --- & --- & $\mathrm{P} 7$ & Yes & Discarded, creases caused by rel. film. \\
\hline 13 & Not Used & & & & & & & & & & \\
\hline 14 & 948A1/M40」 & 22 & 12 & 0.124 & 20 & 20 & --- & --- & $\mathrm{P} 7$ & Yes & \\
\hline 15 & 949/M30GC & 23.5 & 12 & 0.041 & 7 & 7 & $.5 "$ Alum & Yes & --- & --- & \\
\hline 16 & 948A1/M40J & 23.5 & 12 & 0.042 & 7 & 7 & .5" Alum & Yes & --- & --- & \\
\hline 17 & 948A1/M40J & 23.5 & 12 & 0.042 & 7 & 7 & .5" Alum & Yes & --- & --- & \\
\hline
\end{tabular}

Notes "CT": Cannot Trace this information. 


\section{Appendix B:}

\section{Phase I Test Results}




\section{Touchstone Tests:}

1. Longitudinal Compressive Strength

$\begin{array}{lrr}\begin{array}{l}\text { 5 ply/debulk } \\ \text { Specimen }\end{array} & \begin{array}{r}\text { Ult. Load Jlt. Stress } \\ \text { [lb] }\end{array} \\ & \text { [ksi] } \\ \text { NTP-4-26 } & 6860 & 123.6 \\ \text { NTP-4-30 } & 5905 & 106.4 \\ \text { NTP-4-25 } & 5883 & 106.0 \\ & & \\ \text { Ave } & 6216 & 112.0 \\ \text { St Dev } & 558 & 10.05 \\ \text { Cv } & 8.97 & 8.97 \\ & & \\ \text { Ave + StD } & 6774 & 122.0 \\ \text { Ave - StD } & 5658 & 102.0\end{array}$

10 ply/debulk

Specimen Ult. Load Jlt. Stress

[lb] [ksi]

NTP-6-3 $\quad 7309 \quad 131.7$

$\begin{array}{lll}\text { NTP-6-5 } & 6699 & 120.7\end{array}$

NTP-6-4 $7526 \quad 135.6$

NTP-6-6 $\quad 7426 \quad 133.8$

Ave $\quad 7240 \quad 130.5$

St Dev $\quad 371 \quad 6.69$

Cv

$5.13 \quad 5.13$

Ave + StD $\quad 7611 \quad 137.1$

Ave - StD

6869

123.8

2. Longitudinal Compressive Modulus

\begin{tabular}{lr}
\multicolumn{2}{c}{5 plys/debulk } \\
Specimen & $\begin{array}{r}\text { Modulus } \\
\text { [Msi] }\end{array}$ \\
& 18.46 \\
1L-2S & 18.71 \\
1L-3S & 17.86 \\
1L-4S & 17.50 \\
1L-5S & 18.35 \\
1L-XS & 18.18 \\
Ave & 0.488 \\
St Dev & 2.69 \\
Cv & \\
& \\
Ave + StD & 18.66 \\
Ave - StD & 17.69
\end{tabular}

10 plys/debulk

Specimen Modulus

$\begin{array}{lr} & \text { [Msi] } \\ \text { 2L-2S } & 18.23 \\ \text { 2L-3S } & 17.78 \\ \text { 2L-4S } & 17.87 \\ \text { 2L-5S } & 18.63 \\ \text { 2L-XS } & 17.36 \\ \text { Ave } & 17.97 \\ \text { St Dev } & 0.482 \\ \text { Cv } & 2.68 \\ & \\ \text { Ave + StD } & 18.46 \\ \text { Ave - StD } & 17.49\end{array}$

20 ply/debulk

Specimen Ult. Load Jlt. Stress

[lb] [ksi]

NTP-3-28 $6693 \quad 120.6$

NTP-3-26 $7670 \quad 138.2$

NTP-3-22 $\quad 8147 \quad 146.8$

Ave $\quad 7504 \quad 135.2$

St Dev $\quad 741 \quad 13.36$

$\begin{array}{lll}\text { Cv } & 9.88 & 9.88\end{array}$

Ave + StD $\quad 8245 \quad 148.6$

Ave-StD $\quad 6762 \quad 121.8$

20 plys/debulk

Specimen Modulus

$\begin{array}{lr} & \text { [Msi] } \\ \text { 3L-1M } & 17.47 \\ \text { 3L-2M } & 17.75 \\ \text { 3L-3M } & 17.80 \\ \text { 3L-4M } & 18.04 \\ \text { 3L-5M } & 18.75 \\ \text { Ave } & 17.96 \\ \text { St Dev } & 0.487 \\ \text { Cv } & 2.71 \\ & \\ \text { Ave + StD } & 18.45 \\ \text { Ave - StD } & 17.48\end{array}$


3. Transverse Compressive Strength

5 ply/debulk

Specimen Ult. Load Jlt. Stress

$\begin{array}{rrr} & {[\mathrm{lb}]} & {[\mathrm{ksi}]} \\ 1 \mathrm{~T}-4 \mathrm{M} & 1464 & 24.6\end{array}$

$1494-25.3$

$\begin{array}{lll}1 \mathrm{~T}-6 \mathrm{M} & 1535 & 23.6\end{array}$

1T-7M $\quad 1520 \quad 25.4$

1T-9M $\quad 1520 \quad 25.6$

$\begin{array}{lll}\text { Ave } & 1507 & 24.9\end{array}$

St Dev $\quad 28.0 \quad 0.819$

Cv

Ave + St $\quad 1535 \quad 25.7$

Ave - StD $\quad 1479 \quad 24.1$

4. Transverse Compressive Modulus

5 ply/debulk

Specimen Modulus

$\begin{array}{lr} & \text { [Msi] } \\ \text { 1T-6S } & 1.083 \\ \text { 1T-7S } & 1.030 \\ \text { 1T-8S } & 1.047 \\ \text { 1T-9S } & 1.064 \\ \text { 1T-XS } & 1.127 \\ \text { Ave } & 1.070 \\ \text { St Dev } & 0.0374 \\ \text { Cv } & 3.49 \\ & \\ \text { Ave + StC } & 1.108 \\ \text { Ave - StD } & 1.033\end{array}$

10 ply/debulk

Specimen Ult. Load Jlt. Stress

$\begin{array}{lrr} & {[\mathrm{lb}]} & {[\mathrm{ksi}]} \\ \text { 2T-4M } & 1498 & 25.4 \\ \text { 2T-5M } & 1493 & 25.3 \\ \text { 2T-6M } & 1458 & 24.4 \\ \text { 2T-7M } & 1400 & 23.7 \\ \text { 2T-8M } & 1423 & 24.4 \\ \text { Ave } & 1454 & 24.6 \\ \text { St Dev } & 42.9 & 0.709 \\ \text { Cv } & 2.95 & 2.88 \\ & & \\ \text { Ave + St[ } & 1497 & 25.3 \\ \text { Ave - StD } & 1412 & 23.9\end{array}$

$10 \mathrm{ply} /$ debulk

Specimen Modulus

2T-4S $\quad 1.045$

2T-5S $\quad 1.058$

2T-6S $\quad 1.034$

2T-7S $\quad 1.013$

2T-8S 0.992

Ave $\quad 1.028$

St Dev $\quad 0.0262$

Cv $\quad 2.55$

Ave + St $[\quad 1.055$

Ave - StD 1.002 


\section{$\underline{\text { WVU Tests }}$}

1. Longitudinal Compression Strength

\section{7 ply/debulk}

Specimen Ult. Load Ult. Stress

[lb] [ksi]

$\begin{array}{lll}\text { NTP-15-83 } & 3426 & 184 \\ \text { NTP-15-84 } & 3941 & 211\end{array}$

$\begin{array}{lll}\text { NTP-15-84 } & 3510 & 187\end{array}$

$\begin{array}{lll}\text { NTP-15-85 } & 3057 & 164\end{array}$

NTP-15-86 $\quad 3276 \quad 177$

Ave $\quad 3442 \quad 185$

St Dev $\quad 328 \quad 17$

$\begin{array}{lll}\text { Cv } & 9.52 & 9.32\end{array}$

Ave + StD $\quad 3770 \quad 202$

Ave - StD $\quad 3114 \quad 167$

2. Longitudinal Compressive Modulus

$\begin{array}{lrrr}\begin{array}{l}7 \text { plys/debulk } \\ \text { Specimen }\end{array} & \begin{array}{r}\text { Mod 1 } \\ \text { [Msi] }\end{array} & \begin{array}{r}\text { Mod 2 } \\ \text { [Msi] }\end{array} & \begin{array}{r}\text { Ave. Mod. } \\ \text { [Msi] }\end{array} \\ \text { NTP-15-52 } & 23.2 & 23.1 & 23.2 \\ \text { NTP-15-53 } & 21.3 & 24.7 & 23.0 \\ \text { NTP-15-54 } & 21.9 & 24.0 & 22.9 \\ \text { NTP-15-55 } & 23.6 & 21.8 & 22.7 \\ \text { NTP-15-56 } & 21.8 & 24.6 & 23.2 \\ \text { Average } & 22.3 & 23.6 & 23.0 \\ \text { St Dev } & 0.99 & 1.22 & 0.21 \\ \text { Cv } & 4.44 & 5.14 & 0.92 \\ & & & \\ \text { Ave + StD } & 23.3 & 24.8 & 23.2 \\ \text { Ave - StD } & 21.3 & 22.4 & 22.8\end{array}$


5. In-Plane Shear Strength

$\begin{array}{lrr}\begin{array}{l}\text { 5 Ply/Debulk } \\ \text { Specimen }\end{array} & \begin{array}{r}\text { Ult. Load } \\ \text { [lb] }\end{array} & \begin{array}{r}\text { Ult Stress } \\ \text { [psi] }\end{array} \\ \text { NTP-4-9 } & 513 & 9950 \\ \text { NTP-4-10 } & 552 & 10590 \\ \text { NTP-4-11 } & 488 & 9440 \\ \text { NTP-4-14 } & 483 & 9360 \\ \text { NTP-4-16 } & 493 & 9680 \\ \text { Ave } & 506 & 9804 \\ \text { St Dev } & 28 & 496 \\ \text { Cv } & 5.58 & 5.06 \\ \text { Ave + StD } & 534 & 10300 \\ \text { Ave - StD } & 478 & 9308\end{array}$

$\begin{array}{lrr} & \text { [lb] } & \text { [psi] } \\ \text { NTP-2-9 } & 518 & 10380 \\ \text { NTP-2-11 } & 515 & 10360 \\ \text { NTP-2-15 } & 491 & 9940 \\ \text { NTP-2-16 } & 474 & 9680 \\ \text { NTP-2-17 } & 483 & 9830 \\ \text { Ave } & 496 & 10038 \\ \text { St Dev } & 20 & 317 \\ \text { Cv } & 3.93 & 3.16 \\ \text { Ave + StD } & 516 & 10355 \\ \text { Ave - StD } & 477 & 9721\end{array}$

6. In-Plane Shear Modulus

$\begin{array}{clr}\begin{array}{c}\text { 5 Ply/Debulk } \\ \text { Specimen }\end{array} & & \\ \text { NTP-4-9 } & \text { Mod 1 } & \text { [Msi] } \\ & \text { Mod 2 } & 0.492 \\ & \text { Ave Mod } & 0.601 \\ & \text { Twist } & 9.9465 \\ & & \\ \text { NTP-4-10 } & \text { Mod 1 } & \text { [Msi] } \\ & \text { Mod 2 } & 0.604 \\ & \text { Ave Mod } & 0.584 \\ & \text { Twist } & 0.594 \\ & & 1.68 \% \\ & & \\ \text { NTP-4-11 } & \text { Mod 1 } & {[\mathrm{Msi}]} \\ & \text { Mod 2 } & 0.504 \\ & \text { Ave Mod } & 0.622 \\ & \text { Twist } & 0.563 \\ & & 10.48 \%\end{array}$

10 Ply/Debulk

Specimen Ult. Load Ult Stress

20 Ply/Debulk

Specimen Ult. Load Ult Stress

$\begin{array}{lrr} & {[\mathrm{lb}]} & \text { [psi] } \\ \text { NTP-3-9 } & 498 & 9770 \\ \text { NTP-3-11 } & 513 & 10060 \\ \text { NTP-3-12 } & 513 & 10040 \\ \text { NTP-3-14 } & 527 & 10300 \\ \text { NTP-3-17 } & 510 & 10120 \\ \text { Ave } & 512 & 10058 \\ \text { St Dev } & 10 & 191 \\ \text { Cv } & 2.02 & 1.90 \\ \text { Ave + StD } & 523 & 10249 \\ \text { Ave - StD } & 502 & 9867\end{array}$

10 Ply/Debulk

Specimen

0.543

0.47

Mod 1

Ave Mod

Twist

0.5065

$7.21 \%$

[Msi]

NTP-2-11 Mod $1 \quad 0.498$

Mod $2 \quad 0.586$

Ave Mod $\quad 0.542$

Twist

$8.12 \%$

20 Ply/Debulk

$\begin{array}{llr}\text { Specimen } & & \text { [Msi] } \\ \text { NTP-3-9 } & \text { Mod 1 } & 0.5174 \\ & \text { Mod 2 } & 0.5895 \\ & \text { Ave Mod } & 0.55345 \\ & \text { Twist } & 6.51 \% \\ & & \\ \text { NTP-3-11 } & \text { Mod 1 } & \text { [Msi] } \\ & \text { Mod 2 } & 0.498 \\ & \text { Ave Mod } & 0.570 \\ & \text { Twist } & 6.534 \\ & & 6.70 \%\end{array}$

$\begin{array}{llr}\text { NTP-2-15 } & \text { Mod 1 } & 0.564 \\ & \text { Mod 2 } & \text { Not Avail. } \\ & \text { Ave Mod } & 0.564 \\ & \text { Twist } & \text { Not Avail. }\end{array}$

$\begin{array}{ll}\text { NTP-3-12 } & \text { Mod 1 } \\ & \text { Mod 2 } \\ & \text { Ave Mod } \\ & \text { Twist }\end{array}$


5 Ply/Debulk

Specimen

$\begin{array}{llr}\text { NTP-4-14 } & \text { Mod 1 } & 0.557 \\ & \text { Mod 2 } & 0.634 \\ & \text { Ave Mod } & 0.596 \\ & \text { Twist } & 6.47 \% \\ \text { NTP-4-16 } & \text { Mod 1 } & 0.531 \\ & \text { Mod 2 } & 0.634 \\ & \text { Ave Mod } & 0.583 \\ & \text { Twist } & 8.84 \% \\ & \text { Ave Mod } & 0.576 \\ & \text { St Dev } & 0.021 \\ & \text { Cv } & 3.67 \\ & \text { Ave + StD } & 0.597 \\ & \text { Ave - StD } & 0.555 \\ & \text { Ave Twist } & 7.49 \%\end{array}$

7. Transverse Tensile Strength

5 Ply/Debulk

Specimen Ult. Load Ult Stress

$\begin{array}{lrr} & {[\mathrm{lb}]} & {[\mathrm{psi}]} \\ \text { NTP-4-1 } & 561 & 4963 \\ \text { NTP-4-2 } & 486 & 4303 \\ \text { NTP-4-3 } & 534 & 4726 \\ \text { NTP-4-6 } & 496 & 4354 \\ \text { NTP-4-8 } & 560 & 5045 \\ \text { Mean } & 527 & 4678 \\ \text { St Dev } & 35 & 340 \\ \text { Cv } & 6.62 & 7.28 \\ & & \\ \text { Mean+StD } & 562 & 5019 \\ \text { Mean-StD } & 493 & 4338\end{array}$

10 Ply/Debulk

Specimen

NTP-2-16 Mod 1

Mod 2

Ave Mod

Twist

NTP-2-17 Mod 1

Mod 2

Ave Mod

Twist

Ave Mod

St Dev

Cv

Ave + StD
Ave - StD

Ave Twist

10 Ply/Debulk

Specimen

Ult. Load Ult Stress

NTP-2-1

NTP-2-2

NTP-2-6

NTP-2-7

NTP-2-8

Mean

St Dev

Cv

Mean+StD

Mean-StD
20 Ply/Debulk

$\begin{array}{clr}\text { Specimen } & \text { [Msi] } \\ \text { NTP-3-14 } & \text { Mod 1 } & 0.548 \\ & \text { Mod 2 } & 0.549 \\ & \text { Ave Mod } & 0.549 \\ & \text { Twist } & 0.09 \% \\ \text { NTP-3-17 } & \text { Mod 1 } & 0.508 \\ & \text { Mod 2 } & 0.579 \\ & \text { Ave Mod } & 0.543 \\ & \text { Twist } & 6.54 \% \\ & \text { Ave Mod } & 0.537 \\ & \text { St Dev } & 0.019 \\ & \text { Cv } & 3.49 \\ & & \\ & \text { Ave + StD } & 0.556 \\ & \text { Ave - StD } & 0.518 \\ & & \\ & \text { Ave Twist } & 7.59 \%\end{array}$

20 Ply/Debulk

Specimen Ult. Load Ult Stress

$\begin{array}{rrr} & \text { [lb] } & \text { [psi] } \\ \text { NTP-3-2 } & 532 & 4668\end{array}$

NTP-3-3 $\quad 517 \quad 4571$

NTP-3-4 $562 \quad 4929$

NTP-3-5 $\quad 556 \quad 4920$

NTP-3-6 $\quad 535 \quad 4696$

Mean $\quad 540 \quad 4757$

St Dev $\quad 19 \quad 160$

$\mathrm{Cv}$

$3.43 \quad 3.37$

Mean+StD

$559 \quad 4917$

Mean-StD $\quad 522 \quad 4596$ 
8. Transverse Tensile Modulus and Minor Poisson's Ratio

\begin{tabular}{|c|c|c|c|c|c|c|c|c|}
\hline $\begin{array}{l}5 \text { Ply/Debulk } \\
\text { specımen }\end{array}$ & $\begin{array}{r}\mathrm{E}_{2} \\
{[\mathrm{Msi}]}\end{array}$ & $v_{21}$ & $\begin{array}{l}10 \text { Ply/Debulk } \\
\text { specimen }\end{array}$ & $\begin{array}{r}_{2} \\
{[\mathrm{Msi}]}\end{array}$ & $v_{21}$ & $\begin{array}{l}20 \text { Ply/Debulk } \\
\text { specimen }\end{array}$ & $\begin{array}{r}\check{ }_{2} \\
\text { [Msi] }\end{array}$ & $v_{21}$ \\
\hline NTP-4-1 & 1.069 & 0.00965 & NTP-2-1 & 1.084 & 0.00540 & NTP-3-1 & 1.008 & 0.00880 \\
\hline NTP-4-2 & 1.026 & 0.00795 & NTP-2-2 & 1.058 & 0.00882 & NTP-3-2 & 0.978 & 0.00594 \\
\hline NTP-4-6 & 1.131 & 0.00980 & NTP-2-6 & 1.025 & 0.01475 & NTP-3-6 & 1.020 & 0.00774 \\
\hline NTP-4-7 & 1.011 & 0.00990 & NTP-2-7 & 1.049 & 0.00590 & NTP-3-7 & 1.029 & 0.00975 \\
\hline NTP-4-8 & 1.058 & 0.00783 & NTP-2-8 & 0.983 & 0.00984 & NTP-3-8 & 1.004 & 0.00585 \\
\hline Mean & 1.059 & 0.00903 & Mean & 1.040 & 0.00894 & Mean & 1.008 & 0.00762 \\
\hline St Dev & 0.047 & 0.00104 & St Dev & 0.038 & 0.00375 & St Dev & 0.019 & 0.00172 \\
\hline $\mathrm{Cv}$ & 4.40 & 11.54 & $\mathrm{Cv}$ & 3.67 & 41.98 & $\mathrm{Cv}$ & 1.92 & 22.65 \\
\hline Mean+StD & 1.106 & 0.01007 & Mean+StD & 1.078 & 0.01270 & Mean+StD & 1.027 & 0.00934 \\
\hline Mean-StD & 1.012 & 0.00798 & Mean-StD & 1.002 & 0.00519 & Mean-StD & 0.988 & 0.00589 \\
\hline
\end{tabular}

9. Density and Void Content at Location A

Density': Helium Pycnometer, apparent density

Density: Liquid Displacement Method, liquid - isopropanol, apparent density

Density: Helium Pycnometer, sample ground to 30 mesh sieve, theoretical density Location A: 4" from end of panel 12"x22"

5 Plys/Debulk

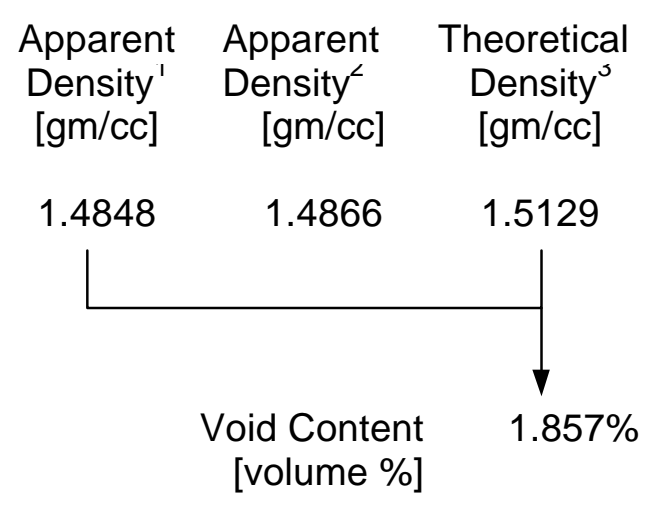

\begin{abstract}
10 Plys/Debulk
\end{abstract}

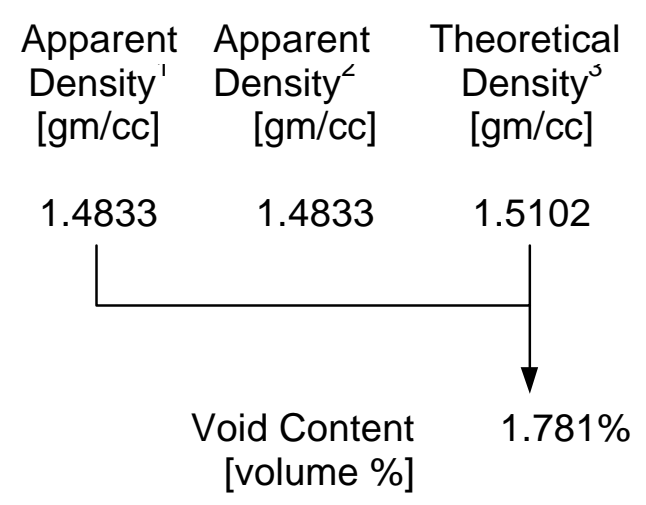

20 Plys/Debulk

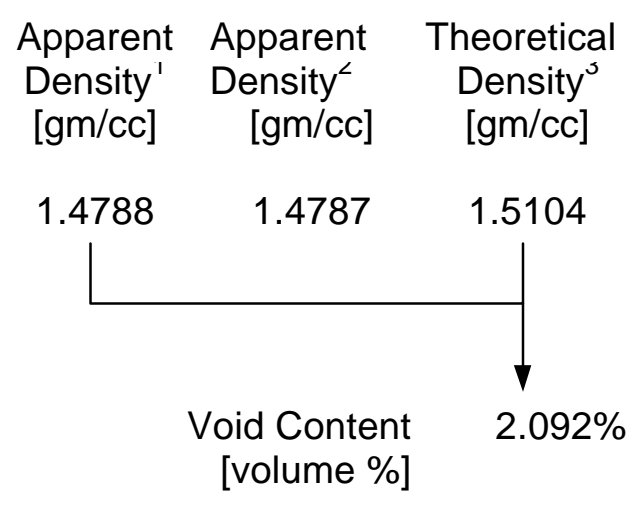


9. Density and Void Content at Location B

Density': Helium Pycnometer, apparent density

Density ${ }^{3}$ : Helium Pycnometer, sample ground to 30 mesh sieve, theoretical density

Location B: At center of panel 12"x22"

5 Plys/Debulk

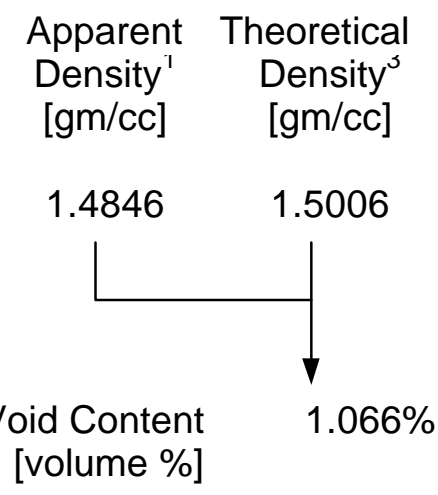

20 Plys/Debulk

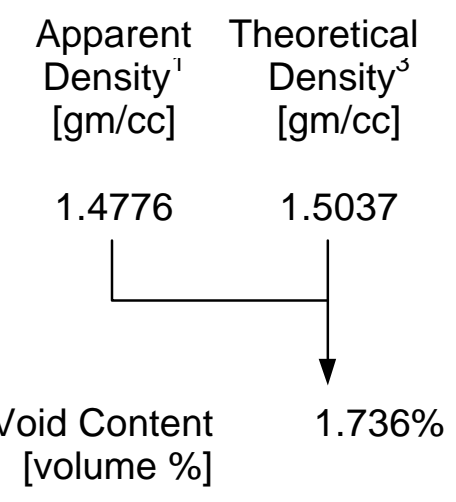




\section{Appendix C:}

Phase II Test Results 


\section{F Longitudinal Compressive Strength}

\author{
Material: $\quad 948 \mathrm{~A} 1$ \\ Tested by: OCM \\ Temp: \\ \# of Plys: $\quad 7$ \\ Sanding: No \\ Bleeder: \\ Caul Plate .5" Aluminum \\ Peel Ply: Both sides \\ Modulus: 24.8 ([Msi] Adjusted OCM data) \\ 22.6 ([Msi] Original OCM data)
}

Specimen Width Thick usec Load StrengthAdj Thick Adj Str

$\begin{array}{llllll} & \text { [in.] } & \text { [in] } & \text { [lbs] } & \text { [ksi] } & \text { [in] [ksi] }\end{array}$

$\begin{array}{lllllll}\text { NTP-11-1 } & 0.501 & 0.040 & 4167 & 208 & 0.038 & 219\end{array}$

$\begin{array}{lllllll}\text { NTP-11-2 } & 0.502 & 0.040 & 4011 & 200 & 0.038 & 210\end{array}$

$\begin{array}{lllllll}\text { NTP-11-3 } & 0.500 & 0.040 & 4077 & 204 & 0.038 & 215\end{array}$

$\begin{array}{lllllll}\text { NTP-11-4 } & 0.500 & 0.038 & 3759 & 198 & 0.038 & 198\end{array}$

$\begin{array}{lllllll}\text { NTP-11-5 } & 0.498 & 0.040 & 3926 & 197 & 0.038 & 207\end{array}$

$\begin{array}{lllllll}\text { NTP-16-21 } & 0.500 & 0.040 & 3074 & 154 & 0.038 & 162\end{array}$

$\begin{array}{lllllll}\text { NTP-16-22 } & 0.501 & 0.040 & 3460 & 173 & 0.038 & 182\end{array}$

$\begin{array}{lllllll}\text { NTP-16-23 } & 0.501 & 0.041 & 3283 & 160 & 0.038 & 172\end{array}$

$\begin{array}{lllllll}\text { NTP-16-24 } & 0.501 & 0.040 & 3492 & 174 & 0.038 & 183\end{array}$

$\begin{array}{lllllll}\text { NTP-16-25 } & 0.501 & 0.041 & 3648 & 178 & 0.038 & 192\end{array}$

$\begin{array}{lrrrrrr}\text { Average } & 0.501 & 0.040 & 3690 & 184 & 0.038 & 194 \\ \text { St Dev } & 0.001 & 0.001 & 362 & 19 & 0.000 & 19\end{array}$

$\begin{array}{lllllll}\mathrm{C} v & 0.22 & 2.04 & 9.81 & 10.45 & 0.00 & 9.83\end{array}$

$\begin{array}{lllllll}\text { Ave + StD } & 0.502 & 0.041 & 4052 & 204 & 0.038 & 213\end{array}$

$\begin{array}{lllllll}\text { Ave- StD } & 0.499 & 0.039 & 3328 & 165 & 0.038 & 175\end{array}$

\begin{tabular}{rr}
$\begin{array}{c}\text { Ult Strain } \\
\text { [ue] }\end{array}$ & $\begin{array}{r}\text { Adj Ult Strain } \\
\text { [ue] } \\
8180\end{array}$ \\
\hline 7823 \\
\hline
\end{tabular}

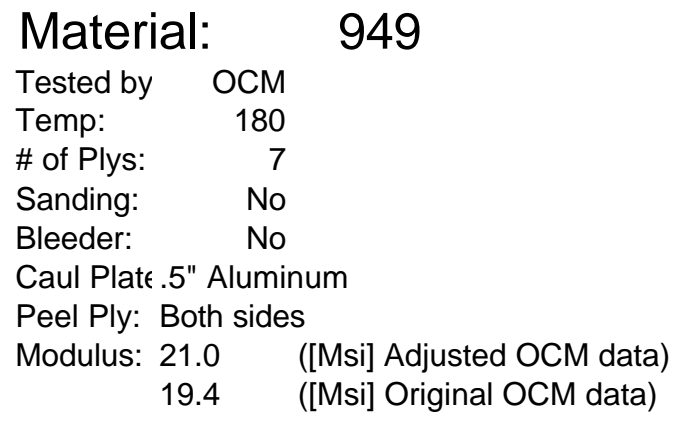

Caul Plate.5" Aluminum

Peel Ply: Both sides

Modulus: $21.0 \quad$ ([Msi] Adjusted OCM data)

$$
19.4 \text { ([Msi] Original OCM data) }
$$

Specimen Width Thick usec Load Strength Adj Thick Adj Str

$\begin{array}{lrrrrrr} & {[\text { in. }} & {[\text { in] }} & \text { [lbs] } & \text { [ksi] } & \text { [in] } & {[\text { ksi] }} \\ \text { NTP-15-1 } & 0.502 & 0.038 & 2710 & 142 & 0.037 & 146 \\ \text { NTP-15-2 } & 0.503 & 0.037 & 2807 & 151 & 0.037 & 151 \\ \text { NTP-15-3 } & 0.500 & 0.037 & 2779 & 150 & 0.037 & 150 \\ \text { NTP-15-4 } & 0.501 & 0.039 & 2683 & 137 & 0.037 & 145 \\ \text { NTP-15-5 } & 0.500 & 0.038 & 2880 & 152 & 0.037 & 156\end{array}$

$\begin{array}{lrrrrrr}\text { Average } & 0.501 & 0.038 & 2772 & 146 & 0.037 & 149 \\ \text { St Dev } & 0.001 & 0.001 & 79 & 6 & 0.000 & 4.360 \\ \text { Cv } & 0.26 & 2.21 & 2.84 & 4.35 & 0.00 & 2.92 \\ & & & & & & \\ \text { Ave + St[ } & 0.503 & 0.039 & 2850 & 153 & 0.037 & 154 \\ \text { Ave - StD } & 0.500 & 0.037 & 2693 & 140 & 0.037 & 145 \\ & & & & & & \\ & & & & \text { Ult Strain } & \text { Adj Ult Strain } \\ & & & & \text { [ue] } & \text { [ue] } \\ & & & & 7531 & & \text { 7095 }\end{array}$




\title{
RTA Longitudinal Compressive Strength
}

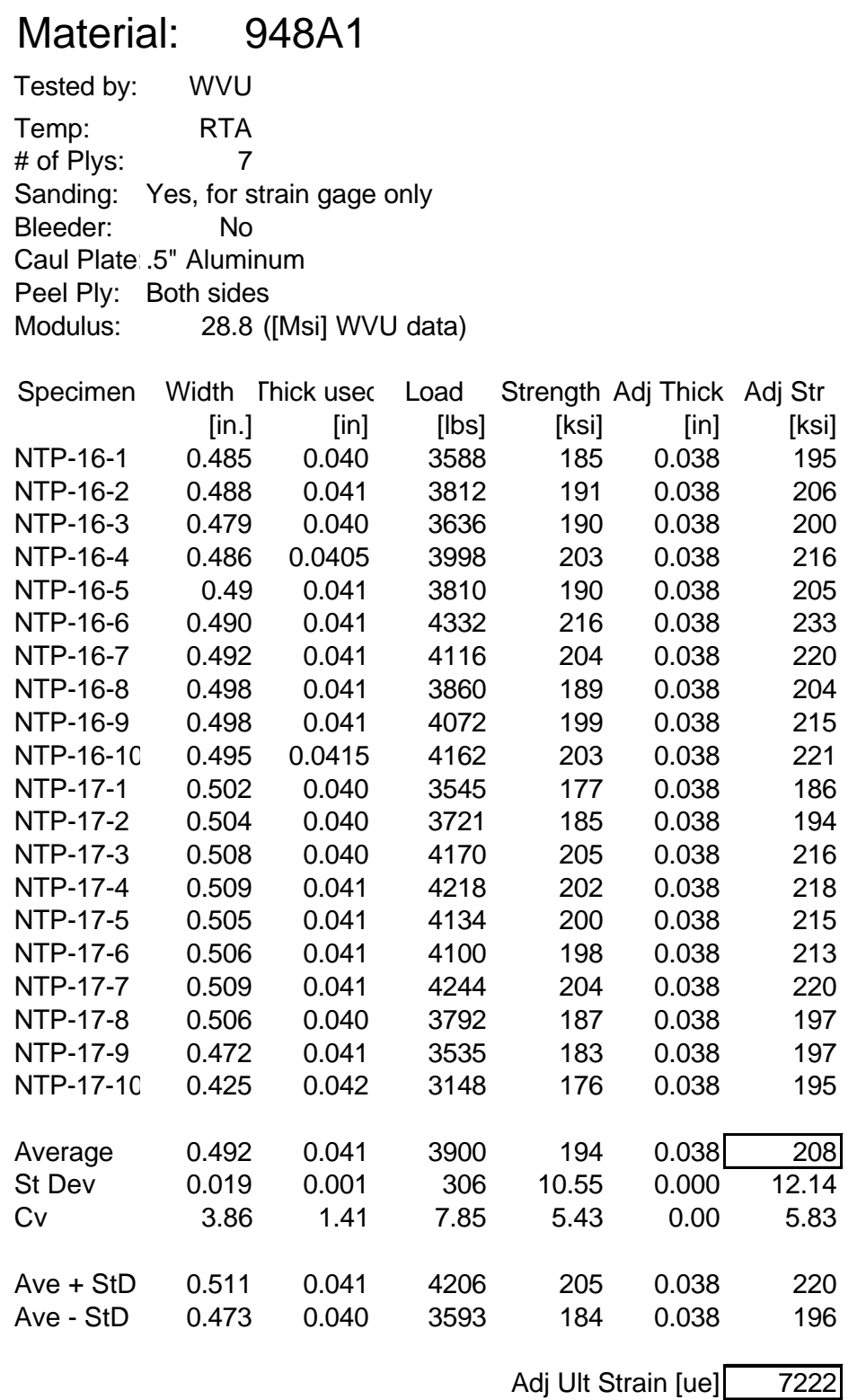

\author{
Material: $\quad 949$ \\ Tested by: WVU \\ Temp: RTA \\ \# of Plys: $\quad 7$ \\ Sanding: Yes, for strain gage only \\ Bleeder: \\ No \\ Caul Plate .5" Aluminum \\ Peel Ply: Both sides \\ Modulus: $\quad 23.0$ ([Msi] WVU data)
}

Specimen Width Thick usec Load Strength Adj Thick Adj Str

[in.] $\quad$ [in] $\quad$ [lbs] $\quad$ [ksi] $\quad$ [in] $[\mathrm{ksi}]$

$\begin{array}{lllllll} & 0.503 & 0.038 & 3426 & 179 & 0.037 & 184\end{array}$

$\begin{array}{lllllll}\text { NTP-15-8: } & 0.504 & 0.039 & 3941 & 200 & 0.037 & 211\end{array}$

$\begin{array}{lllllll}\text { NTP-15-8، } & 0.506 & 0.039 & 3510 & 180 & 0.037 & 187\end{array}$

$\begin{array}{lllllll}\text { NTP-15-8! } & 0.503 & 0.038 & 3057 & 160 & 0.037 & 164\end{array}$

$\begin{array}{lllllll}\text { NTP-15-8l } & 0.501 & 0.038 & 3276 & 172 & 0.037 & 177\end{array}$

Adj Ult Strain [ue] 7222

$\begin{array}{lrrrrrr}\text { Average } & 0.503 & 0.038 & 3442 & 178 & 0.037 & 185 \\ \text { St Dev } & 0.002 & 0.000 & 328 & 14.73 & 0.000 & 17.26 \\ \text { Cv } & 0.38 & 1.17 & 9.52 & 8.25 & 0.00 & 9.34 \\ & & & & & & \\ \text { Ave + StD } & 0.505 & 0.039 & 3769 & 193 & 0.037 & 202 \\ \text { Ave - StD } & 0.501 & 0.038 & 3114 & 164 & 0.037 & 168\end{array}$

Adj Ult Strain [ue] 8043 


\section{-125 F Longitudinal Compressive Strength}

$\begin{array}{lc}\text { Material: } & \text { 948A1 } \\ \text { Tested by } & \text { OCM } \\ \text { Temp: } & -125 \\ \text { \# of Plys: } & 7 \\ \text { Sanding: } & \text { No } \\ \text { Bleeder: } & \text { No } \\ \text { Caul Plat } .5 " \text { Aluminum } \\ \text { Peel Ply: } & \text { Both sides } \\ \text { Thick.: } & .042-.043 \text { unsanded } \\ & 0.038 \quad \text { sanded } \\ \text { Modulus: } & 41.7 \quad \text { ([Msi] Adjusted OCM data) } \\ & 36.9 \quad \text { ([Msi] Original OCM data) }\end{array}$

Specimen Width Thick Load Strength Adj Thick Adj Str

$\begin{array}{lrrrrrr} & \text { [in.] } & {[\mathrm{in}]} & {[\mathrm{lbs}]} & {[\mathrm{ksi}]} & {[\mathrm{in}]} & {[\mathrm{ksi}]} \\ \text { NTP-11-2 } & 0.501 & 0.040 & 4448 & 222 & 0.038 & 234 \\ \text { NTP-11-2 } & 0.496 & 0.039 & 3812 & 197 & 0.038 & 202 \\ \text { NTP-11-2 } & 0.501 & 0.040 & 4135 & 206 & 0.038 & 217 \\ \text { NTP-11-2 } & 0.499 & 0.039 & 4565 & 235 & 0.038 & 241 \\ \text { NTP-11-2 } & 0.501 & 0.040 & 4176 & 208 & 0.038 & 219 \\ & & & & & & \\ \text { Average } & 0.500 & 0.040 & 4227 & 214 & 0.038 & 223 \\ \text { St Dev } & 0.002 & 0.001 & 294 & 15 & 0.000 & 15 \\ \text { Cv } & 0.44 & 1.38 & 7 & 6.87 & 0.00 & 6.76 \\ & & & & & & \\ \text { Ave + St[ } & 0.502 & 0.040 & 4521 & 228 & 0.038 & 238 \\ \text { Ave- StD } & 0.497 & 0.039 & 3933 & 199 & 0.038 & 208\end{array}$

\begin{tabular}{cr}
$\begin{array}{c}\text { Ult Strain } \\
\text { [ue] }\end{array}$ & Adj Ult Strain \\
5790 & {$[\mathrm{ue]}$} \\
\hline 5348 \\
\end{tabular}

\author{
Material: $\quad 949$ \\ Tested by: OCM \\ Temp: $\quad-125$ \\ \# of Plys: $\quad 7$ \\ Sanding: No \\ Caul Plate: .5" Aluminum \\ Peel Ply: Both sides \\ Thick.: $\quad .041-.042$ unsanded \\ $\begin{array}{llc} & 0.037 & \text { sanded } \\ \text { Modulus: } & 41.8 \quad \text { ([Msi] Adjusted OCM data) }\end{array}$ \\ 38.4 ([Msi] Original OCM data)
}

Specimen Width Thick Load StrengthAdj Thick Adj Str

$\begin{array}{lrrrrrr} & {[\mathrm{in} .]} & {[\mathrm{in}]} & {[\mathrm{lbs}]} & {[\mathrm{ksi}]} & {[\mathrm{in}]} & {[\mathrm{ksi}]} \\ \text { NTP-15-21 } & 0.498 & 0.038 & 4377 & 231 & 0.037 & 238 \\ \text { NTP-15-22 } & 0.500 & 0.037 & 3997 & 216 & 0.037 & 216 \\ \text { NTP-15-23 } & 0.500 & 0.039 & 4334 & 222 & 0.037 & 234 \\ \text { NTP-15-24 } & 0.501 & 0.036 & 4107 & 228 & 0.037 & 222 \\ \text { NTP-15-25 } & 0.501 & 0.039 & 4091 & 209 & 0.037 & 221 \\ & & & & & & \\ \text { Average } & 0.500 & 0.038 & 4181 & 221 & 0.037 & 226 \\ \text { St Dev } & 0.001 & 0.001 & 165 & 9 & 0.000 & 9 \\ \text { Cv } & 0.24 & 3.45 & 4 & 3.99 & 0.00 & 4.13 \\ & & & & & & \\ \text { Ave + StD } & 0.501 & 0.039 & 4346 & 230 & 0.037 & 235 \\ \text { Ave - StD } & 0.499 & 0.036 & 4016 & 213 & 0.037 & 217\end{array}$

Ult Strain Adj Ult Strain

\begin{tabular}{rr} 
[ue] & [ue] \\
5764 & 5407 \\
\hline
\end{tabular}




\section{F Longitudinal Compressive Modulus}

\begin{tabular}{|c|c|}
\hline \\
\hline \multicolumn{2}{|c|}{$\begin{array}{l}\text { Material: } \quad \text { 948A1 } \\
\text { Tested by: }\end{array}$} \\
\hline Temp & 180 \\
\hline \# of Plys: & 7 \\
\hline Sanding: & No \\
\hline Bleeder: & No \\
\hline Caul Plate: & .5 " Aluminum \\
\hline Peel Ply: & Both sides \\
\hline Thick.: & $\begin{array}{l}0.042-.043 \text { unsanded } \\
0.038 \quad \text { sanded }\end{array}$ \\
\hline
\end{tabular}

Specimen Thick used Modulus Thick to use Adj. Mod.

$\begin{array}{lrrrr} & {[\mathrm{in}]} & {[\mathrm{Msi}]} & {[\mathrm{in}]} & {[\mathrm{Msi}]} \\ \text { NTP-11-11 } & 0.042 & 22.70 & 0.038 & 25.1 \\ \text { NTP-11-12 } & 0.042 & 22.84 & 0.038 & 25.2 \\ \text { NTP-11-13 } & 0.042 & 20.93 & 0.038 & 23.1 \\ \text { NTP-11-14 } & 0.041 & 23.85 & 0.038 & 25.7 \\ \text { NTP-11-15 } & 0.042 & 22.45 & 0.038 & 24.8 \\ & & & & \\ \text { Average } & 0.042 & 22.6 & 0.038 & 24.8 \\ \text { St Dev } & 0.000 & 1.05 & 0.00 & 0.99 \\ \text { Cv } & 1.07 & 4.67 & 0.00 & 4.00 \\ & & & & \\ \text { Ave + StD } & 0.042 & 23.6 & 0.038 & 25.8 \\ \text { Ave - StD } & 0.041 & 21.5 & 0.038 & 23.8\end{array}$

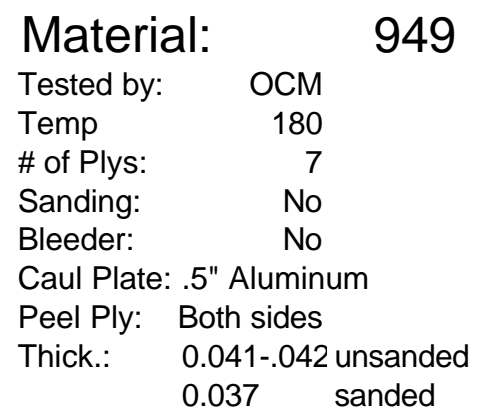

Specimen Thick used Modulus Thick to use Adj. Mod

$\begin{array}{lrrrr} & {[\mathrm{in}]} & {[\mathrm{Msi}]} & {[\mathrm{in}]} & {[\mathrm{Msi}]} \\ \text { NTP-15-11 } & 0.040 & 19.60 & 0.037 & 21.2 \\ \text { NTP-15-12 } & 0.040 & 19.27 & 0.037 & 20.8 \\ \text { NTP-15-13 } & 0.039 & 20.02 & 0.037 & 21.1 \\ \text { NTP-15-14 } & 0.041 & 18.78 & 0.037 & 20.8 \\ \text { NTP-15-15 } & 0.040 & 19.52 & 0.037 & 21.1 \\ & & & & \\ \text { Average } & 0.040 & 19.4 & 0.037 & 21.0 \\ \text { St Dev } & 0.001 & 0.46 & 0.00 & 0.17 \\ \text { Cv } & 1.77 & 2.35 & 0.00 & 0.83 \\ & & & & \\ \text { Ave + StD } & 0.041 & 19.9 & 0.037 & 21.2 \\ \text { Ave - StD } & 0.039 & 19.0 & 0.037 & 20.8\end{array}$




\section{RTA Longitudinal Compressive Modulus}

\begin{tabular}{lc} 
Material: & 948A1 \\
Tested By: & WVU \\
Temp & RTA \\
\# of Plys: & 7 \\
Sanding: & Yes, for strain gage only \\
Bleeder: & No \\
Caul Plate: & .5 Aluminum \\
Peel Ply: & 3oth sides \\
Thick.: & $0.042-.04$ i unsanded \\
\multicolumn{4}{c}{0.038 sanded } \\
Strain Range 0 to 1000 ue
\end{tabular}

Specimen $\quad$ hick used Mod 1 Mod 2 Ave. Mod.

[in] [Msi] [Msi] [Msi]

$\begin{array}{lllll}\text { NTP-11-71 } & 0.038 & 26.64 & 26.69 & 26.67\end{array}$

$\begin{array}{lllll}\text { NTP-11-72 } & 0.038 & 27.68 & 29.81 & 28.75\end{array}$

$\begin{array}{lllll}\text { NTP-11-73 } & 0.038 & 29.17 & 29.18 & 29.18\end{array}$

$\begin{array}{lllll}\text { NTP-11-74 } & 0.038 & 29.51 & 29.95 & 29.73\end{array}$

NTP-11-75 0.038

Average $\quad 0.038$

St Dev $\quad 0.000$

Cv

Ave $+\mathrm{StD}$

Ave - StD

0.038

0.038
32.14

\section{0}

2.09

7.20

31.1

26.9

\author{
Material: \\ Tested By: $\quad$ WVU \\ Temp \\ \# of Plys: \\ Bleeder: \\ Caul Plate: .5" Aluminum \\ Peel Ply: Both sides \\ Thick.: 0.041-.04є unsanded \\ 0.037 sanded \\ Strain Range: 0 to 1000 ue
}

\begin{tabular}{lrrrr} 
Specimen & Thick used & Mod 1 & \multicolumn{2}{c}{ Mod 2 Ave. Mod. } \\
& {$[$ in] } & {$[$ Msi] } & {$[$ Msi] } & {$[$ Msi] } \\
NTP-15-52 & 0.037 & 23.23 & 23.09 & 23.16 \\
NTP-15-53 & 0.037 & 21.30 & 24.65 & 22.98 \\
NTP-15-54 & 0.037 & 21.85 & 24.00 & 22.93 \\
NTP-15-55 & 0.037 & 23.56 & 21.77 & 22.67 \\
NTP-15-56 & 0.037 & 21.76 & 24.62 & 23.19 \\
& & & & \\
Average & 0.037 & 22.3 & 23.6 & 23.0 \\
St Dev & 0.000 & 0.99 & 1.22 & 0.21 \\
Cv & 0.00 & 4.44 & 5.14 & 0.92 \\
& & & & \\
Ave + StD & 0.037 & 23.3 & 24.8 & 23.2 \\
Ave - StD & 0.037 & 21.3 & 22.4 & 22.8
\end{tabular}




\section{-125 F Longitudinal Compressive Modulus}

\begin{tabular}{|c|c|}
\hline \multirow{2}{*}{\multicolumn{2}{|c|}{$\begin{array}{l}\text { Material: } \\
\text { Tested By: }\end{array}$}} \\
\hline & \\
\hline & -125 \\
\hline & \\
\hline Sand & No \\
\hline Bleeder: & No \\
\hline Caul Plate: & $.5 \mathrm{l}$ Aluminum \\
\hline $\begin{array}{ll}\text { Peel Ply: } & 3 c \\
\text { Thick.: } & 0\end{array}$ & $\begin{array}{l}\text { sides } \\
2-.04: \text { uns } \\
8 \text { sar }\end{array}$ \\
\hline
\end{tabular}

Specimen "hick used Modulus 'hick to use Adj. Mod.

$\begin{array}{lrrrr} & {[\mathrm{in}]} & {[\mathrm{Msi}]} & {[\mathrm{in}]} & {[\mathrm{Msi}]} \\ \text { NTP-11-31 } & 0.043 & 39.36 & 0.038 & 44.5 \\ \text { NTP-11-32 } & 0.044 & 34.28 & 0.038 & 39.7 \\ \text { NTP-11-33 } & 0.043 & 38.20 & 0.038 & 43.2 \\ \text { NTP-11-34 } & 0.043 & 36.49 & 0.038 & 41.3 \\ \text { NTP-11-35 } & 0.042 & 35.98 & 0.038 & 39.8 \\ & & & & \\ \text { Average } & 0.043 & 36.9 & 0.038 & 41.7 \\ \text { St Dev } & 0.001 & 1.98 & 0.00 & 2.14 \\ \text { Cv } & 1.64 & 5.36 & 0.00 & 5.13 \\ & & & & \\ \text { Ave + StD } & 0.044 & 38.8 & 0.038 & 43.8 \\ \text { Ave - StD } & 0.042 & 34.9 & 0.038 & 39.6\end{array}$

\author{
Material: $\quad 949$ \\ Tested By: OCM \\ Temp $\quad-125$ \\ \# of Plys: $\quad 7$ \\ Sanding: No \\ Bleeder: No \\ Caul Plate: .5" Aluminum \\ Peel Ply: 3oth sides \\ Thick.: $\quad 0.041-.04$ unsanded \\ 0.037 sanded
}

Specimen hick used Modulus `hick to use Adj. Mod.

$\begin{array}{lrrrr} & {[\mathrm{in}]} & {[\mathrm{Msi}]} & {[\mathrm{in}]} & {[\mathrm{Msi}]} \\ \text { NTP-15-31 } & 0.041 & 39.36 & 0.037 & 43.6 \\ \text { NTP-15-32 } & 0.040 & 34.27 & 0.037 & 37.0 \\ \text { NTP-15-33 } & 0.039 & 42.45 & 0.037 & 44.7 \\ \text { NTP-15-34 } & 0.041 & 40.15 & 0.037 & 44.5 \\ \text { NTP-15-35 } & 0.040 & 35.99 & 0.037 & 38.9 \\ & & & & \\ \text { Average } & 0.040 & 38.4 & 0.037 & 41.8 \\ \text { St Dev } & 0.001 & 3.29 & 0.00 & 3.54 \\ \text { Cv } & 2.08 & 8.55 & 0.00 & 8.48 \\ & & & & \\ \text { Ave + StD } & 0.041 & 41.7 & 0.037 & 45.3 \\ \text { Ave - StD } & 0.039 & 35.2 & 0.037 & 38.2\end{array}$




\section{RTA Transverse Compressive Strength}

\author{
Material: $948 \mathrm{~A} 1$ \\ Tested By: $\quad$ WVU \\ Temp RTA \\ \# of Plys: \\ Sanding: \\ Bleeder: \\ Caul Plate: \\ Peel Ply: \\ 220 grit, lightly sanded \\ Yes \\ no \\ no \\ Strain Range: 1000 to 3000 ue
}

$\begin{array}{lrrrr}\text { Specimen } & \begin{array}{r}\text { Width } \\ {[\mathrm{in}]}\end{array} & \text { Thick used } & \begin{array}{r}\text { Load } \\ {[\mathrm{in}]}\end{array} & \begin{array}{r}\text { Stress } \\ {[\mathrm{ksi}]}\end{array} \\ & 0.510 & 0.120 & 1665 & 27.2 \\ \text { NTP-14-31 } & 0.505 & 0.120 & 1745 & 28.8 \\ \text { NTP-14-32 } & 0.498 & 0.119 & 1671 & 28.2 \\ \text { NTP-14-33 } & 0.19 & \\ \text { NTP-14-34 } & 0.499 & 0.119 & 1478 & 24.9 \\ \text { NTP-14-35 } & 0.500 & 0.119 & 1577 & 26.5 \\ \text { NTP-14-37 } & 0.497 & 0.119 & 1619 & 27.4 \\ & & & & \\ \text { Average } & 0.501 & 0.119 & 1625 & 27.2 \\ \text { St Dev } & 0.005 & 0.001 & 92 & 1.37 \\ \text { Cv } & 1.01 & 0.43 & 5.65 & 5.06 \\ & & & & \\ \text { Ave + StD } & 0.507 & 0.120 & 1717 & 28.5 \\ \text { Ave - StD } & 0.496 & 0.119 & 1534 & 25.8\end{array}$

$\begin{array}{lc}\text { Material: } & 949 \\ \text { Tested By: } & \begin{array}{c}949 \\ \text { Touchstone }\end{array} \\ \text { Temp } & \text { RTA } \\ \text { \# of Plys: } & 20 \\ \text { Sanding: } & \text { No } \\ \text { Bleeder: } & \text { Yes } \\ \text { Caul Plate: } & \text { no } \\ \text { Peel Ply: } & \text { no } \\ \text { Strain Range: } & 1000 \text { to } 3000 \text { ue }\end{array}$

$\begin{array}{lrrrr}\text { Specimen } & \begin{array}{r}\text { Width } \\ \text { [in] }\end{array} & \begin{array}{r}\text { Thick } \\ \text { [in] }\end{array} & \begin{array}{r}\text { Load } \\ {[\mathrm{lb}]}\end{array} & \begin{array}{r}\text { Stress } \\ {[\mathrm{ksi}]}\end{array} \\ \text { 1T-4M } & 0.499 & 0.119 & 1464 & 24.6 \\ \text { 1T-5M } & 0.494 & 0.119 & 1494 & 25.3 \\ \text { 1T-6M } & 0.499 & 0.130 & 1535 & 23.6 \\ \text { 1T-7M } & 0.498 & 0.120 & 1520 & 25.4 \\ \text { 1T-9M } & 0.497 & 0.120 & 1520 & 25.6 \\ & & & & \\ & & & & \\ \text { Average } & 0.497 & 0.122 & 1507 & 24.9 \\ \text { St Dev } & 0.002 & 0.005 & 28 & 0.819 \\ \text { Cv } & 0.42 & 3.88 & 1.86 & 3.29 \\ & & & & \\ \text { Ave + StD } & 0.499 & 0.126 & 1535 & 25.7 \\ \text { Ave - StD } & 0.495 & 0.117 & 1479 & 24.1\end{array}$




\section{RTA Transverse Compressive Modulus}

\author{
Material: $\quad 948 \mathrm{~A} 1$ \\ Tested By: WVU \\ Temp \\ \# of Plys: \\ Sanding: 220 grit, lightly sanded \\ Bleeder: \\ Caul Plate: \\ Peel Ply: \\ Strain Range 1000 to 3000 ue
}

$\begin{array}{lrrrrr}\text { Specimen } & \text { Width } & \begin{array}{r}\text { Thick } \\ \text { [in] }\end{array} & \begin{array}{r}\text { Mod 1 } \\ {[\text { in] }}\end{array} & \begin{array}{r}\text { Mod 2 } \\ \text { [Msi] }\end{array} & \begin{array}{r}\text { Ave. Mod. } \\ \text { [Msi] }\end{array} \\ \text { NTP-14-41 } & 0.487 & 0.123 & 1.31 & 1.09 & 1.20 \\ \text { NTP-14-42 } & 0.47 & 0.126 & 1.12 & 1.07 & 1.09 \\ \text { NTP-14-43 } & 0.502 & 0.127 & 1.04 & 1.05 & 1.04 \\ \text { NTP-14-44 } & 0.522 & 0.121 & 1.08 & 1.20 & 1.14 \\ \text { NTP-14-45 } & 0.501 & 0.126 & 1.10 & 1.43 & 1.27 \\ & & & & & \\ \text { Average } & 0.496 & 0.125 & 1.13 & 1.17 & 1.15 \\ \text { St Dev } & 0.019 & 0.003 & 0.10 & 0.16 & 0.09 \\ \text { Cv } & 3.89 & 2.01 & 9.29 & 13.56 & 7.63 \\ & & & & & \\ \text { Ave + StD } & 0.516 & 0.127 & 1.23 & 1.33 & 1.24 \\ \text { Ave - StD } & 0.477 & 0.122 & 1.02 & 1.01 & 1.06\end{array}$

\author{
Material: $\quad 949$ \\ Tested By: Touchstone \\ Temp RTA \\ \# of Plys: 20 \\ Sanding: No \\ Bleeder: Yes \\ Caul Plate: no \\ Peel Ply: \\ no \\ Strain Ran 1000 to 3000 ue
}

$\begin{array}{lrrr}\text { Specimen } & \begin{array}{r}\text { Width } \\ \text { [in] }\end{array} & \begin{array}{r}\text { Thick } \\ \text { [in] }\end{array} & \begin{array}{r}\text { Mod 1 } \\ {[\text { Msi] }}\end{array} \\ & 0.503 & 0.119 & 1.08 \\ \text { 1T-6S } & 0.504 & 0.119 & 1.03 \\ \text { 1T-7S } & 0.502 & 0.119 & 1.05 \\ \text { 1T-8S } & 0.498 & 0.120 & 1.06 \\ \text { 1T-9S } & 0.500 & 0.118 & 1.13 \\ \text { 1T-10S } & & & \\ & & & \\ \text { Average } & 0.501 & 0.119 & 1.07 \\ \text { St Dev } & 0.002 & 0.001 & 0.04 \\ \text { Cv } & 0.48 & 0.59 & 3.49 \\ & & & \\ \text { Ave + StD } & 0.504 & 0.120 & 1.11 \\ \text { Ave - StD } & 0.499 & 0.118 & 1.03\end{array}$




\section{F In-Plane Shear Properties}

$\begin{array}{lcc}\text { Material: } & \text { 948A1 } \\ \text { Tested } & \text { OCM } \\ \text { Temp: } & 180 \mathrm{~F} \\ \text { \# of Plys: } & 20 \\ \text { Sanding: } & 220 \text { grit, very lightly } \\ \text { Bleeder: } & \text { No } \\ \text { Caul Plate } & \text { No } \\ \text { Peel Ply: } & \text { No }\end{array}$

Specimen Width Thick Ult. Load Strength Modulus

$\begin{array}{lrrrrr} & {[\mathrm{in}]} & {[\mathrm{in}]} & {[\mathrm{lbs}]} & {[\mathrm{ksi}]} & {[\mathrm{Msi}]} \\ \text { NTP-14-1 } & 0.445 & 0.125 & 499 & 8.97 & 0.426 \\ \text { NTP-14-2 } & 0.447 & 0.124 & 492 & 8.88 & 0.404 \\ \text { NTP-14-3 } & 0.444 & 0.124 & 495 & 8.99 & 0.433 \\ \text { NTP-14-4 } & 0.446 & 0.123 & 496 & 9.04 & 0.467 \\ \text { NTP-14-5 } & 0.445 & 0.124 & 485 & 8.79 & 0.467 \\ & & & & & \\ \text { Average } & 0.445 & 0.124 & 493 & 8.93 & 0.439 \\ \text { St Dev } & 0.001 & 0.001 & 5 & 0.10 & 0.027 \\ \text { Cv } & 0.26 & 0.57 & 1.08 & 1.12 & 6.23 \\ \text { Ave+StD } & & & & & \\ \text { Ave-StD } & & & & 9.03 & 0.467 \\ & & & & 8.83 & 0.412\end{array}$

\author{
Material: $\quad 949$ \\ Tested by: OCM \\ Temp: $\quad 180 \mathrm{~F}$ \\ \# of Plys: 20 \\ Sanding: 220 grit, very lightly \\ Bleeder: No \\ Caul Plate: No \\ Peel Ply: $\quad$ No
}

\begin{tabular}{|c|c|c|c|c|c|}
\hline Specimen & $\begin{array}{l}\text { Width } \\
\text { [in] }\end{array}$ & $\begin{array}{l}\text { Thick } \\
\text { [in] }\end{array}$ & $\begin{array}{r}\text { Ult. Load } \\
\text { [lbs] }\end{array}$ & $\begin{array}{r}\text { Strength } \\
\text { [ksi] }\end{array}$ & $\begin{array}{l}\text { Modulus } \\
\text { [Msi] }\end{array}$ \\
\hline NTP-4-19-" & 0.443 & 0.123 & 315 & 5.78 & 0.351 \\
\hline NTP-4-19- & 0.444 & 0.124 & 334 & 6.07 & 0.398 \\
\hline NTP-4-19-ي & 0.443 & 0.125 & 319 & 5.76 & 0.348 \\
\hline NTP-4-19-८ & 0.445 & 0.123 & 339 & 6.19 & 0.356 \\
\hline NTP-4-19 & 0.438 & 0.124 & 356 & 6.55 & 0.371 \\
\hline Average & 0.443 & 0.124 & 333 & 6.07 & 0.365 \\
\hline St Dev & 0.003 & 0.001 & 16 & 0.33 & 0.021 \\
\hline Cv & 0.61 & 0.68 & 4.95 & 5.40 & 5.64 \\
\hline & & & & 6.40 & 0.385 \\
\hline Ave-StD & & & & 5.74 & 0.344 \\
\hline
\end{tabular}




\section{RTA In-Plane Shear Properties}

\author{
Material: $\quad 948 \mathrm{~A} 1$ \\ Tested by: WVU \\ Temp: RTA \\ \# of Plys: $\quad 20$ \\ Sanding: 220 grit, very lightly \\ Bleeder: No \\ Caul Plate: No \\ Peel Ply: No
}

$\begin{array}{lrrrrrr}\text { Specimen } & \text { Thick } & \text { Mod 1 } & \text { Mod 2 } & \text { Twist Ave Mod Strength } \\ & {[\text { in] }} & {[\mathrm{Msi}]} & {[\mathrm{Msi}]} & {[\%]} & {[\mathrm{Msi}]} & {[\mathrm{ksi}]} \\ \text { NTP-14-21 } & 0.124 & 0.6117 & 0.6695 & 4.51 \% & 0.6406 & 11.33 \\ \text { NTP-14-25 } & 0.122 & 0.6514 & 0.6023 & 3.92 \% & 0.6269 & 11.31 \\ \text { NTP-14-26 } & 0.122 & 0.6357 & 0.6094 & 2.11 \% & 0.6226 & 11.53 \\ \text { NTP-14-27 } & 0.122 & 0.5889 & 0.6473 & 4.72 \% & 0.6181 & 11.49 \\ \text { NTP-14-28 } & 0.122 & 0.5269 & 0.7055 & \# \# \# \# & 0.6162 & 11.07 \\ & & & & & & \\ \text { Average } & 0.122 & 0.6029 & 0.6468 & 5.95 \% & 0.625 & 11.35 \\ \text { St Dev } & 0.001 & 0.0487 & 0.043 & 4.88 \% & 0.010 & 0.18 \\ \text { Cv } & 0.731 & 8.07 & 6.62 & 82.06 & 1.56 & 1.59 \\ & & & & & & \\ \text { Ave+StD } & & & & & 0.635 & 11.53 \\ \text { Ave-StD } & & & & & 0.615 & 11.16\end{array}$

\author{
Material: 949 \\ Tested by: WVU \\ Temp: RTA \\ \# of Plys: $\quad 20$ \\ Sanding: $\quad 40 / 80 / 150$ grit \\ Bleeder: No \\ Caul Plate: No \\ Peel Ply: No
}

$\begin{array}{lrrrrrr}\text { Specimen } & \text { Thick } & \text { Mod 1 } & \text { Mod 2 } & \text { Twist } & \text { Ave Mod Strength } \\ & {[\text { in] }} & {[\mathrm{Msi}]} & {[\mathrm{Msi}]} & {[\%]} & {[\mathrm{Msi}]} & {[\mathrm{ksi}]} \\ \text { NTP-4-9 } & 0.112 & 0.4919 & 0.6012 & 10.00 \% & 0.5466 & 9.95 \\ \text { NTP-4-10 } & 0.113 & 0.6040 & 0.5842 & 1.67 \% & 0.5941 & 10.59 \\ \text { NTP-4-11 } & 0.112 & 0.5042 & 0.6216 & 10.43 \% & 0.5629 & 9.44 \\ \text { NTP-4-14 } & 0.112 & 0.5569 & 0.6341 & 6.48 \% & 0.5955 & 9.36 \\ \text { NTP-4-16 } & 0.111 & 0.5307 & 0.6342 & 8.88 \% & 0.5825 & 9.68 \\ & & & & & & \\ \text { Average } & 0.112 & 0.5375 & 0.6151 & 7.49 \% & 0.576 & 9.80 \\ \text { St Dev } & 0.001 & 0.0448 & 0.022 & 3.60 \% & 0.021 & 0.50 \\ \text { Cv } & 0.631 & 8.34 & 3.56 & 48.03 & 3.67 & 5.07 \\ & & & & & & \\ \text { Ave+StD } & & & & & 0.597 & 10.30 \\ \text { Ave-StD } & & & & & 0.555 & 9.31\end{array}$




\section{-125 F In-Plane Shear Properties}

Material: $948 \mathrm{~A} 1$

Tested by:

Temp:

\# of Plys:

Sanding: 220 grit, lightly

Bleeder: No

Caul Plate: No

Peel Ply:

No

$\begin{array}{lrrrrr}\text { Specimen } & \begin{array}{r}\text { Width } \\ {[\mathrm{in}]}\end{array} & \begin{array}{r}\text { Thick } \\ {[\mathrm{in}]}\end{array} & \begin{array}{r}\text { Ult. Load } \\ \text { [lbs] }\end{array} & \begin{array}{r}\text { Strength } \\ {[\mathrm{ksi}]}\end{array} & \begin{array}{r}\text { Modulus } \\ {[\mathrm{Msi}]}\end{array} \\ \text { NTP-14-11 } & 0.445 & 0.125 & 761 & 13.68 & 0.660 \\ \text { NTP-14-12 } & 0.446 & 0.124 & 784 & 14.18 & 0.635 \\ \text { NTP-14-13 } & 0.446 & 0.126 & 847 & 15.07 & 0.672 \\ \text { NTP-14-14 } & 0.445 & 0.124 & 735 & 13.32 & 0.711 \\ \text { NTP-14-15 } & 0.446 & 0.123 & 831 & 15.15 & 0.704 \\ & & & & & \\ \text { Average } & 0.446 & 0.124 & 792 & 14.28 & 0.676 \\ \text { St Dev } & 0.001 & 0.001 & 47 & 0.82 & 0.031 \\ \text { Cv } & 0.12 & 0.92 & 5.93 & 5.72 & 4.65 \\ & & & & & \\ \text { Ave+StD } & & & & 15.10 & 0.708 \\ \text { Ave-StD } & & & & 13.46 & 0.645\end{array}$

$\begin{array}{lc}\text { Material: } & \mathbf{9 4 9} \\ \text { Tested by: } & \text { OCM } \\ \text { Temp: } & -125 \mathrm{~F} \\ \text { \# of Plys: } & 20 \\ \text { Sanding: } & 220 \text { grit, lightly } \\ \text { Bleeder: } & \text { No } \\ \text { Caul Plate: } & \text { No } \\ \text { Peel Ply: } & \text { No }\end{array}$

\begin{tabular}{|c|c|c|c|c|c|}
\hline Specimen & $\begin{array}{l}\text { Width } \\
\text { [in] }\end{array}$ & $\begin{array}{l}\text { Thick } \\
\text { [in] }\end{array}$ & $\begin{array}{l}\text { Ult. Load } \\
\text { [lbs] }\end{array}$ & $\begin{array}{r}\text { Strength } \\
{[\mathrm{ksi}]}\end{array}$ & $\begin{array}{l}\text { Modulus } \\
\text { [Msi] }\end{array}$ \\
\hline NTP-4-19-11 & 0.443 & 0.126 & 947 & 16.97 & 0.646 \\
\hline NTP-4-19-12 & 0.445 & 0.126 & 900 & 16.05 & 0.623 \\
\hline NTP-4-19-13 & 0.445 & 0.127 & 930 & 16.46 & 0.631 \\
\hline NTP-4-19-14 & 0.442 & 0.129 & 870 & 15.26 & 0.603 \\
\hline NTP-4-19-15 & 0.444 & 0.128 & 871 & 15.33 & 0.632 \\
\hline Average & 0.444 & 0.127 & 904 & 16.01 & 0.627 \\
\hline St Dev & 0.001 & 0.001 & 35 & 0.73 & 0.016 \\
\hline Cv & 0.29 & 1.03 & 3.83 & 4.58 & 2.51 \\
\hline Ave+StD & & & & 16.74 & 0.643 \\
\hline Ave-StD & & & & 15.28 & 0.611 \\
\hline
\end{tabular}




\section{F Longitudinal Tensile Properties}

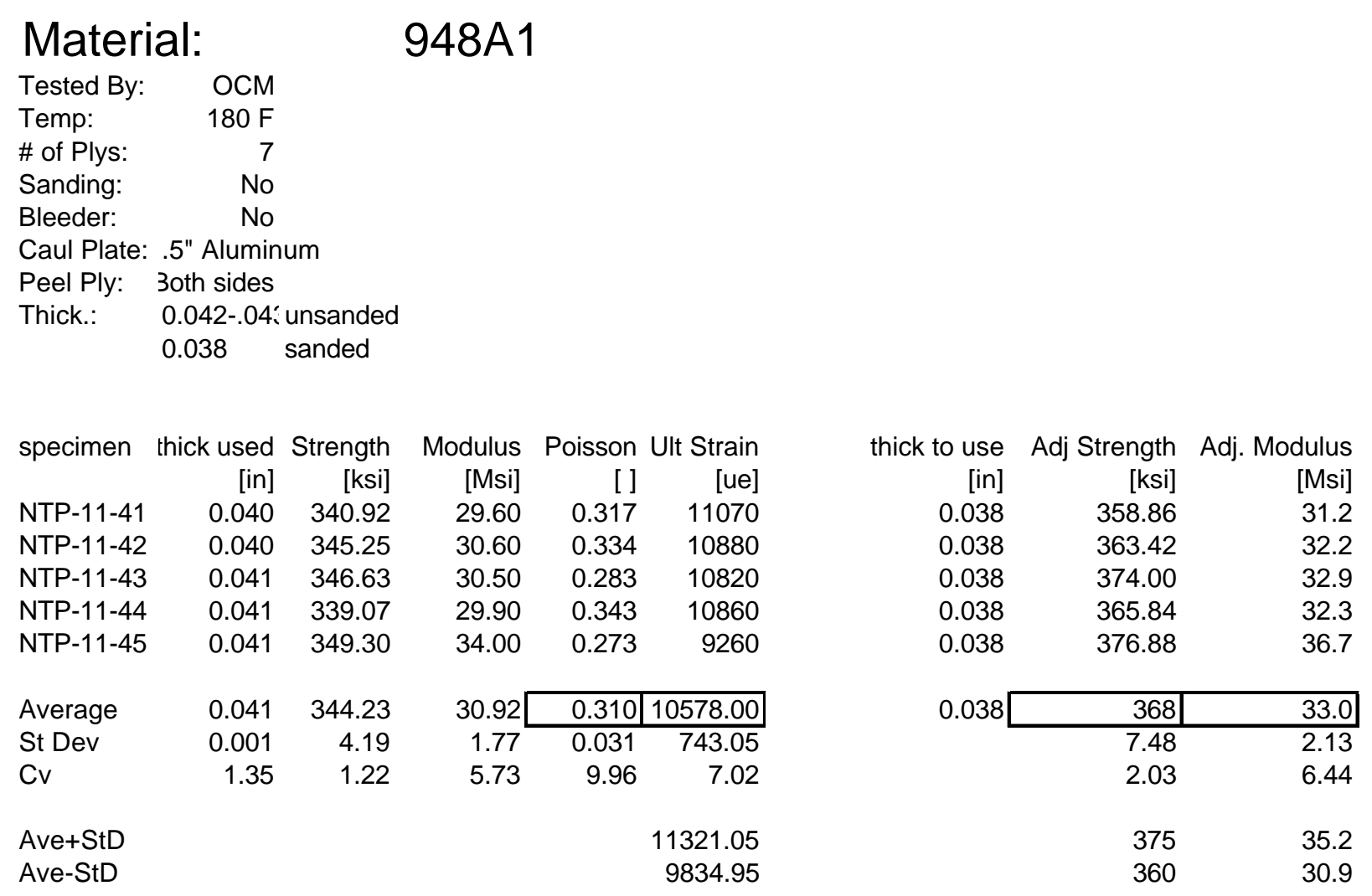




\section{RTA Longitudinal Tensile Properties}

\author{
Material: $948 \mathrm{~A} 1$ \\ Tested by: WVU \\ Temp: RTA \\ \# of Plys: \\ Sanding: Yes, for strain gage only \\ Bleeder: No \\ Caul Plate: .5" aluminum \\ Peel Ply: both sides \\ Thick: $\quad$ 042-.043 unsanded \\ 0.038 sanded
}

\begin{tabular}{|c|c|c|c|c|c|c|c|}
\hline Specimen & $\begin{array}{l}\text { Width } \\
\text { [in.] }\end{array}$ & $\begin{array}{l}\text { Thick } \\
\text { [in] }\end{array}$ & $\begin{array}{c}\text { Load } \\
{[\text { [lbs] }}\end{array}$ & $\begin{array}{l}\text { Strength } \\
\text { [ksi] }\end{array}$ & $\begin{array}{l}\text { Mod } \\
\text { [Msi] }\end{array}$ & $\begin{array}{r}\text { Poisson } \\
\text { [ ] }\end{array}$ & $\begin{array}{l}\text { Ult. Strain } \\
\text { [uin/in] }\end{array}$ \\
\hline NTP-11-81 & 0.479 & 0.038 & 5418 & 298 & 32.3 & 0.277 & 8777 \\
\hline NTP-11-82 & 0.486 & 0.038 & 6278 & 340 & 32.2 & 0.302 & 10059 \\
\hline NTP-11-83 & 0.459 & 0.038 & 6008 & 344 & 32.2 & 0.270 & 10046 \\
\hline NTP-11-84 & 0.490 & 0.038 & 6294 & 338 & 33.3 & 0.265 & 9717 \\
\hline NTP-11-85 & 0.471 & 0.038 & 6026 & 337 & 33.2 & 0.348 & 9729 \\
\hline NTP-11-86 & 0.494 & 0.038 & 6710 & 357 & 32.0 & 0.265 & 10596 \\
\hline Average & 0.480 & 0.038 & 6122 & 336 & 32.5 & 0.288 & 9821 \\
\hline St Dev & 0.013 & 0.000 & 428 & 20 & 0.6 & 0.033 & 603 \\
\hline Cv & 2.72 & 0.00 & 7.00 & 5.99 & 1.74 & 11.31 & 6.14 \\
\hline & & & & 356 & 33.1 & 0.320 & 10424 \\
\hline Ave-StD & & & & 316 & 32.0 & 0.255 & 9218 \\
\hline
\end{tabular}

\author{
Material: $\quad 949$ \\ Tested by: WVU \\ $\begin{array}{lr}\text { Temp: } & \text { RTA } \\ \text { \# of Plys: } & 7\end{array}$ \\ Sanding: Yes, for strain gage only \\ Bleeder: No \\ Caul Plate: .5" aluminum \\ Peel Ply: both sides \\ Thick: J41-.042 unsanded \\ 0.037 sanded
}

\begin{tabular}{lrrrrrrr} 
Specimen & Width & \multicolumn{1}{c}{ Thick } & \multicolumn{2}{c}{ Load } & Strength & \multicolumn{3}{c}{ Mod } & \multicolumn{2}{r}{ Poisson Ult. Strain } \\
& {$[$ in.] } & {$[$ in] } & {$[$ [bs] } & {$[\mathrm{ksi}]$} & {$[$ Msi] } & {[]} & [uin/in] \\
NTP-15-61 & 0.468 & 0.037 & 7764 & 448 & 24.5 & 0.238 & 16895 \\
NTP-15-62 & 0.448 & 0.037 & 7868 & 475 & 25.0 & 0.296 & 17114 \\
NTP-15-63 & 0.455 & 0.037 & 7304 & 434 & 24.9 & 0.262 & 16577 \\
NTP-15-64 & 0.467 & 0.037 & 7250 & 420 & 24.0 & 0.290 & 16052 \\
NTP-15-65 & 0.455 & 0.037 & 8172 & 485 & 24.8 & 0.248 & 18054 \\
NTP-15-66 & 0.468 & 0.037 & 7642 & 441 & 25.1 & 0.316 & 16430 \\
& & & & & & & \\
Average & 0.460 & 0.037 & 7667 & 451 & 24.7 & 0.275 & 16854 \\
St Dev & 0.009 & 0.000 & 350 & 25 & 0.4 & 0.030 & 694 \\
Cv & 1.87 & 0.00 & 4.56 & 5.55 & 1.65 & 11.05 & 4.12 \\
& & & & & & & \\
Ave+StD & & & & 476 & 25.1 & 0.305 & 17548 \\
Ave-StD & & & & 426 & 24.3 & 0.245 & 16160
\end{tabular}




\title{
-125 F Longitudinal Tensile Properties
}

\author{
Material: $\quad 948 \mathrm{~A} 1$ \\ Tested By: OCM \\ Temp: $\quad-125 \mathrm{~F}$ \\ \# of Plys: 7 \\ Sanding: No \\ Bleeder: $\quad$ No
Caul Plate: \\ Caul Plate: $\quad$.5" Aluminum \\ Thick.: $\quad 0.042-.043$ unsanded \\ 0.038 sanded
}

$\begin{array}{lrrrrr}\text { specimen } & \begin{array}{r}\text { thick used } \\ \text { [in] }\end{array} & \begin{array}{r}\text { Strength } \\ {[\mathrm{ksi}]}\end{array} & \begin{array}{r}\text { Modulus } \\ {[\mathrm{Msi}]}\end{array} & \begin{array}{r}\text { Poisson } \\ {[\text { ] }}\end{array} & \begin{array}{r}\text { Ult Strain } \\ {[\mathrm{ue}]}\end{array} \\ \text { NTP-11-51 } & 0.041 & 266.59 & 29.80 & 0.279 & 8330 \\ \text { NTP-11-52 } & 0.041 & 286.24 & 29.70 & 0.305 & 9370 \\ \text { NTP-11-53 } & 0.041 & 281.63 & 29.70 & 0.299 & 8990 \\ \text { NTP-11-54 } & 0.041 & 217.13 & 29.40 & 0.214 & 7370 \\ \text { NTP-11-55 } & 0.041 & 291.66 & 28.10 & 0.290 & 9620 \\ & & & & & \\ \text { Average } & 0.041 & 268.65 & 29.34 & 0.277 & 8736.00 \\ \text { St Dev } & 0.000 & 30.27 & 0.71 & 0.037 & 905.36 \\ \text { Cv } & 0.00 & 11.27 & 2.42 & 13.26 & 10.36\end{array}$

\begin{tabular}{rrr}
$\begin{array}{rr}\text { thick to use } \\
\text { [in] }\end{array}$ & $\begin{array}{r}\text { Adj Strength } \\
\text { [ksi] }\end{array}$ & $\begin{array}{r}\text { Adj. Modulus } \\
\text { [Msi] }\end{array}$ \\
0.038 & 287.64 & 32.2 \\
0.038 & 308.84 & 32.0 \\
0.038 & 303.86 & 32.0 \\
0.038 & 234.27 & 31.7 \\
0.038 & 314.69 & 30.3 \\
& \\
\cline { 2 - 3 } 0.038 & 290 & 31.7 \\
\cline { 3 - 3 } & 33 & 0.8 \\
& 11.27 & 2.42
\end{tabular}




\section{RTA Transverse Tensile Properties}

\author{
Material: $948 \mathrm{~A} 1$ \\ Tested by: WVU \\ Temp: \\ \# of Plys: \\ Sanding: 220 grit, lightly sanded \\ Bleeder: Yes \\ Caul Plate: No \\ Peel Ply:
}

\author{
Material: 949 \\ Tested WVU \\ Temp: RTA \\ \# of Plys: 20 \\ Sanding: 40/80/150 grit \\ Bleeder: Yes \\ Caul Plate No \\ Peel Ply: No
}

\begin{tabular}{|c|c|c|c|c|c|c|}
\hline Specimen & $\begin{array}{r}\text { Width } \\
\text { [in.] }\end{array}$ & $\begin{array}{r}\text { Thick } \\
\text { [in] }\end{array}$ & $\begin{array}{c}\text { Load } \\
\text { [lbs] }\end{array}$ & $\begin{array}{r}\text { trength } \\
{[\mathrm{ksi}]}\end{array}$ & $\begin{array}{r}\text { Mod } \\
\text { [Msi] }\end{array}$ & $\begin{array}{l}\text { Mino } \\
\text { Poissor }\end{array}$ \\
\hline TP-14-51 & 0.983 & 0.123 & 613 & 5.070 & 0.9573 & 0.00 \\
\hline TP-1 & 9 & 0.122 & & & ---- & --- \\
\hline TP-14-5 & .006 & 0.126 & 689 & 5.436 & 1.0310 & 0.016 \\
\hline TP-1 & .999 & 0.127 & ---- & ---- & 1.0168 & 0.01 \\
\hline & & 0.126 & 691 & 5.523 & 0.9872 & \\
\hline ГP-14-5 & 00 & 0.126 & 664 & 5.270 & 1.0146 & 0.0 \\
\hline er & 996 & 0.125 & 679 & 5.47 & 1.00 & \\
\hline & & & 45 & & & \\
\hline & & & 5.62 & 6.81 & 2.93 & \\
\hline
\end{tabular}

\begin{tabular}{|c|c|c|c|c|c|c|}
\hline Specimen & $\begin{array}{r}\text { Width } \\
\text { [in.] }\end{array}$ & $\begin{array}{r}\text { Thick } \\
\text { [in] }\end{array}$ & $\begin{array}{r}\text { Load } \\
{[\mathrm{lb}]}\end{array}$ & $\begin{array}{r}\text { Strength } \\
\text { [ksi] }\end{array}$ & $\begin{array}{r}\text { Mod } \\
\text { [Msi] }\end{array}$ & $\begin{array}{r}\text { Minor } \\
\text { Poisson }\end{array}$ \\
\hline NTP-4-1 & 1.000 & 0.113 & 561 & 4.963 & 1.069 & 0.00965 \\
\hline NTP-4-2 & 1.000 & 0.113 & 486 & 4.303 & 1.026 & 0.00795 \\
\hline NTP-4-3 & 1.000 & 0.113 & 534 & 4.726 & ---- & ---- \\
\hline NTP-4-6 & 1.000 & 0.114 & 496 & 4.354 & 1.131 & 0.0098 \\
\hline NTP-4-7 & 1.000 & 0.116 & --- & --- & 1.011 & 0.00990 \\
\hline NTP-4-8 & 1.000 & 0.111 & 560 & 5.045 & 1.058 & 0.0078 \\
\hline Average & 1.000 & 0.113 & 527[ & 4.68 & 1.06 & 0.00903 \\
\hline St Dev & 0.000 & 0.002 & 35 & 0.34 & 0.05 & 0.00104 \\
\hline Cv & 0.00 & 1.44 & 6.62 & 7.28 & 4.40 & 11.5 \\
\hline
\end{tabular}




\section{Apparent Densitv and Void Content}

\begin{tabular}{|c|c|c|c|c|c|c|}
\hline Material & \# Plys & Plys/Debulk & Location & $\begin{array}{l}\text { Apparent } \\
\text { Density } \\
\text { [gm/cc] }\end{array}$ & $\begin{array}{c}\text { Theoretical } \\
\text { Density } \\
{[\mathrm{gm} / \mathrm{cc}]}\end{array}$ & $\begin{array}{l}\text { Void } \\
\text { Content } \\
{[\% \text { vol] }}\end{array}$ \\
\hline 949 & 20 & 5 & panel, edge & 1.4848 & 1.5129 & $1.857 \%$ \\
\hline 949 & 20 & 10 & panel, edge & 1.4833 & 1.5102 & $1.781 \%$ \\
\hline 949 & 20 & 20 & panel, edge & 1.4788 & 1.5104 & $2.092 \%$ \\
\hline 949 & 20 & 5 & panel, center & 1.4846 & 1.5006 & $1.066 \%$ \\
\hline 949 & 20 & 20 & panel, center & 1.4776 & 1.5037 & $1.736 \%$ \\
\hline 949 & 7 & 7 & panel, center & 1.5172 & 1.5398 & $1.468 \%$ \\
\hline 949 & $\sim 89$ & 10 & beam, near end,web & 1.4931 & 1.5342 & $2.679 \%$ \\
\hline 949 & $\sim 65$ & 10 & beam: near center,web & 1.4649 & 1.5302 & $4.267 \%$ \\
\hline 949 & $\sim 65$ & 10 & beam, near center,edge & 1.4583 & 1.5292 & $4.636 \%$ \\
\hline Material & \# Plys & Plys/Debulk & Location & $\begin{array}{l}\text { Apparent } \\
{[\mathrm{gm} / \mathrm{cc}]}\end{array}$ & $\begin{array}{c}\text { Theoretical } \\
{[\mathrm{gm} / \mathrm{cc}]}\end{array}$ & $\begin{array}{c}\text { Void } \\
\text { Content } \\
\text { [\%vol] }\end{array}$ \\
\hline 948 & 20 & 20 & panel, edge & 1.5043 & 1.5353 & $2.019 \%$ \\
\hline
\end{tabular}




\section{Apparent Density and Void Content Continued}

\begin{abstract}
Apparent Density: Helium Pycnometer
Panel Locations

Location A: 4" from edge on 12" x 22" x .125" panel

Location B: Center of $12^{\prime \prime} \times 22^{\prime \prime} \times 0.125^{\prime \prime}$ panel

Location C: Center of $12 "$ × 22" x $0.042 "$ panel
\end{abstract}

Theoretical Density: Helium Pycnometer, sample ground to pass through 30 mesh sieve

\section{Beam Locations}

Location A: Near Beam End, Near Web

Location B: Near Beam Center (about 42" from end), Near Web

Location C: Near Beam Center (about 42" from end), Near Flange Edge

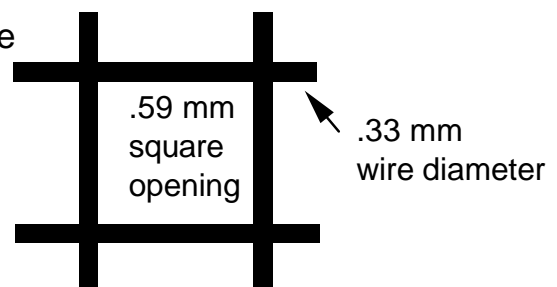

30 mesh sieve 


\section{Glass Transition Temperature and Coefficient of Thermal}

Glass Transition Temperature

\begin{tabular}{|c|c|c|}
\hline Material: & 948A1 HYE & E/M40J \\
\hline Specimen & Maximum & Temperature \\
\hline & $\begin{array}{l}\text { Value } \\
\operatorname{Tan}(\delta)\end{array}$ & {$[F]$} \\
\hline NTP-11-91 & 0.322 & 302 \\
\hline NTP-11-92 & 0.275 & 303 \\
\hline Average & & 303 \\
\hline
\end{tabular}

\begin{tabular}{|c|c|c|}
\hline Material: & 949 HYE/N & 130GC \\
\hline Specimen & Maximum & Temperature \\
\hline & $\begin{array}{l}\text { Value } \\
\operatorname{Tan}(\delta)\end{array}$ & {$[F]$} \\
\hline NTP-15-71 & 0.358 & 249 \\
\hline NTP-15-72 & 0.516 & 258 \\
\hline Average & & 254 \\
\hline
\end{tabular}

Longitudinal/Transverse Coefficient of Thermal Expansion

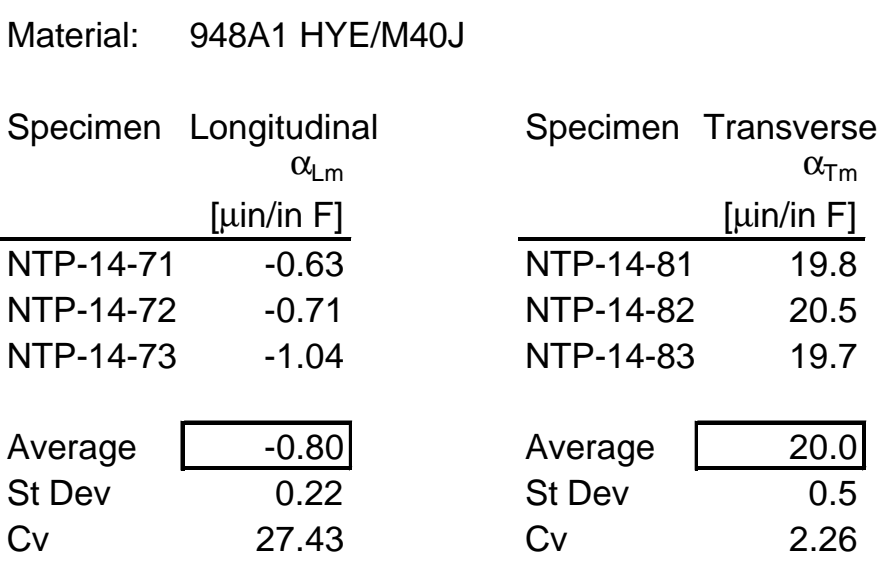

\begin{tabular}{|c|c|c|c|}
\hline Material: & 949 HYE/M30GC & & \\
\hline Specimen & $\begin{array}{c}\text { Longitudinal } \\
\alpha_{\mathrm{Lm}} \\
{[\mu \mathrm{in} / \mathrm{in} \mathrm{F}]}\end{array}$ & Specimen & $\begin{array}{r}\text { sverse } \\
\alpha_{T m} \\
\text { in/in F] }\end{array}$ \\
\hline NTP-2-21 & -0.55 & NTP-2-31 & 18.1 \\
\hline NTP-2-22 & -2.13 & NTP-2-32 & 19.5 \\
\hline NTP-2-23 & -0.62 & NTP-2-33 & 18.1 \\
\hline Average & -1.10 & Average & 18.6 \\
\hline St Dev & 0.89 & St Dev & 0.8 \\
\hline $\mathrm{Cv}$ & 81.24 & $\mathrm{Cv}$ & 4.41 \\
\hline
\end{tabular}

